University of South Florida

DIGITAL COMMONS

Digital Commons @ University of

@ UNIVERSITY OF SOUTH FLORIDA

South Florida

\title{
Understanding Curb Management and Targeted Incentive Policies to Increase Transportation Network Company Pooling and Public Transit Linkages
}

\author{
Susan Shaheen \\ Wesley Darling \\ Jacquelyn Broader \\ Adam Cohen
}

Follow this and additional works at: https://digitalcommons.usf.edu/cutr_nicr

\section{Scholar Commons Citation}

Shaheen, Susan; Darling, Wesley; Broader, Jacquelyn; and Cohen, Adam, "Understanding Curb Management and Targeted Incentive Policies to Increase Transportation Network Company Pooling and Public Transit Linkages" (2021). Research Reports. 3.

https://digitalcommons.usf.edu/cutr_nicr/3

This Article is brought to you for free and open access by the National Institute for Congestion Reduction (NICR) 2019- at Digital Commons @ University of South Florida. It has been accepted for inclusion in Research Reports by an authorized administrator of Digital Commons @ University of South Florida. For more information, please contact digitalcommons@usf.edu. 


\title{
NATIONAL INSTITUTE FOR CONGESTION REDUCTION
}

\author{
FINAL REPORT \\ OCTOBER 2021
}

Understanding Curb Management and Targeted Incentive Policies to Increase Transportation Network Company Pooling and Public Transit Linkages

Susan Shaheen

Wesley Darling

Jacquelyn Broader

Adam Cohen

For:

National Institute for Congestion Reduction

University of South Florida

Center for Urban Transportation Research | University of South Florida

4202 E. Fowler Avenue, ENG030, Tampa, FL 33620-5375

nicr@usf.edu 


\section{DISCLAIMER}

The contents of this report reflect the views of the authors, who are responsible for the facts and the accuracy of the information presented herein. This document is disseminated in the interest of information exchange.

The report is funded, partially or entirely, by a grant from the U.S. Department of Transportation's University Transportation Centers Program. However, the U.S. Government assumes no liability for the contents or use thereof. 


\section{Technical Report Documentation Page}

\begin{tabular}{|c|c|c|c|}
\hline 1. Report No. & 2. Government Accession No. & \multicolumn{2}{|c|}{ 3. Recipient's Catalog No. } \\
\hline \multirow{2}{*}{\multicolumn{2}{|c|}{$\begin{array}{l}\text { Understanding Curb Management and Targeted Incentive Policies to Increase } \\
\text { Transportation Network Company Pooling and Public Transit Linkages }\end{array}$}} & \multicolumn{2}{|l|}{ August 2021} \\
\hline & & \multicolumn{2}{|c|}{ 6. Performing Organization Code } \\
\hline \multicolumn{2}{|l|}{ 7. Author(s) } & \multirow{2}{*}{\multicolumn{2}{|c|}{ 8. Performing Organization Report No. }} \\
\hline \multicolumn{2}{|c|}{ Susan Shaheen, Wesley Darling, Jacquelyn Broader, Adam Cohen } & & \\
\hline \multicolumn{2}{|c|}{ 9. Performing Organization Name and Address } & \multicolumn{2}{|c|}{ 10. Work Unit No. (TRAIS) } \\
\hline \multicolumn{2}{|l|}{ Transportation Sustainability Research Center } & & \\
\hline \multirow{3}{*}{\multicolumn{2}{|c|}{$\begin{array}{l}\text { 12. Sponsoring Organization Name and Address } \\
\text { U.S. Department of Transportation } \\
\text { University Transportation Centers } \\
1200 \text { New Jersey Avenue, SE } \\
\text { Washington, DC } 20590 \\
\text { United States }\end{array}$}} & \multirow{2}{*}{\multicolumn{2}{|c|}{ 13. Type of Report and Period Covered }} \\
\hline & & & \\
\hline & & \multicolumn{2}{|c|}{ 14. Sponsoring Agency Code } \\
\hline \multicolumn{4}{|l|}{ 16. Abstract } \\
\hline \multicolumn{4}{|c|}{$\begin{array}{l}\text { Transportation network company (TNCS) rides that are shared amongst users (i.e., pooled) can offer a variety of benefits including increased } \\
\text { mobility and reduced transportation emissions. However, very few TNC users select pooled trips and not all pooled rides are matched with } \\
\text { other riders. This report supports increased pooling by exploring different pooling strategies and incentives. TNC users were actively engaged } \\
\text { to offer insights through the photovoice methodology (a participatory research method that allows community members to use } \\
\text { photography to communicate their personal experiences and perceptions). The researchers gathered further information through interviews } \\
\text { with four photovoice experts and } 10 \text { pooling stakeholders, four photovoice groups and one individual interview with a total of } 15 \text { TNC users, } \\
\text { and a workshop with five expert stakeholders and } 12 \text { photovoice group participants. The different research methods resulted in the } \\
\text { development of four key takeaways and five policy recommendations. }\end{array}$} \\
\hline \multicolumn{2}{|c|}{$\begin{array}{l}\text { 17. Key Words } \\
\text { curb management, equity, incentives, pooling, public transportation, ridehailing, } \\
\text { transportation network companies, TNCs }\end{array}$} & \multicolumn{2}{|c|}{ 18. Distribution Statement } \\
\hline 19. Security Classification (of this report) & 20. Security Classification (of this page) & 21. No. of Pages & 22. Price \\
\hline Unclassified. & Unclassified. & 110 & \\
\hline
\end{tabular}




\section{Table of Contents}

\section{Contents}

DISCLAIMER. ...ii

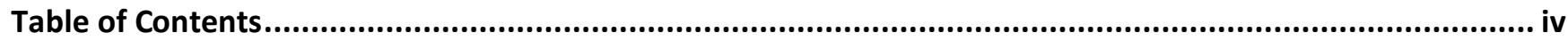

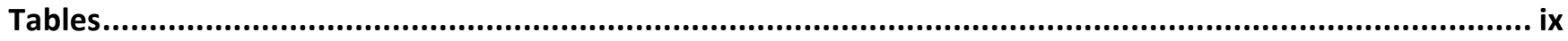

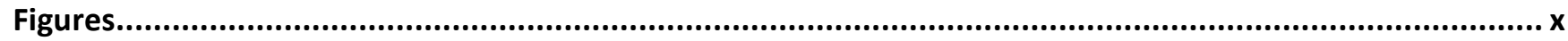

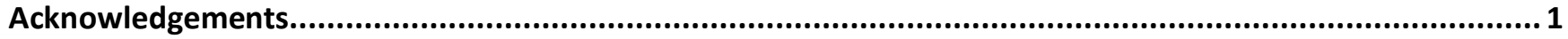

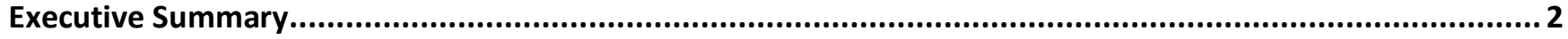

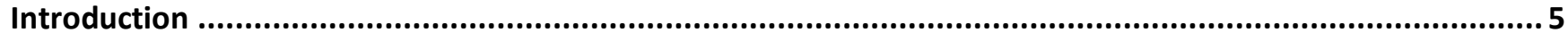

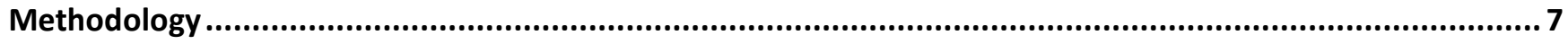

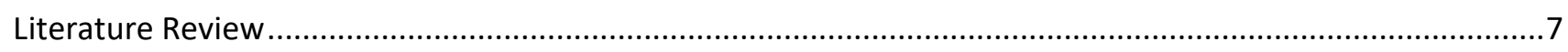

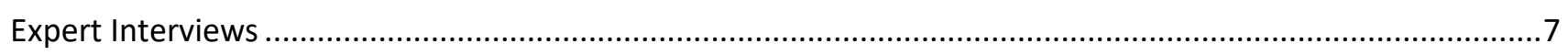

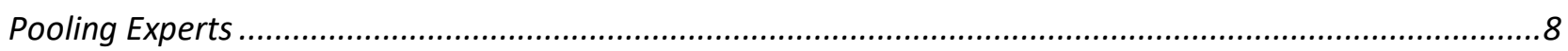

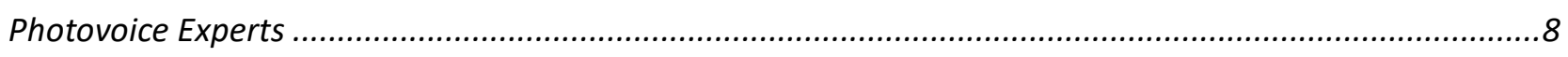

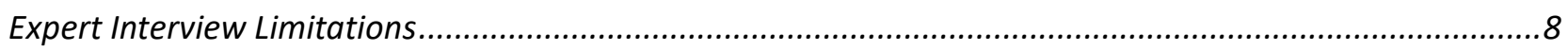

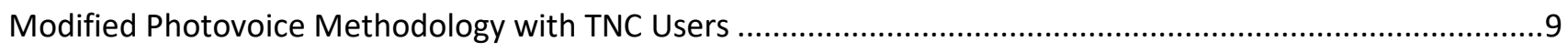

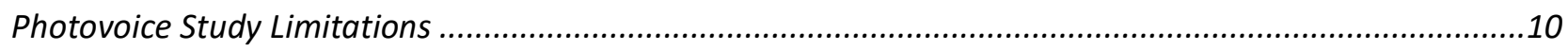

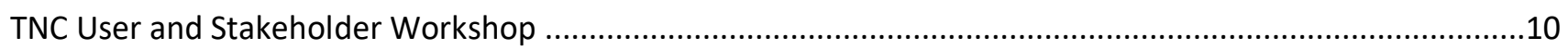

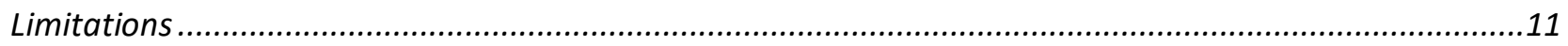

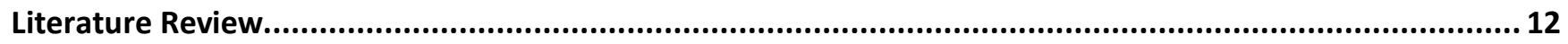

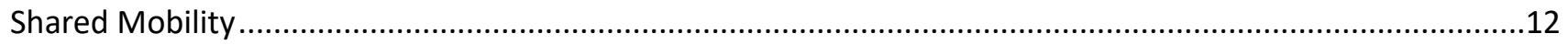

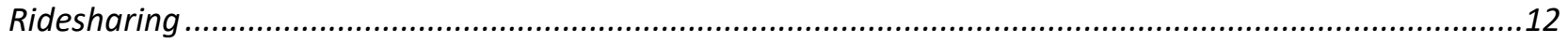

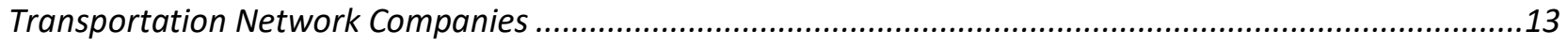

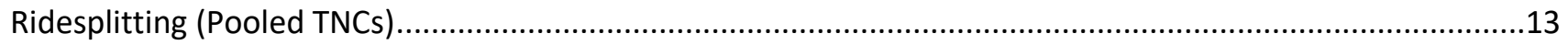

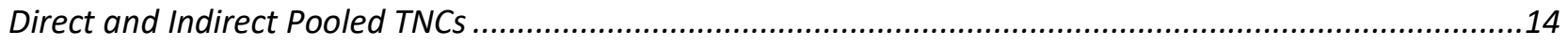

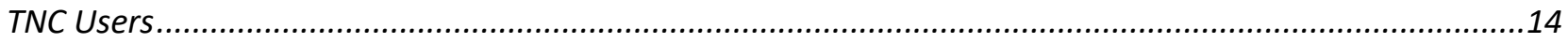

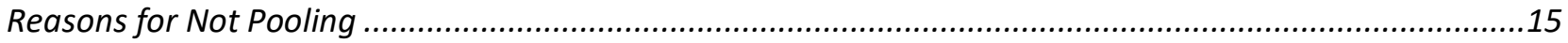

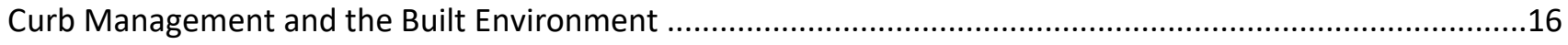

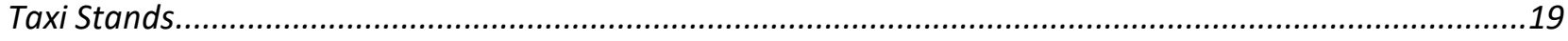

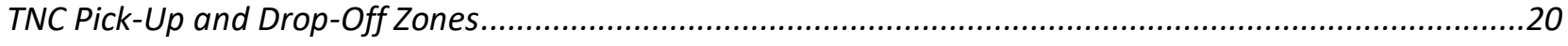

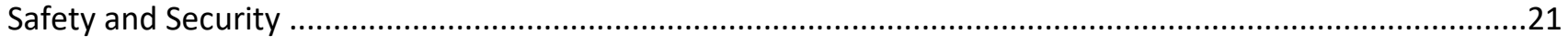

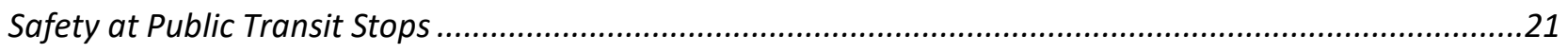

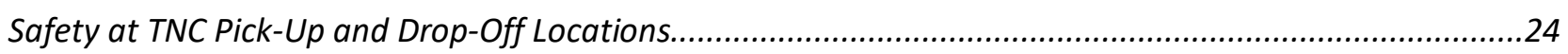




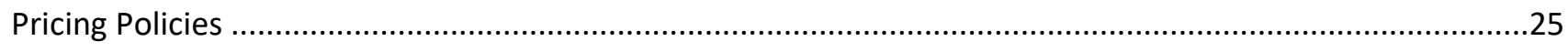

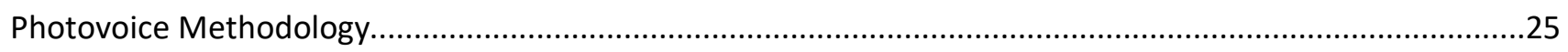

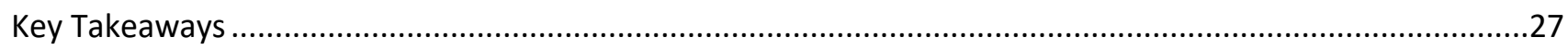

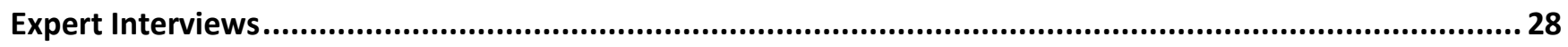

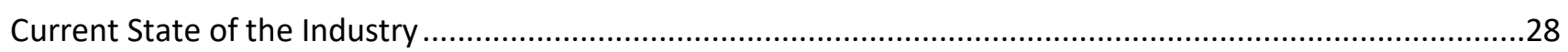

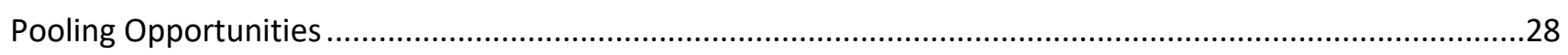

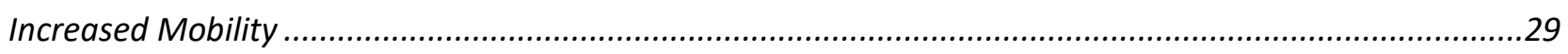

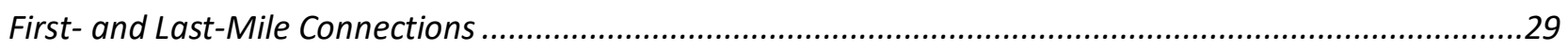

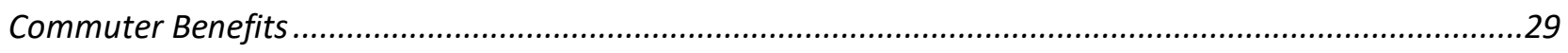

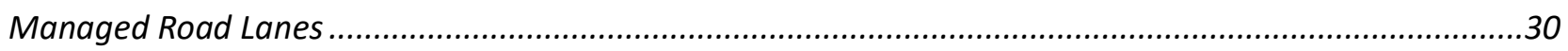

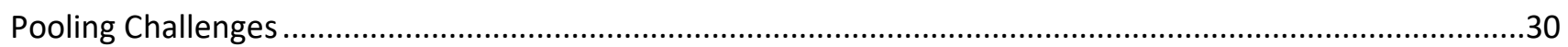

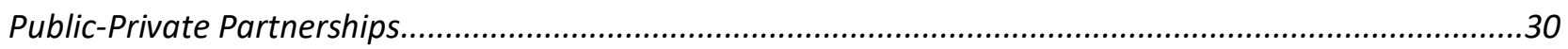

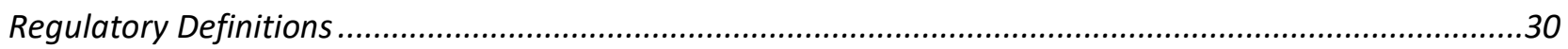

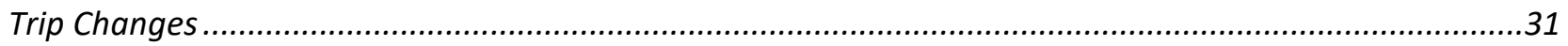

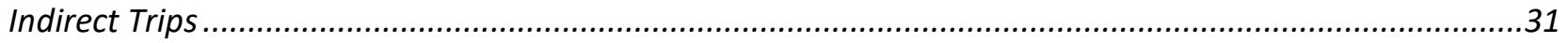

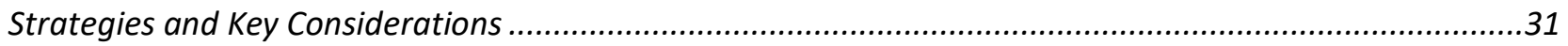

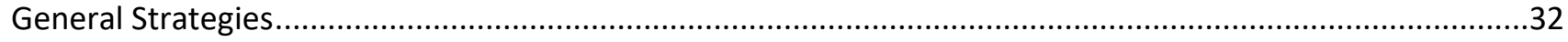

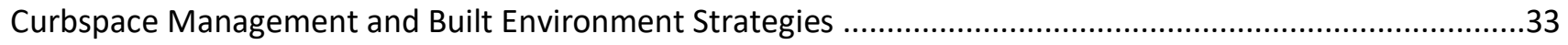

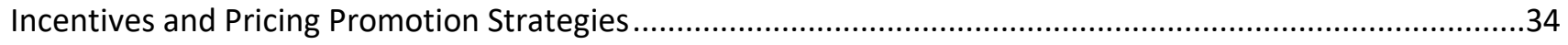

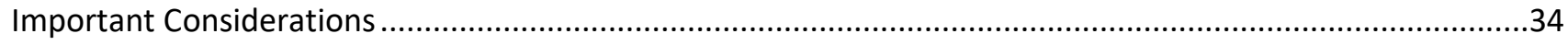

Key Takeaways

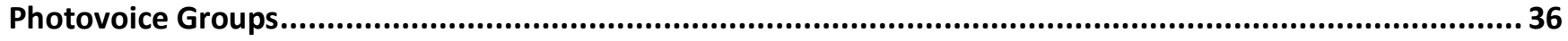

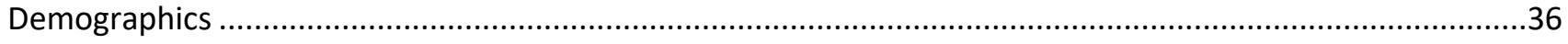

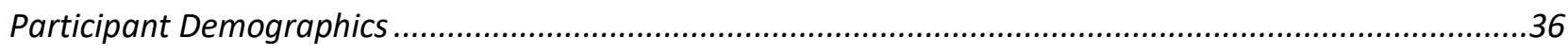

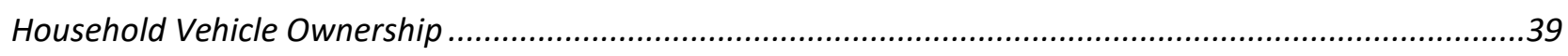

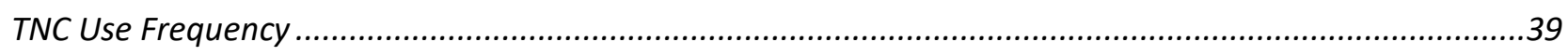

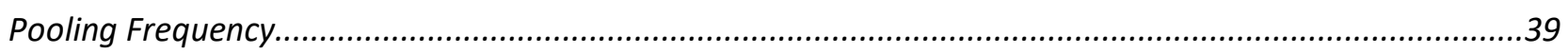

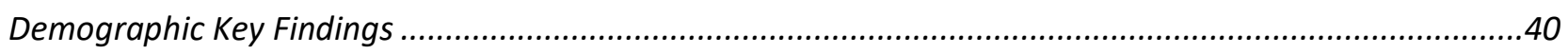

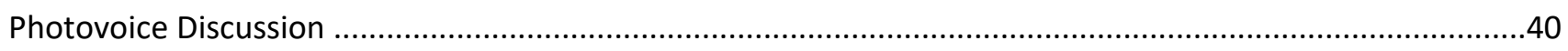

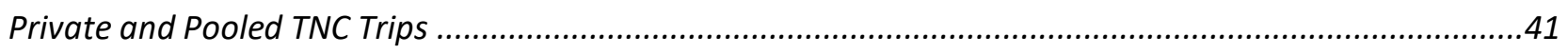

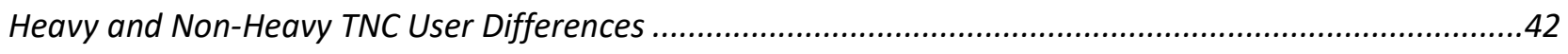

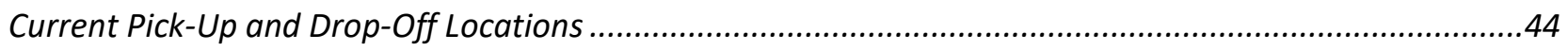

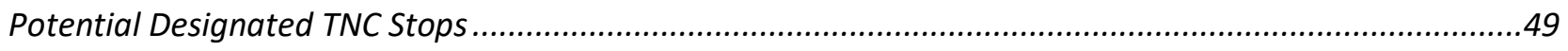

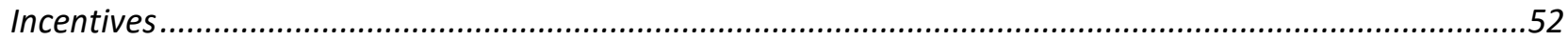


COVID-19 Impacts.

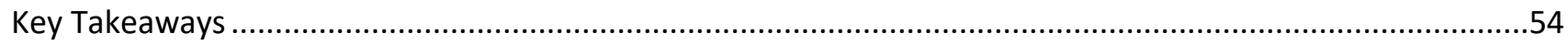

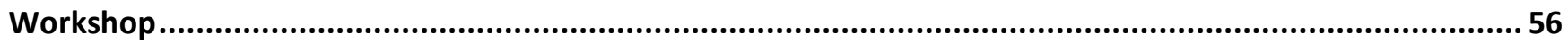

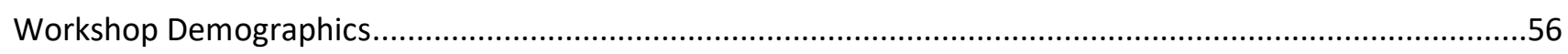

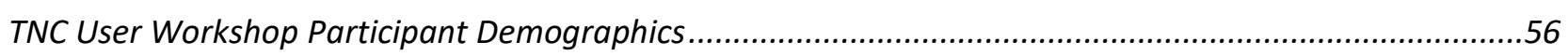

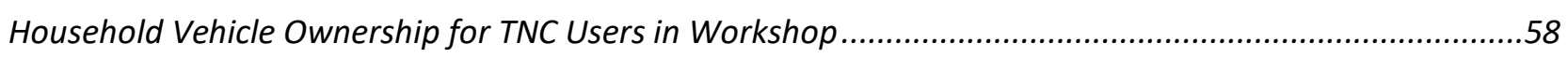

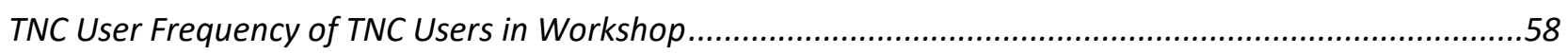

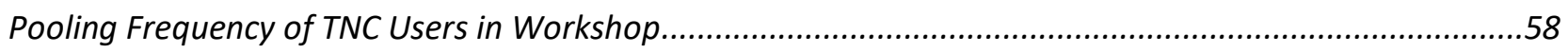

Expert Stakeholder Organizations Represented in Workshop.................................................................59

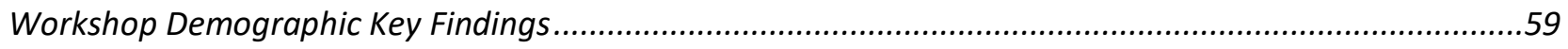

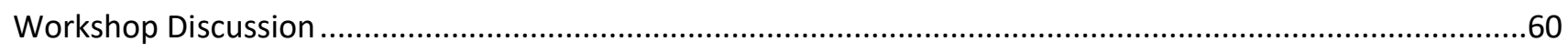

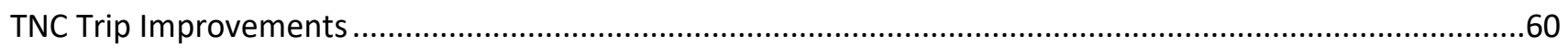

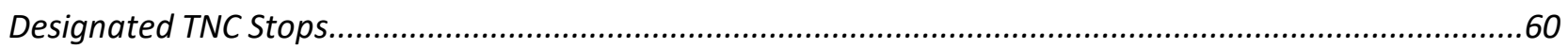

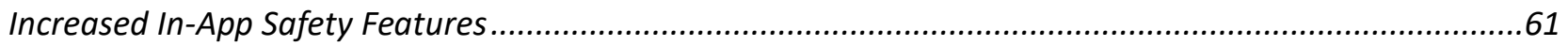

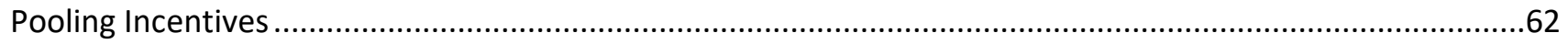

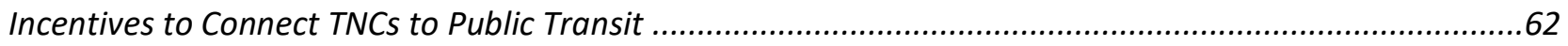

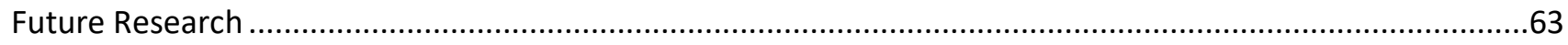

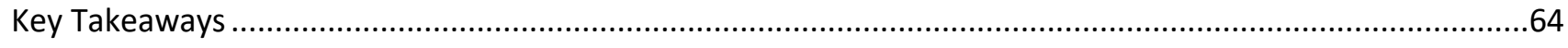

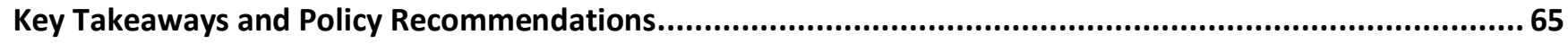

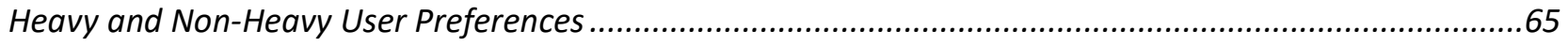

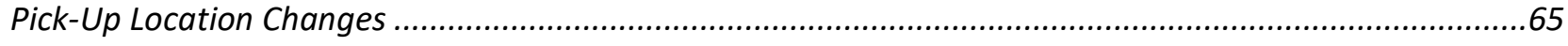

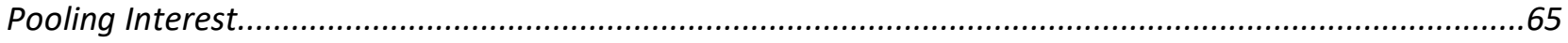

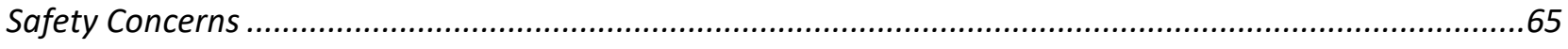

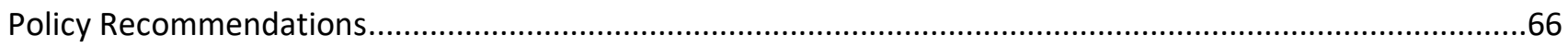

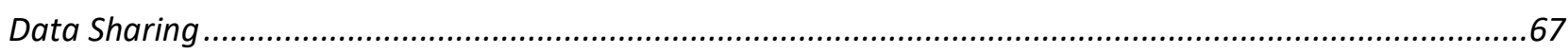

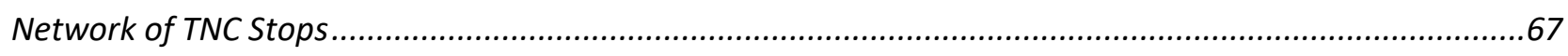

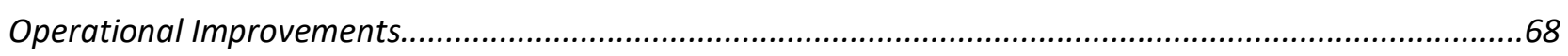

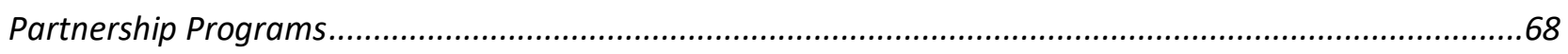

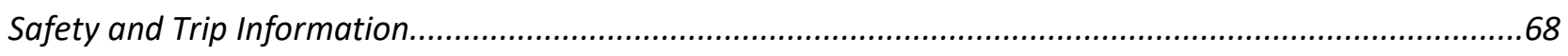

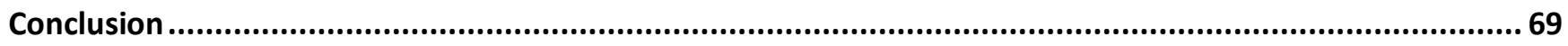

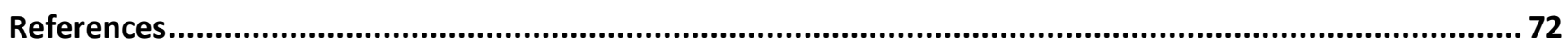

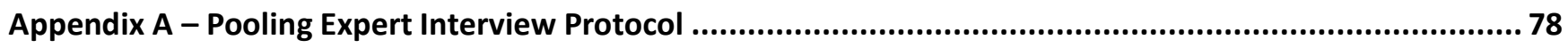

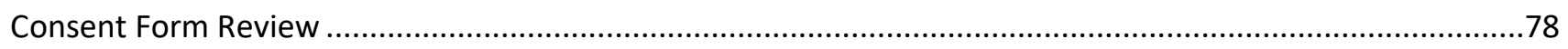

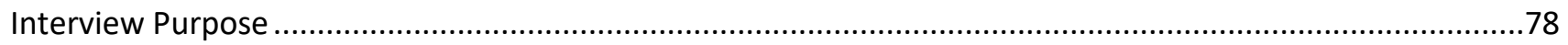


Interview Questions

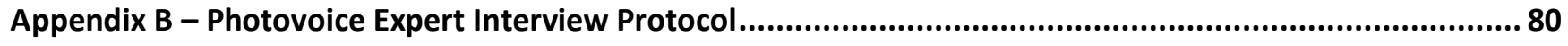

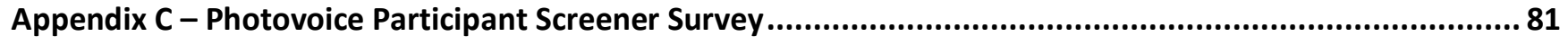

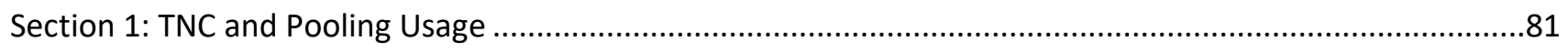

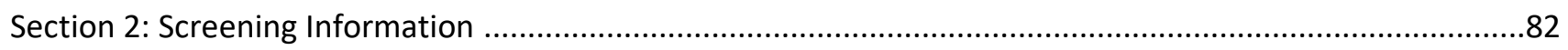

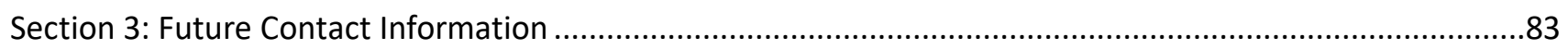

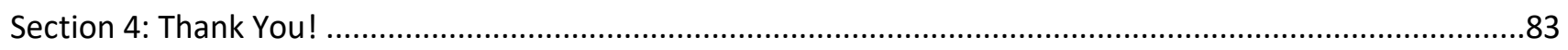

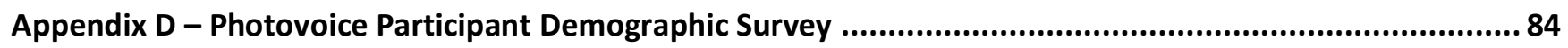

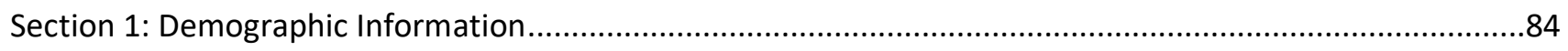

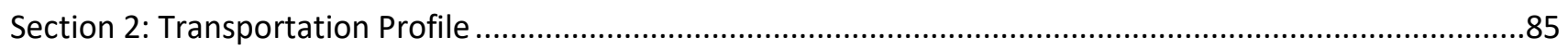

Section 3: Private Transportation Network Company (e.g., Uber or Lyft) and usage .....................................87

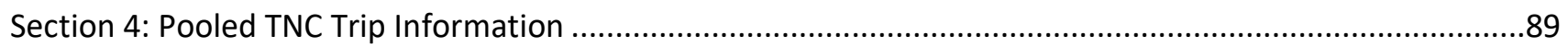

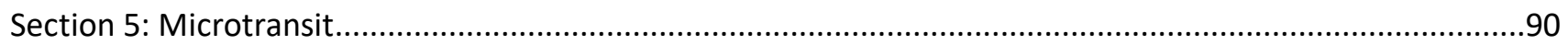

Section 6: Pooled/Private TNC Trip Preferences ....................................................................................91

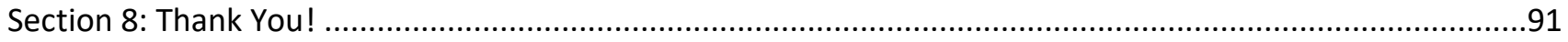

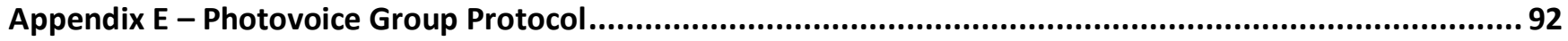

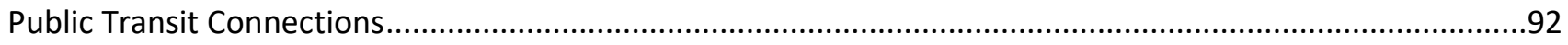

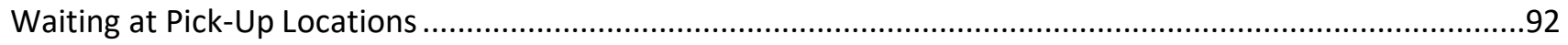

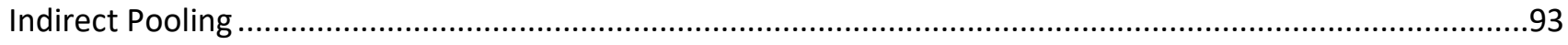

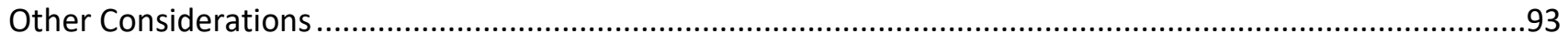

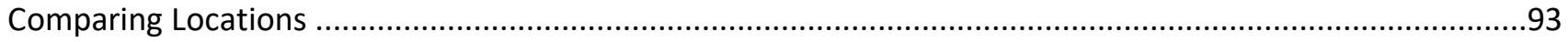

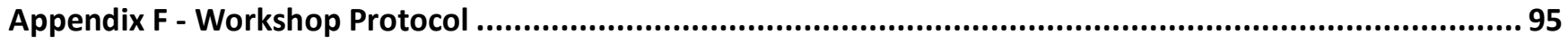

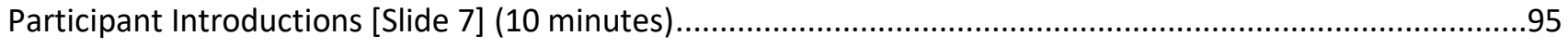

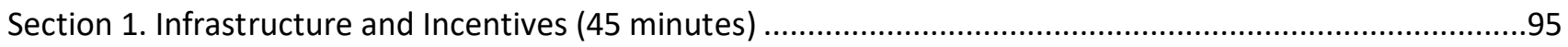

Infrastructure/Built Environment Features at TNC Waiting Locations and Public Transit Stops ..................95

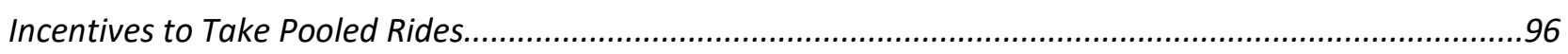

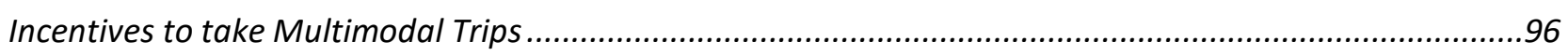

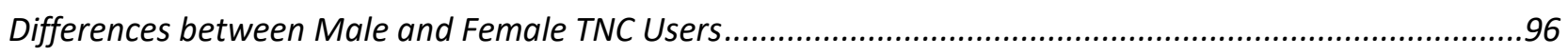

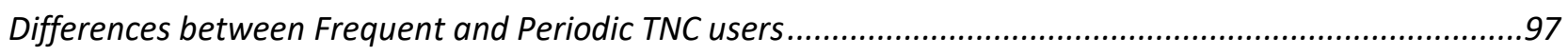

Section 2. Key Recommendation Feedback (45 minutes) .........................................................................98

Recommendation \#1. Increased in-app safety information [Slide 25] ...................................................98

Recommendation \#2. Leverage geofencing and location features to uniquely address the different safety preferences and concerns of male and female TNC users [Slide 26] .......................................................98 
Recommendation \#3. Deploy a network of designated TNC stops to address safety concerns and driver connection challenges [Slide 27] ....

Wrap-up [Slide 28-29] (5 minutes).... 


\section{Tables}

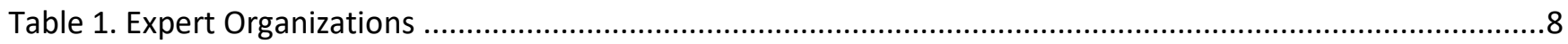

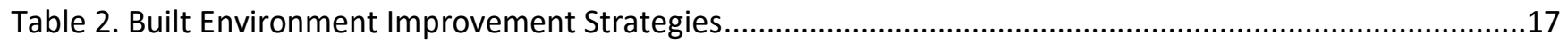

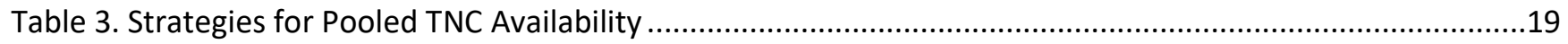

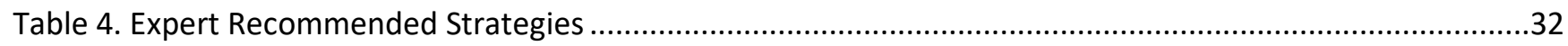

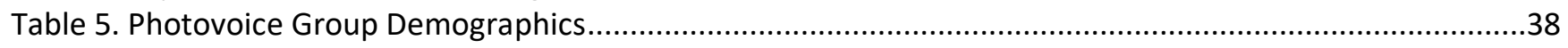

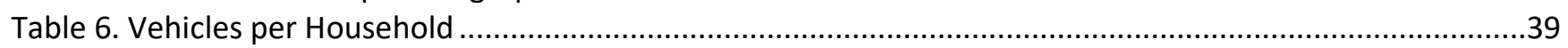

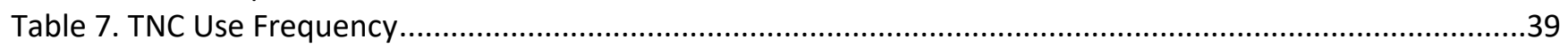

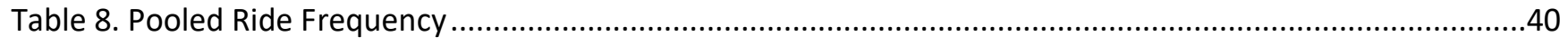

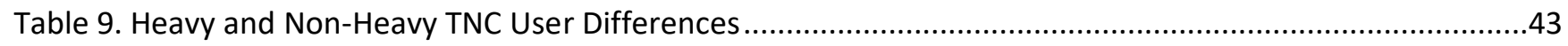

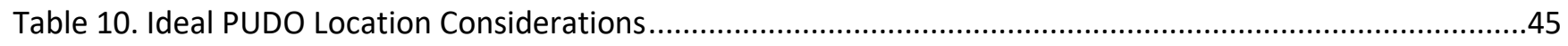

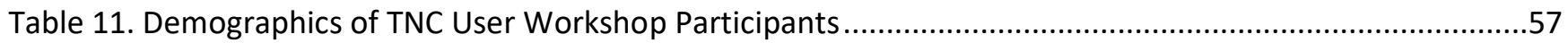

Table 12. Vehicles per Household for TNC User Workshop Participants ........................................................58

Table 13. TNC Use Frequency of TNC User Workshop Participants .....................................................................58

Table 14. Pooled Ride Frequency of TNC User Workshop Participants ...........................................................59

Table 15. Stakeholder Organizations Represented in Workshop ................................................................59

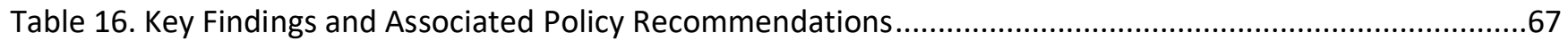




\section{Figures}

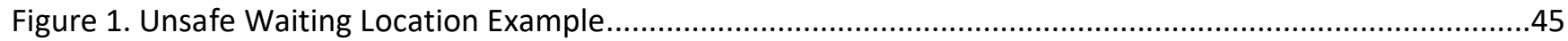

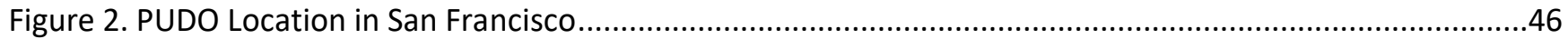

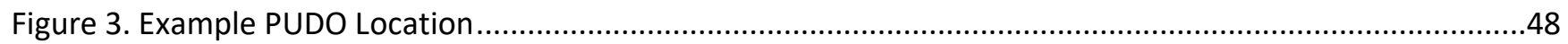

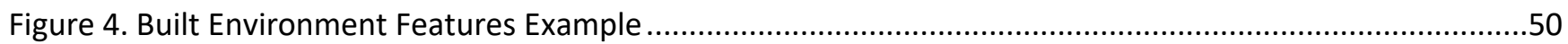

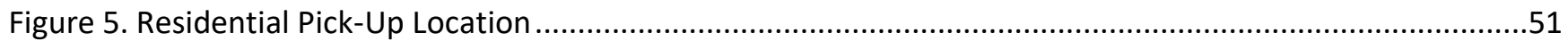




\section{Acknowledgements}

The Transportation Sustainability Research Center (TSRC) of the Institute of Transportation Studies at the University of California, Berkeley would like to thank the USDOT for generously funding this study. The authors would like to thank the transportation professionals, public agencies, and service providers who made this research possible. The contents of this report reflect the views of the authors and do not necessarily indicate sponsor endorsement. 


\section{Executive Summary}

Transportation network companies (TNCs), also known as ridehailing and ridesourcing (e.g., Uber, Lyft), can increase individual mobility and access by allowing travelers to request and pay for rides on-demand using an online-enabled application that connects them with drivers who are using their personal vehicles. However, research has found that TNCs can increase congestion and vehicle emissions, particularly in urban areas. As a result, public agencies are exploring ways to increase the occupancy of TNC vehicles to maintain their benefits while mitigating potential challenges through pooling, or shared ride options. Although pooled TNC rides are typically cheaper than private TNC rides, riders only use higher-occupancy TNC services a fraction of the time (i.e., $20 \%$ to $40 \%$ of TNC trips, depending on the location). Additionally, only about half of pooled trips are actually matched with other riders, rendering the potential benefits moot.

This research explores the reasons behind why more TNC users are not pooling and proposes strategies to increase the use of shared rides. The research builds off of prior literature that has identified built environment changes and incentives as potentially effective strategies to shift users to pooling. However, nearly all previous studies on TNC users relied on quantitative methods with no "live" feedback from users, and the two studies that had focus groups have limitations that prevent broader applicability of the findings. This research addresses these gaps by employing a mixed-methods approach structured around the participatory "photovoice" research methodology, which gathers viewpoints and perspectives from participants through photography and focus groups discussions.

To complete the research, the authors first conducted a literature review on shared mobility, pooled TNC users, and strategies to increase pooling. The literature review helped inform the development of the subsequent expert interview and photovoice group protocols. The researchers then interviewed photovoice $(n=4)$ and pooling experts $(n=10)$ to learn more about the photovoice methodology and opportunities and challenges pooling currently faces. The interview findings informed the development of the photovoice group and pooling workshop protocols.

From March 2021 through May 2021, the authors recruited 15 TNC users located in the San Francisco Bay Area to participate in the photovoice activity. The participants visited three TNC pick-up locations of their choosing and took a minimum of five photographs of built environment features at each location. Participants shared their photographs with the researchers along with one-to-two sentence captions. After submitting photographs, participants engaged in a 1.5-hour small group discussion held over Zoom with two-to-three other TNC users. The authors conducted five small group discussions and one individual interview. In each discussion, participants shared their photographs; reflected on built environment features; and discussed their preferences related to TNCs, incentives to pool and walk to pick-up locations, and use of TNCs to connect to public transit. In July 2021, the researchers held a two-hour Zoom workshop with 12 photovoice participants and five pooling stakeholders. During the workshop photovoice participants shared their photographs and pooling experiences with stakeholders, and all provided feedback on key findings and recommendations developed through the small group discussions. The research helped identify differences between heavy TNC users (i.e., individuals who use TNCs more than three times a week) and non-heavy users (i.e., individuals who use TNCs three times or less per week) and male and female users.

Additionally, the research resulted in four key findings and policy recommendations:

1. Built Environment Preferences: The research revealed that TNC users preferred several built environment characteristics at waiting locations. For example, the participants preferred waiting 
locations that were equipped with good lighting, shelter or protection, and seating and located in safe neighborhoods, near retail options, and away from homeless encampments. However, non-heavy TNC users had more preferences for pick-up locations, likely due to their infrequency and lower familiarity with taking TNC trips. These findings developed into the recommendation of creating designating pickup and drop-off locations to improve the TNC waiting experience and driver and rider connections. Stakeholders could use existing infrastructure (e.g., retail locations) as initial locations for these stops. Despite the potential benefits of this idea, stakeholders were concerned with dedicated pick-up stop maintenance, especially concerning homeless individuals.

2. Incentive Policies: The research revealed that TNC users were incentivized to make decisions based on cost and time savings and trip purpose. For example, riders often selected pooled services as the more affordable, but potentially longer, modal option for non-urgent trips (e.g., to a recreational activity, returning home from work). However, heavy and non-heavy TNC users preferred different incentive types. Heavy TNC users preferred indirect and multimodal discounts because those options minimize their per-trip cost, while non-heavy TNC users preferred discounts to take direct pooled trips. To address this, TNCs could position direct pooling as the default service in terms of pricing and price indirect pooling and multimodal pooling as more heavily discounted options. TNCs could still make private trips available but price them as a more expensive option to disincentivize their use. Stakeholders could also alter commuter benefits to allow employers to leverage these options, and policies could be changed to support the use of pooling in electric and efficient vehicles.

3. Pooling and Public Transit Connections: Only a few TNC users in the group had used TNCs to connect to public transit. Participants predominantly made connections when public transit was difficult to reach by walking, without a first- or last-mile connection, and/or with luggage. Users who did not use TNCs to connect to public transit mostly chose not to because it was easier to stay on one mode (e.g., public transit) for their entire trip. Additionally, a late TNC pick up or drop off could result in a missed timed transfer for public transit. TNC users shared that they would be more interested in using TNCs to connect to public transit if timed transfers between the modes were available, multimodal trip planning were simplified, and riders could receive a transfer discount. As a result, the research team proposed facilitating public transit connections by increasing multimodal trip planning options in TNC apps (e.g., adding walking directions to and from public transit stops and stations). Additionally, TNCs and public transit agencies could partner to develop discounts for mode transfers.

4. Safety Preferences: The photovoice groups and workshop revealed that personal safety is one of the top concerns for TNCs users in deciding when to pool. Participants shared common concerns including being approached on the street, robbed, and/or attacked. Locations with low lighting, prevalence of trash, and people loitering contributed to these concerns. When feeling unsafe, TNC users often wait indoors (e.g., in their home, in a retailer) when hailing a TNC ride. Female riders, in particular, were concerned with threats to their personal safety. Female TNC users often took additional precautions to help ensure their safety (e.g., putting a different pick-up or drop-off address to protect their privacy, having a male walk them out to the TNC vehicle). To address safety concerns, the research team proposed that TNCs consider offering riders more upfront trip information (e.g., route information, number of passengers) and trip options (e.g., ability to select driver gender and/or sharing trip information with an emergency contact).

The research team also identified future research needs including:

- Driver and Rider Goal Alignment: Future research and/or policy may also be needed to align the goals of TNC drivers and users. Drivers and users often have different goals: drivers want to complete as many trips as quickly as possible, while users want safe and comfortable rides. Research into how 
driver incentive policies can be used to make the driver experience more closely reflect the user experience could help realign driver and user goals.

- Gender-Based Differences: Future research can be conducted to explore the current gender-based equity challenges related to the TNC waiting experience. Male and female TNC users perceive the safety of waiting for a TNC differently, largely because the time spent waiting in public can be longer for female users (as noted in the literature), as it puts them at a greater risk for being attacked, approached, or harassed. Research to investigate these differences can explore how incentives compared to built environment improvements impact female users' decision to pool and wait in public. Strategies that aid male and female users in feeling more safe waiting in public for TNCs are needed to make pooling more equitable for all users. This is key along with ensuring more equitable wait times across genders.

- Pooling and Social Equity: Pooling experts highlighted that future research is necessary to evaluate the equity impacts of the different strategies proposed to improve pooling. Equity areas of concern include employing subsidies to encourage lower-income users to pool when appropriate. Additionally, research can explore how user preferences (e.g., avoiding neighborhoods associated with high crimes rates) can impact service area equity (e.g., where drivers are willing to operate and pick up and drop off passengers). 


\section{Introduction}

Transportation network companies (TNCs, also known as ridehailing and ridesourcing) allow travelers to order and pay for rides on-demand using an online-enabled application that connects them with drivers using their personal vehicles. While TNCs can increase individual mobility and access to destinations, they can also contribute to increased congestion and emissions. In response, the public sector is interested in strategies that can be employed to increase TNC vehicle occupancy through pooling (International Transport Forum, 2017; Anair et al., 2020). Typically, travelers have two pooling options available to them:

- Direct Pooling: Users with different origins and destinations along a common route are picked up and dropped off by the same vehicle and share the ride. This option is generally cheaper than private TNC rider.

- Indirect Pooling: Users opt to walk a short distance from their original origin and destination points to pick-up and drop-off points that are optimized for the route. This option is typically associated with additional cost savings and examples include Uber Express Pool and Lyft Shared Saver.

Although cost savings and environmental benefits can be important motivators for travelers to share a ride, pooled TNC options (direct and indirect) only account for approximately $20 \%$ of TNC trips. Additionally, only a portion of the $20 \%$ of riders who select pooled trips are actually matched with other riders (Gehrke et al., 2018; Young et al., 2020). To better understand these findings this research aims to answer four key questions:

1. Why are not more people taking pooled TNC trips?

2. How do different factors of the pooled TNC experience (e.g., the built environment, feelings of safety and security) impact a TNC user's decision to pool?

3. What differences exist between "heavy" TNC users (i.e., users who take TNCs more than three times per week) and "non-heavy" TNC users (i.e., users who take TNCs three or fewer times per week)?" ${ }^{1}$

4. How can TNC users be encouraged to share rides and/or connect their rides to public transit?

Prior to this research only a limited number of studies engaged with TNC users to understand how their underlying experiences and beliefs influence travel behavior decisions. As a result, and to best answer the research questions, this study features the photovoice method. Photovoice is a

\section{Common Terms and Definitions}

Transportation network companies

(TNCS) allow travelers to order and pay for rides on-demand using an online-enabled application that connects them with drivers using their personal vehicles.

Direct pooling refers to users with different origins and destinations along a common route being picked up and dropped off by the same vehicle.

Indirect pooling refers to when users opt to walk a short distance from their origin and destination points to pick-up and drop-off points that are optimized for the route.

Heavy TNC users take TNC trips more than three times per week.

Non-heavy TNC users take TNC trips three times or less per week.

Pick-up/drop-off (PUDO) locations are where passengers meet their driver or depart from their ride.

Estimated time of arrival (ETA) is the approximate time a trip will end.

${ }^{1}$ The definition of heavy and non-heavy TNC users is based on findings from Lazarus et al. (2021) and Shaheen et al. (2021). 
qualitative, participatory research method that allows community members to use photography to communicate their personal experiences and perceptions of their surroundings. The photovoice methodology helped the researchers better understand how TNC pooling might be improved (and increased in share) through modifications to the built environment, app-based routing, and incentives to encourage using it and linking trips to public transit. The researchers also examined differences in response to pooling and first- and last-mile TNCs connections to public transit between heavy and non-heavy users.

This report includes seven sections:

1. Methodology: Description of each of the four research methods employed (literature review, expert interviews, adapted photovoice methodology [due to COVID-19], and TNC user and stakeholder workshop);

2. Literature Review: Overview of background information, research, and literature on relevant topic areas including shared mobility, pooled TNC rides, pooling strategies, and the photovoice methodology;

3. Expert Interviews: Summary of interviews with four photovoice experts and 10 pooling experts;

4. Photovoice Group Findings: Key findings from the photovoice group on a variety of topic areas including direct and indirect pooling experience, current pick-up/drop-off (PUDO) locations, and opinions on a network of PUDO locations;

5. Workshop Findings: Results of the workshop held with 12 TNC users and five key transportation stakeholders on topic areas including designated TNC stops, in-app safety features, pooling incentives, and public transit connection incentives;

6. Policy Recommendations: Discussion of potential policy levers used to encourage pooled TNC rides and TNC use to connect to and from public transit; and

7. Conclusion: Summary of the study. 


\section{Methodology}

The research team employed a mixed-methods approach to understand current behaviors and perceptions of strategies to improve the pooled trip experience, and how to increase the number of pooled trips and TNC firstand last-mile connections to public transit.

\section{Literature Review}

The research team reviewed over 100 journal articles and reports between August and September 2020. Topics researched include: transportation network companies, ridesharing (carpooling and vanpooling), shared ride services, carsharing, direct and indirect TNC trips, curbspace management, the built environment, public transit stop safety, PUDO location safety, taxi stands, and designated PUDO locations. Despite best efforts to encompass as much of the relevant literature in the review as available, the growth in shared mobility literature may result in some research being inadvertently missed.

The literature review was then narrowed to explore pooled TNC services, who uses pooled TNCs, what factors influence traveler willingness to pool, and what can be changed to increase the number of users deciding to pool and to connect to public transit via TNC services. Additional facets of the pooled TNC experience were explored through literature on curb management and the built environment, including taxi stands and designated PUDO locations, and safety in public spaces and at these waiting locations. Strategies for improving each of these factors were also researched. Key findings from the literature review helped to inform the development of the expert interview protocol. The literature review also informed the methodological design of the photovoice method (described later on in the methodological discussion). This was particularly important due to photovoice's new application to transportation engineering.

\section{Expert Interviews}

To fill gaps in the literature review, 14 expert interviews were conducted from October 2020 to February 2021. The interviews focused on the photovoice methodology and best practices, pooling opportunities and challenges, and pooling considerations that could benefit from further research. The interviews included two groups of experts: 1 ) stakeholders involved with pooling ( $n=10)$, and 2 ) individuals with experience employing the photovoice method $(n=4)$. Interviews were conducted virtually using Zoom, and each lasted approximately one hour. Experts were asked pre-arranged sets of questions, although certain subjects were explored further based on the individual's area of expertise. The protocols for the pooling and photovoice experts can be found in

References

(@MCO), O. I. (2017). You can now pick up UberX and Lyft from MCO! Retrieved from Twitter: https://twitter.com/mco/status/910595720603979776

Alonso-Gonzalez, M., Cats, O., van Oort, N., Hoogendoorn-Lanser, S., \& Hoogendoorn, a. (2020). What are the determinants of the willingness to share rides in pooled on-demand services? Transportation .

American Public Transportation Association. (2012). Design of On-Street Transit Stops and Access from Surrounding Areas. Washington, D.C.: American Public Transportation Association.

Amirkiaee, S., \& Evangelopoulos, N. (2018). Why do people rideshare? An experimental study. Transportation Research Part F: Traffic Psychology and Behavior, 55.

Anair, D., Martin, J., Pinto de Moura, M., \& Gouldman, J. (2020). Ride-Hailing's Climate Risks. Oakland: Union of Concerned Scientists.

Aono, S. (2019). Identifying Best Practices for Mobility Hubs. Vancouver: University of British Columbia. 
Aw, E., Basha, N., Ng, S., \& Sambasivan, M. (2019). To grab or not to grab? The role of trust and perceived value in on-demand ridesharing services. Asia Pacific Journal of Marketing and Logistics, 31.

BAAQMD. (2014). Regulation 14 Mobile Source Emissions Reduction Measures Rule 1: Bay Area Commuter Benefits Program. San Francisco, California.

Bell, L., Beltran, G., Berry, E., Calhoun, D., Hankins, T., \& Hester, L. (2018). Public Transit and Social Responsibility: Homelessness. Washington, D.C.: American Public Transportation Association.

Bhuiyan, J. (2018). Uber's new 'Express Pool' is all about getting more riders to share rides. Retrieved from Vox: https://www.vox.com/2018/2/21/17032598/uber-express-pool-transit-bus-cheaper

Brantingham, P., \& Brantingham, P. (1993). Environment, routine and situation: Toward a pattern theory of crime. In R. Clarke, \& M. Felson, Routine activity and rational choice: Advances in criminological theory (Vol. 5, pp. 259-294). Piscataway, NJ: Transaction.

Brownson, R., Baker, E., Houseman, R., Brennan, L., \& Bacak, S. (2001). Environmental and Policy Determinants of Physical Activity in the United States. American Journal of Public Health, 91(12), 995-2003.

Castleden, H., Garvin, T., \& First Nation, H. (2008). Modifying Photovoice for community-based Indigenous research. Social Science \& Medicine, 66.

Centers for Disease Control. (2021). People at Increased Risk And Other People Who Need to Take Extra Precautions. Retrieved from Centers for Disease Control and Prevention: https://www.cdc.gov/coronavirus/2019-ncov/need-extra-precautions/index.html

Chan, N., \& Shaheen, S. (2011). Ridesharing in North America: Past, Present, and Future. Transport Reviews, 32.

Clewlow, R., \& Mishra, G. (2017). Disruptive Transportation: The Adoption, Utilization, and Impacts of RideHailing in the United States. Institute of Transportation Studies.

Cohen, A., \& Shaheen, S. (2018). Planning for Shared Mobility.

Cohen, L., \& Felson, M. (1979). Social change and crime trends: A routine activity approach. American Sociological Review, 44, 588-698.

Conway, M., Salon, D., \& King, D. (2018). Trends in Taxi Use and the Advent of Ridehailing, 1995-2017: Evidence from teh US National Household Travel Survey. Urban Science.

Cornish, D., \& Clarke, R. (1986). The Reasoning Criminal. New York: Springer-Verlag.

CPUC. (2021). Transportation Network Companies Background. Retrieved from California Public Utilities Commission: https://www.cpuc.ca.gov/tncinfo/

Erhardt, G., Roy, S., Cooper, D., Sana, B., Chen, M., \& Castiglione, J. (2019). Do transportation network companies decrease or increase congestion? Science Advances.

Etherington, D. (2018). Uber officially launches Uber Express POOL, a new twist on shared rides. Retrieved from TechCrunch: https://techcrunch.com/2018/02/21/uber-officially-launches-uber-express-pool-a-newtwist-on-shared-rides/

Ewing, R., \& Handy, S. (2009). Measuring the Unmeasurable: Urban Design Qualities Related to Walkability. Journal of Urban Design.

Fehr and Peers. (2018). San Francisco Curb Study. San Francisco: Fehr and Peers. Retrieved from https://www.fehrandpeers.com/curbs-of-the-future/

Gehrke, S., Felix, A., \& Reardon, T. (2018). A Survey of Ride-Hailing Passengers in Metro Boston. Boston: Metropolitan Area Planning Council.

Gerell, M. (2018). Bus Stops and Violence, Are Risky Places Really Risky? European Journal of Criminal Policy and Research, 24, 351-371.

Goodall, W., Fishman, T., Bornstein, J., \& Bonthron, B. (2017). The rise of mobility as a service. Deloitte Review. Goodchild, A., MacKenzie, D., Ranjbari, A., Machado, J., \& Chiara, G. (2019). Curb Allocation Change Project: Final Report. Seattle: University of Washington.

Gordon, M., \& Riger, S. (1989). The Female Fear. New York: The Free Press. 
Graehler, G., Mucci, A., \& Erhardt, G. (2019). Understanding the Recent Transit Ridership Decline in Major US Cities: Service Cuts or Emerging Modes? 2019 Transportation Research Board Annual Meeting.

Grahn, R., Harper, C., Hendrickson, C., Qian, Z., \& Matthew, H. (2019). Socioeconomic and usage characteristics of transportation network company (TNC) riders. Transportation, 47.

Hannay, J., Dudley, R., Milan, S., \& Leibovitz, P. (2013). Combining Photovoice and foucs groups: engaging Latina teens in community assessment. American Journal of Preventative Medicine.

Henao, A. (2017). Impacts of Ridesourcing - Lyft and Uber - on Transportation Including VMT, Mode Replacement, Parking, and Travel Behavior. Denver: University of Colorado.

Henao, A., \& Marshall, W. (2018). The impacts of ride-hailing on vehicle miles traveled. Transportation, 21732174.

Hergenrather, K., Rhodes, S., Cowan, C., Bardhoshi, G., \& Pula, S. (2009). Photovoice as community-based participatory research: a qualitative review. American Journal of Health and Behavior.

Institute of Transportation Engineers. (2018). Curbside Management Practitioners Guide. Washington, D.C.: Institute of Transportation Engineers. Retrieved from https://s23705.pcdn.co/wpcontent/uploads/2019/03/ITE-Kerbside-Curbside-Management-Guide.pdf

International Transport Forum. (2017). Shared Mobility Simulations for Helsinki. Paris: International Transport Forum.

International Transport Forum. (2018). The Shared-Use City: Managing the Curb. Paris: International Transport Forum. Retrieved from https://www.itf-oecd.org/sites/default/files/docs/shared-use-city-managingcurb_5.pdf

Jacobs, J. (1961). The Life and Death of Great American Cities. New York: Vintage Books.

Jiang, S., Chen, L., Mislove, A., \& Wilson, C. (2018). On Ridesharing Competition and Accessibility: Evidence from Uber, Lyft, and Taxi. 2018 World Wide Web Conference on World Wide Web.

Jiao, J., \& Wang, F. (2019). Shared mobility and transit-dependent population: A new equity opportunity or issue? International Journal of Sustainable Transportation.

Jin, S., Kong, H., \& Sui, D. (2019). Uber, Public Transit, and Urban Transportation Equity: A Case Study in New York. The Professional Geographer.

Kang, S., Mondal, A., Bhat, A., \& Bhat, C. (2020). Pooled Versus Private Ride-Hailing: A Joint Revealed and Stated Preference Analysis Recognizing Psycho-Social Factors. Austin: The University of Texas at Austin.

Kim, S., Chang, J., Park, H., Song, S., Cha, C., Kim, J., \& Kang, N. (2020). Autonomous Taxi Service Design and User Experience. International Journal of Human-Computer Interation, 36(5), 429-448.

La Vigne, N. (1997). Visibility and Vigilance: Metro's Situational Approach to Preventing Subway Crime. Washington: National Institute of Justice.

Lavieri, P., \& Bhat, C. (2019). Investigating objective and subjective factors influencing the adoption, frequency, and characteristics of ride-hailing trips. Transportation Research Part C: Emerging Technologies.

Lavieri, P., Dias, F., Juri, N., Kuhr, J., \& Bhat, C. (2018). A Model of Ridesourcing Demand Generation and Distribution. Transportation Research Record.

Lazarus, J., Caicedo, J., Bayen, A., \& Shaheen, S. (2021). To Pool or Not to Pool? Understanding Opportunities and Challenges to Expand the Market for Pooling. Transportation Research Part A: Policy and Practice.

LeighFisher. (2010). Airport Curbside and Terminal Area Roadway Operations. Airport Cooperative Research Program.

Lekach, S. (2019). Lyft rolls out its own version of Uber Express Pool called 'Shared Saver'. Retrieved from Mashable: https://mashable.com/article/lyft-shared-saver-uber-express-pool/

Levin, D. (2006). Which way is up: towards accessible wayfinding in transit stations. Cambridge: Massachusetts Institute of Technology.

Lewis, E., \& MacKenzie, D. (2017). UberHOP in Seattle: Who, Why, and How? Transportation Research Record. 
Li, X., Hu, S., Fan, W., \& Deng, K. (2018). Modeling an enhanced ridesharing system with meet points and time windows. PloS ONE.

Li, Z., Hong, Y., \& Zhang, Z. (2016). An empirical analysis of on-demand ride-sharing and traffic congestion. International Conference of System Sciences. Dublin.

Lippke, K., \& Noyce, C. (2020). Public Acceptance and Adoption of Shared-ride Services in the Ride-hailing industry. University of Michigan.

Livingstone-Lee, S., Skelton, R., \& Livingston, L. (2014). Transit Apps for People with Brain Injury and Other Cognitive Disabilities: The State of the Art. Assistive Technology.

Lo, J., \& Morsemann, S. (2018). The Perfect uberPOOL: A Case Study on Trade-Offs. Ethnographic Praxis in Industry Conference.

Los Angeles Department of City Planning. (2016). Mobility Hubs: A Reader's Guide. Los Angeles: Los Angeles Department of City Planning.

Loukaitou-Sideris, A. (1999). Hot Spots of Bus Stop Crime: The Importance of Environmental Attributes. Journal of the American Planning Association, 65(4), 395-411.

Loukaitou-Sideris, A. (2005). Is It Safe to Walk Here? Design and Policy Responses to Women's Fear of Victimization in Public Places. Research on Women's Issues in Transportation, Report of a Conference, Volume 2: Technical Papers. Washington, D.C.: Transportation Research Board.

Lu, R. (2018). Pushed from the Curb: Optimizing Curb Space for Use by Ride-sourcing Vehicles. Los Angeles: University of California. Retrieved from https://escholarship.org/content/qt25p966dh/qt25p966dh_noSplash_970a2e35099554d365f630d9a1 7cc1d3.pdf.

Lynch, G., \& Atkins, S. (1988). The Influence of Personal Security Fears on Women's Travel Patterns. Transportation, 15, 255-277.

Mandle, P., \& Box, S. (2017). Transportation Network Companies: Challenges and Opportunities for Airport Operators. Washington: The National Academies Press.

Manville, M., Taylor, B., \& Blumenberg, E. (2018). Falling Transit Ridership: California and Southern California. Los Angeles: University of California Institute of Transportation Studies. Retrieved from https://www.its.ucla.edu/2018/01/31/new-report-its-scholars-on-the-cause-of-californias-fallingtransit-ridership/.

Miles, D. (2019). Help students, staff stay safe when using rideshare apps. Student Affairs Today, 22(5), 6.

Moody, J., \& Zhao, J. (2020). Adoption of Exclusive and Pooled TNC Services in Singapore and the US. Journal of Transportation Engineering Part A: Systems.

Moody, J., Middleton, S., \& Zhao, J. (2019). Rider-to-rider discriminatory attitudes and ridesharing behavior. Transportation Research Part F: Traffic Psychology and Behavior, 62.

Moreira-Matias, L., Fernandes, R., Gama, J., Ferreira, M., Mendes-Moreira, J., \& Damas, L. (2012). An Online Recommendation System for the Taxi Stand choice Problem (Poster). IEEE Vehicular Networking Conference.

Moudon, A., Bassok, A., \& Kang, M. (2018). Safe from Crime at Location-Specific Transit Facilities: Final Project Report. Washington State Transportation Center. Retrieved from https://www.wsdot.wa.gov/research/reports/fullreports/882-1.pdf.

Murphy, C., \& Feigon, S. (2016). Shared Mobility ad the Transformation of Public Trust. American Public Transportation Association.

National Association of City Transportation Officials. (2017). Curb Appeal: Curbside Management Strategies for Improving Transit Reliability. National Association of City Transportation Officials. Retrieved from https://nacto.org/wp-content/uploads/2017/11/NACTO-Curb-Appeal-Curbside-Management.pdf.

Newman, O. (1972). Defensible Space: Crime Prevention through Urban Design. New York: MacMillan. 
Newton, A., \& Ceccato, V. (2015). Theoretical perspectives of safety and security in transit environments. In V. Ceccato, \& A. Newton, Safety and Security in Transit Environments: An Interdisciplinary Approach (pp. 23-36). New York: Palgrave Macmillan.

Pew Research Center. (2021). Who owns cellphones and smartphones. Retrieved from Pew Research Center: https://www.pewresearch.org/internet/fact-sheet/mobile/

Pratt, A., Morris, E., Zhou, Y., Khan, S., \& Chowdhury, M. (2019). What do riders tweet abou the people they meet? Analyzing online commentary about UberPool and Lyft Shared/Lyft Line. Transportation Research Part F: Traffic Psychology and Behavior.

Qu, Z., Wang, X., Song, X., Pan, Z., \& Li, H. (2019). Location Optimization for Urban Taxi Stands Based on Taxi GPS Trajectory Big Data. IEEE Access, 7, 62273-62283.

Rayle, L., Dai, D., Chan, N., Cervero, R., \& Shaheen, S. (2016). Just a better taxi? A survey-based comparison of taxis, transit, and ridesourcing services in San Francisco. Transportation Policy.

Reason, P., \& Bradbury, H. (2001). Handbook of Action Research - Participative Inquiry and Practice. London: Sage.

Ross, C. (2000). Walking, Exercising, and Smoking: Does Neighborhood Matter? Social Science and Medicine, 15(2), 265-274.

SAE International. (2018). Taxonomy and Definitoins for Terms Related to Shared Mobility and Enabling Technologies. Detroit: SAE International .

Salanova, J., \& Romeu, M. (2018). Modeling framework for comparing taxi operational modes: Case study in Barcelona. Transportation Research Procedia, 33, 59-66.

Saldaña, J. (2013). The Coding Manual for Qualitative Researchers. Los Angeles: SAGE.

Sarriera, J., Alvarez, G., Blynn, K., Alesbury, A., Scully, T., \& Zhao, J. (2017). To Share or Not To Share: Investigating the Social Aspects of Dynamic Ridesharing. Transportation Research Record J.

Sartori Do Amaral, C., Chamorro-Koc, M., Beatson, A., \& Tuzovic, S. (2019). Enabling self-determination through transformative service design and digital technologies: studying mobility experiences of people with disability. International Association of Societities of Design Research Conference, (pp. 1-16).

Schaller Consulting . (2017). Unsustainable? The Growth of App-Based Ride Services and Traffic, Travel, and the Futrue of New York City. New York City: Schaller Consulting.

Schaller Consulting. (2018). The New Automobility: Lyft, Uber, and the Future of American Cities. New York City: Schaller Consulting.

Schaller Consulting. (2019). Making the Most of the Curb: Managing passenger and parcel pick-up and drop-off on congested city streets. New York: Schaller Consulting.

SFMTA. (2020). Curb Management Strategy. San Francisco.

Shaheen, S. (2018). Chapter 4: Shared Mobility: The Potential of Ride Hailing and Pooling. Berkeley: University of California, Berkeley: Transportation Sustainability Research Center.

Shaheen, S., \& Cohen, A. (2018). Shared ride services in North America: definitions, impacts, and the future of pooling. Transport Reviews.

Shaheen, S., \& Cohen, A. (2019). Shared Micromobility Policy Toolkit: Docked and Dockless Bike and Scooter Sharing. Berkeley: University of California, Berkeley.

Shaheen, S., Bell, C., Cohen, A., \& Yelchuru, B. (2017). Travel Behavior: Shared Mobility and Transportation Equity. Washington: Federal Highway Administration.

Shaheen, S., Chan, N., \& Gaynor, T. (2016). Casual carpooling in the San Francisco Bay Area: Understanding user characteristics, behaviors, and motiviations. Transport Policy, 165-173.

Shaheen, S., Cohen, A., \& Bayen, A. (2018). The Benefits of Carpooling. Berkeley: University of California, Berkeley: Transportation Sustainability Research Center. 
Shaheen, S., Cohen, A., \& Zohdy, I. (2016). Shared Mobility: Current Practices and Guiding Principles. Washington, D.C.: Federal Highway Administration.

Shaheen, S., Cohen, A., Chan, N., \& Bansal, A. (2020). Chapter 13: Sharing strategies: carsharing, shared micromobility (bikesharing and scooter sharing), transportation network companies, microtransit, and other innovative mobility modes. Transportation, Land Use, and Environmental Planning.

Shaheen, S., Cohen, A., Randolph, M., Farrar, E., Davis, R., \& Nichols, A. (2019). Shared Mobility Policy Playbook. California Department of Transportation.

Shaheen, S., Lazarus, J., Caicedo, J., \& Bayen, A. (2021). To Pool or Not to Pool Understanding the Time and Price Tradeoffs of On-Demand Ride Users - Opportunities, Challenges, and Social Equity Considerations for Policies to Promote Shared-Ride Services. UC Office of the President: University of California Institute of Transportation Studies.

Sitter, K., \& Mitchell, J. (2020). Perceptions of Paratransit Accessibility Among Persons with Disabilities: An Adapted Photovoice Study. Health Promotional Practice.

Stanko, E. (1990). Everyday Violence: Women's and Men's Experience of Personal Danger. London: Pandora.

Stucky, T., \& Smith, S. (2017). Exploring the conditional effects of bus stops on crime. Security Journal, 30, 290309.

True, G., Rigg, K., \& Butler, A. (2014). Understanding Barriers to Mental Health Care for Recent War Veterans Through Photovoice. Quality Healthy, 1-13.

United States Census Bureau. (2019, June 3). 2019: ACS 1-Year Estimates Data Profiles. Retrieved from United States Census Bureau: https://data.census.gov/cedsci/table?g=310M500US41860\&tid=ACSDP1Y2019.DP05

Valentine, G. (1990). Women's Fear and the Design of Public Space. Built Environment, 16(4), 288-303.

Van Audenhove, L. (2007). Expert Interviews and Interview Techniques for Policy Analysis. Vrije Universiteit Brussel.

Wang, C., \& Burris, M. (1997). Photovoice: concept, methodology, and use for participatory needs assessment. Health Educational Behavior.

Wasserman, J., Taylor, B., Blumenberg, E., Garrett, M., King, H., Paul, J., . . Schouten, A. (2020). What's Behind Recent Transit Ridership Trends in the Bay Area? Volume II: Trends among Major Transit Operators. University of California Institute of Transportation Studies. Retrieved from https://escholarship.org/uc/item/96w4g18f

Weber, B. (2019). Uber and urban crime. Transportation Research Part A Policy and Practice, 130, 496-506.

Wekerkle, G., \& Whitzman, C. (1995). Safe Cities: Guidelines for Planning, Design and Management. New York: Van Nostrand Reinhold.

Wilson, J., \& Kelling, G. (1982). Broken Windows: The Police and Neighborhood Safety. Atlantic Monthly, 249(3), 29-38.

Young, M., \& Farber, S. (2019). Ride-hailing Platforms Are Shaping the Futrue of Mobility, but for Whom? OSF Preprints.

Young, M., \& Farber, S. (2019). The who, why, and when of Uber and other ride-hailing trips: An examination of a large sample household travel survey. Transportation Research Part A: Policy and Practice.

Young, M., Farber, S., \& Palm, M. (2020). The true cost of sharing: A detour penality analysis between UberPool and UberX trips in Toronto. Transportation Research Part D: Transport and Environment.

Zahnow, R., \& Corcoran, J. (2019). Crime and bus stops: An examination using transit smart card and crime data. Environment and Planning B: Urban Analytics and City Science, 1-18.

Zhang, W., \& Ukkusuri, S. (2021). Share-a-Cab: Scalable Clustering Taxi Group Ride Stand From Huge Geolocation Data. IEEE Access, 9, 9771-9776. 
Zheng, H., Chen, X., \& Chen, X. (2019). How Does On-Demand Ridesplitting Influence Vehicle Use and Purchase Willingness? A Case Study in Hangzhou, China. IEEE Intellient Transportation Systems Magazine. 
Appendix A - Pooling Expert Interview Protocol and Appendix B - Photovoice Expert Interview Protocol, respectively. Table 1 summarizes the organizations represented in the expert interviews. 
Table 1. Expert Organizations

\begin{tabular}{|c|c|c|c|c|c|}
\hline \multirow[b]{2}{*}{ Subject Area } & \multirow[b]{2}{*}{ Organization } & \multicolumn{4}{|c|}{ Sector } \\
\hline & & $\begin{array}{c}\text { Academic } \\
(n=3)\end{array}$ & $\begin{array}{c}\text { Non-Profit } \\
(n=1)\end{array}$ & $\begin{array}{l}\text { Private } \\
(n=4)\end{array}$ & $\begin{array}{l}\text { Public } \\
\text { ( } n=4)\end{array}$ \\
\hline \multirow{4}{*}{ Photovoice } & Photovoice Worldwide & & & $\mathrm{X}$ & \\
\hline & Kent State University & $\mathrm{x}$ & & & \\
\hline & University of Buffalo & $\mathrm{x}$ & & & \\
\hline & University of California, Berkeley & $\mathrm{x}$ & & & \\
\hline \multirow{8}{*}{ Pooling } & Alameda-Contra Costa Transit District (AC Transit) & & & & $\mathrm{X}$ \\
\hline & California Public Utilities Commission & & & & $\mathrm{x}$ \\
\hline & City of Oakland & & & & $x$ \\
\hline & Lyft & & & $\mathrm{X}$ & \\
\hline & San Francisco Bay Area Rapid Transit District (BART) & & $\mathrm{X}$ & & $\mathrm{X}$ \\
\hline & TransForm & & & & \\
\hline & Uber & & & $\mathrm{X}$ & \\
\hline & Via & & & $\mathrm{x}$ & \\
\hline
\end{tabular}

\section{Pooling Experts}

Ten pooling experts from the public, private, and non-profit sectors were interviewed for insights on current pooling practices. The research team conducted the interviews virtually in January and February 2021. While the interviews followed the pooling stakeholder protocol, specific details in the questions were modified to reflect each expert's organization and interactions with pooled mobility services. The subject areas covered included: current state of the industry, opportunities, challenges, and best practices. Findings resulting from the pooling expert interviews were used to develop the protocol for the small group discussions with TNC users in the photovoice portion of the study.

\section{Photovoice Experts}

The interviews with photovoice experts helped enhance the research team's understanding of the photovoice method. The interviews also provided insights into methodological changes that would need to be employed in response to the global pandemic. Interviews with photovoice experts helped to ensure the proposed modifications maintained the core tenets behind the photovoice methodology.

In October 2020, interviews with four experts from the fields of public health, city and regional planning, and sociology were conducted. Experts were first asked a series of pre-arranged questions regarding best practices for administering the photovoice methodology in both a physical and virtual environment. The experts were then shown a brief presentation outlining the research team's proposed modifications to the photovoice method for this study and were asked to provide feedback and recommendations for improvement. These recommendations informed the development of the modified photovoice methodology implemented as part of this study.

\section{Expert Interview Limitations}

As with any expert interview study, the knowledge obtained from the photovoice and pooling experts may not be entirely unbiased (Van Audenhove, 2007). The authors attempted to mitigate receiving potentially biased responses by asking interviewees standard questions, and an effort was made to interview multiple experts 
from a broad swathe of sectors. Additionally, all interviewee responses were aggregated for the analysis to ensure the objectivity of the final results.

\section{Modified Photovoice Methodology with TNC Users}

The authors used a modified photovoice methodology to explore how different aspects of the built environment and waiting experience at TNC pick-up locations impact pooling and first- and last-mile public transit decisions. The research focused on TNC users in the San Francisco Bay Area. Recruitment began in March 2021 using a screening survey posted on Craigslist. Photovoice group recruitment concluded in May 2021 to allow time for scheduling the photovoice groups, recruiting workshop participants, analyzing photovoice group and workshop findings, and completing the final report before the project conclusion in August 2021. The Craigslist postings were tagged with different Bay Area city zip codes to collect the widest variety of participants possible. The postings included a brief summary of the project, what participation entailed, description of the incentive offered, researcher contact information, and link to the screener survey. The screener survey collected information on frequency of TNC use (private and pooled), ability to take photographs at TNC PUDO locations, availability to attend photovoice group discussions over Zoom, agreement to follow all local COVID-19 protocols, and basic contact information. The responses to the screening survey allowed for a balance of heavy and non-heavy TNC users to be recruited for the study. A copy of the screener survey can be found in Appendix C - Photovoice Participant Screener Survey.

Following the screening survey, recruited TNC users filled out a short survey containing travel behavior and demographic questions. The results from the travel survey allowed the research team to ensure that study participants represented a variety of demographic characteristics (e.g., household income, age). The research team recruited 15 TNC users (seven heavy and eight non-heavy TNC users) to participate in the study. A copy of the demographic survey can be found in Appendix D - Photovoice Participant Demographic Survey.

The photovoice groups were small (i.e., two to four participants) to allow for a more in-depth discussion of each group of participants' photos and experiences. Four small group discussions and one individual interview were held with study participants. The small group discussions were recorded, transcribed, and coded based on the "generic" coding method presented in Saldaña (2013).

Prior to the photovoice session participants were asked to complete a series of tasks including:

1. Locations: Visit three different locations where they had either previously been or could see themselves being picked up by a TNC,

2. Photographs: Take a minimum of five photographs at each location capturing the area and any built environment features that could positively or negatively impact the waiting experience,

3. Captions: Share the photographs along with one to two sentence captions via an online form, and

4. Travel Survey: Complete a survey with travel behavior and demographic questions.

Following their photography submission, participants engaged in a 1.5-hour small group discussion with other TNC users over Zoom. A conversation was facilitated between TNC users around the photos they shared and their prior TNC experiences. This allowed the researchers to learn how the waiting experience impacts a user's decision to select the pooled option and discuss potential ways the waiting experience could be improved. Topics of conversation also included TNC and public transit connections, safety and security at and around pickup locations as well as in TNC vehicles, desired waiting amenities and built environment features, incentives 
(e.g., discounts and promotions) for different TNC trip types, and COVID-19 impacts. The photovoice group protocol can be found in Appendix E - Photovoice Group Protocol.

\section{Photovoice Study Limitations}

The modified photovoice methodology employed in this study has several limitations. First, photovoice studies are typically conducted in-person because it allows for greater interaction and gives an opportunity for participants and facilitators to build trust, leading to deeper conversations and insights. Because this study was conducted remotely due to pandemic health and safety guidelines, all participant-facilitator interactions were held over Zoom, which could have led some participants to be less forthcoming in their responses due to a lack of rapport.

Other limitations included strict screening requirements. Because photovoice was implemented remotely, participants were screened for their ability to take and upload photographs (i.e., owning a smartphone or mobile phone with a camera and Internet capabilities) and their ability to use the Zoom teleconferencing tool (i.e., having access to a computer with a webcam and Internet connection). Traditional photovoice studies, as described in the literature, typically involve the facilitators providing a means of capturing images for participants that do not have access to a camera. This is because many photovoice studies focus on underserved communities that may not have access to the Internet or cameras. By meeting in person, it removes the need for teleconferencing software or a means to upload images. The protocol the research team used in this study required participants to provide their own cameras and have access to the Internet to complete the photovoice procedures. This may have restricted participation in the study, potentially excluding populations with limited Internet or mobile phone access (which, according to Centers for Disease Control (2021), are predominantly individuals that are low-income and without college degrees). Future research could implement a similar photovoice methodology with TNC users but with a specific focus on making participation accessible to potentially underserved communities.

In addition to potential financial barriers, concerns regarding COVID-19 exposure could have negatively impacted recruitment. Because participants were asked to take photographs outside during the COVID-19 pandemic, they were asked to abstain from participating in the study if they self-identified as being vulnerable to COVID-19. This could have screened out TNC users that are older adults, people with pre-existing medical conditions, pregnant women, or other groups, which could have also contributed to a non-representative study population (Centers for Disease Control, 2021). A future implementation of photovoice, which is not conducted during a pandemic, could likely avoid these same limitations. Finally, because a small sample $(n=15)$ of TNC users participated in the photovoice study, these users and their pooling behaviors may not be representative of that of the larger population of customers in the San Francisco Bay Area.

\section{TNC User and Stakeholder Workshop}

The research team conducted a two-hour long workshop in July 2021 over Zoom with TNC users and transportation stakeholders. The workshop included 12 photovoice group participants and five transportation stakeholders. During the conclusion of the photovoice groups, participants were asked if they would be interested in participating in a workshop with other transportation stakeholders. At the time, a brief description of the workshop was provided. Once a workshop date was finalized (as it was dictated by the stakeholders' availability) the research team reached out to the photovoice participants who had expressed interest in participating in the workshop. Individuals who were interested and able to participate were selected. Similarly, the stakeholders who participated in the workshop were recruited from the pool of experts 
who had previously been interviewed. During their interviews, the experts were asked if they would like to continue to be involved in the project. The research team reached out to the individuals who expressed interest for workshop participation.

The workshop group was presented with the photovoice findings and recommendations. The participants then offered improvements for walking to and waiting at TNC pick-up locations, taking pooled trips, connecting TNC and public transit trips, and developing incentives. The workshop protocol can be found in Appendix $F$ Workshop Protocol. The workshop used various survey tools (e.g., online surveys) so user responses could be collected qualitatively and quantitatively. The workshop was also designed to facilitate and encourage discussions between the TNC users and stakeholders to understand what riders want and organizations can realistically provide. The key findings informed the policy directives for areas to improve the experience of waiting for and taking a pooled TNC.

\section{Limitations}

Because the workshop was held remotely, it faced similar limitations as to that of the photovoice discussions, though interactive activities were used to increase participation and spur conversation. Participation in the workshop necessitated smartphone or computer ownership, Internet access, and a baseline level of technology fluency. Additionally, the TNC users were individuals who had previously participated in the focus group workshop, so they were bound by the previously mentioned limitations (e.g., potential exclusion of populations without smartphones and those at risk for COVID-19). 


\section{Literature Review}

The research team reviewed over 100 pieces of literature to gain insight on a variety of topic areas including:

- Shared Mobility: Information on different services including carsharing, shared rides, and transportation network companies;

- Ridesplitting: Different versions of shared TNC rides including direct and pooled trips, pooled trip users, and reasons for not selecting pooled services;

- Curb Management and the Built Environment: Strategies for managing the curb and built environment features, particularly for pooled rides;

- Pricing Policies: Financial strategies to encourage pooled rides;

- Safety and Security: User considerations for personal safety and security; and

- Photovoice Methodology: Information on the photovoice methodology.

The following subsections provide further information on these topic areas.

\section{Shared Mobility}

Workplace changes (e.g., increase in telework and part-time workers with varying schedules), consumer spending (e.g., increase in online shopping and food delivery), and technology (e.g., wide-spread availability of the Internet, increased smartphone use, Internet-based payment technologies) have led to new travel behaviors using shared mobility (Shaheen et al., 2016b). Shared mobility, a facet of the growing shared economy, allows users to gain short-term access to a variety of transportation modes, none of which require actual vehicle ownership. Shared mobility includes diverse modes, such as bikesharing, carsharing, transportation network companies, and scooter sharing.

One particular area of interest within shared mobility is the changes that are occurring to "traditional" single occupancy vehicle use. These changes include services (e.g., ridesharing, TNCs, ridesplitting) that share the ultimate goal of increasing the use of existing automobile infrastructure through a Mobility on Demand or Mobility as a Service model. However, these modes have several key differences and they are discussed in the following subsections.

\section{Ridesharing}

There are several types of shared ride services. Ridesharing (also known as carpooling or vanpooling) involves a person sharing a ride in a vehicle that they do not own with one or more additional people (including the driver) in which the driver and passenger(s) share a common origin or destination (Shaheen et al., 2018). Ridesharing can be formally arranged either based on acquaintance (e.g., workplace carpool group) or based on membership in an organization (e.g., carpool app, like Waze Carpool or Scoop) or it can be arranged in an ad hoc, informal manner through the use of "slug lines" or casual carpool pick-up spots (Chan \& Shaheen, 2011). One study on casual carpooling (i.e., carpooling that involves walking to a pick-up spot to take a shared ride with a stranger) found that the majority of casual carpool users walk to their destination, and the most important reasons these users choose to share a ride are to save time and money (Shaheen et al., 2016a). Although there may be some form of cost reimbursement to the driver (for mileage and gas), ridesharing is generally noncommercial and incidental due to regulatory issues (Chan \& Shaheen, 2011). Ridesharing behavior has proven to be difficult to research and record. However, the following benefits have been identified through empirical study: vehicle miles traveled (VMT), fuel consumption, greenhouse gas (GHG) emissions, low-income and minority household exposure to traffic-related air pollution, land use required for parking, 
driving/vehicular cost, and travel time (due to being able to travel in high occupancy vehicle lanes) (Shaheen et al., 2019).

\section{Transportation Network Companies}

TNCs provide travelers with pre-arranged and on-demand rides for compensation using an online-enabled application or platform (e.g., smart phone apps) to connect travelers with drivers using their personal, rented, or leased vehicles. Digital applications are typically used for booking, electronic payment, and ratings. TNC drivers share neither the origin nor the destination with the user, and they are driving the user expressly for commercial purposes (whereas ridesharing drivers take passengers for incidental purposes).

TNCs impacts have been mixed. While there is evidence that private TNC trips are often used as a substitute to public transit (Rayle et al., 2016; Lewis and MacKenzie, 2017; Clewlow and Mishra 2017; Henao and Marshall, 2018; Gehrke et al., 2018), many other studies have found evidence that TNCs can serve as a public transit complement (Murphy \& Feigon, 2016; Conway et al., 2018; Grahn et al., 2019). TNCs impacts on a city's traffic congestion are similarly inconclusive, with some studies determining that for specific cities, TNCs contribute to congestion (Schaller Consulting , 2017; Henao, 2017; Gehrke et al., 2018), while other studies have shown that TNCs have no impact on congestion (Rayle et al., 2016; Clewlow \& Mishra, 2017) or have even decreased congestion (Li et al., 2016). Ultimately, TNC impacts on existing transportation systems are heavily dependent on the city in question, in particular its available public transit, urban density, and built environment (Shaheen et al., 2019). One consistent benefit of TNCs, however, is that they can fill a mobility gap in areas with poor transit service (Lavieri et al., 2018) and increase mobility in previously mobility-limited populations (e.g., persons with physical and cognitive disabilities, individuals who cannot afford automobile ownership) (Shaheen 2018).

\section{Ridesplitting (Pooled TNCs)}

Ridesplitting (also known as pooled TNCs) bridges the gap between ridesharing and private TNCs. Ridesplitting includes services, such as Uber Pool and Lyft Shared. The services involve the on-demand ordering of a ride through a smartphone app, which involves a driver making a trip for commercial purposes (where the driver shares neither the origin nor destination with riders). When a pooled TNC trip is called, however, the application algorithmically groups passengers that are traveling in a shared direction, and slight detours are made to pick up and drop off passengers for the pooled trip (Shaheen, 2018). Ridesplitting could lessen many of the negative effects of private TNC trips by splitting them among several riders. A report by the Union of Concerned Scientists found that non-pooled TNC trips produce approximately $47 \%$ more emissions per person than the same trip length in a private vehicle due to unoccupied time and deadheading (i.e., the miles driven in the vehicle in order to reach the next rider). The same report found that a pooled TNC trip produces about the same emissions per person as a private vehicle trip due to deadheading. However, if deadheading could be reduced (e.g., by encouraging passengers to walk a short distance to a pick-up spot that is more directly on the route - otherwise known as indirect pooling) a pooled TNC trip would have only $60 \%$ of the emissions per person of a comparable private vehicle trip (Anair et al., 2020). A simulation model used by the International Transport Forum (2018) found that if $20 \%$ of private car trips were replaced by shared trips, carbon dioxide emissions could be reduced by amounts similar to those of other policy methods like congestion pricing. The simulation model additionally found that pooling TNC trips can help reduce congestion and can free up public space (International Transport Forum, 2017). For the remainder of this literature review, the "ridesplitting" mode will be referred to as "pooled TNC(s)" as this is the dominant nomenclature used in the literature. 
Pooled TNCs have also been identified as a way to make mobility access more equitable by reducing the price of taking a ride (by splitting the fare across several riders) and providing flexible transport in areas where there may be public transit coverage gaps. This allows users to employ the service on an as-needed basis, which can reduce the need for private vehicle ownership (Shaheen et al., 2017). An analysis of trip data from DiDi, a Chinese TNC, found that pooled TNC trips reduced the amount of daily vehicle usage by $2.6 \%$. In the intermediate term, these changing travel habits and preferences were shown to lead to a $3.6 \%$ reduction in private car ownership, and in the long term, could lead to a reduction in car purchase willingness (Zheng et al., 2019).

\section{Direct and Indirect Pooled TNCS}

A further subset within the pooled TNC mode are direct trips and indirect trips. Direct trips are the more commonly selected pooled TNC option (discussed in the ridesplitting section above). Direct trips involve each rider being picked up and dropped off directly at their selected origin and destination points (examples of these services include Uber Pool and Lyft Shared) (Shaheen \& Cohen, 2018). Indirect pooled TNC trips are a relatively new feature, with Uber launching Express Pool in 2018 and Lyft launching Shared Saver in 2019 (Etherington, 2018; Lekach, 2019). Indirect pooled TNC trips require users to walk a short distance (i.e., five to eight minutes) from their original origin and destination points to make use of optimal straight-line routing and minimize turns and driver deadheading. ${ }^{2}$ Straight-line routing can minimize in-vehicle time and other uncertainties related to pooled TNC options (Schaller Consulting, 2018). Through simulation, straight-line routing has been shown to reduce total travel time by $2.7 \%$ to $3.8 \%$ for small-scale TNC systems, with even greater potential benefit for larger fleets (Li et al., 2018). TNCs offer this option at a 30\% to 50\% discount to incentivize users to select it (Shaheen \& Cohen, 2018). The incentive may make indirect pooled TNCs a viable option for increasing mobility in low-income and immigrant households that previously found private car ownership unaffordable (Shaheen, 2018).

At present, the magnitude of the benefit of pooled TNCs is uncertain, and heavily contingent on the number of trips that are pooled. Pooled TNC services only comprise about $20 \%$ of TNC trips and many pooled trips only take a single rider due to a scarcity in riders on a shared route (Gehrke et al., 2018). A study of TNC trip data in Toronto found that out of the 15\% of pooled TNC trips taken from September 2016 to March 2017, only 52\% of these trips contained more than one rider (Young et al., 2020). Although this statistic is based on self-reported data, the benefits of pooling only truly begin to take effect once a critical mass of ridership is reached, some analyses stating $75 \%$ of users must take pooled trips before the mileage per person is less than that of a private ride (Schaller Consulting, 2018).

\section{TNC Users}

Demographic survey data of TNC users has shown that the typical user is young (i.e., age 25 to 34 ), welleducated (i.e., at least a bachelor's degree) and middle-income (i.e., \$50,000 in annual household income), with a roughly even split between male and female (Schaller Consulting, 2018). Car ownership among TNC users is low (Sarriera et al., 2017), and users that do not own a car were found to use TNCs more than 2.5 times as often as those who do in urban areas and up to 6.6 times more often in suburban areas (Schaller Consulting, 2018). TNC users predominantly take trips to commute to work and for social or recreational purposes (Schaller Consulting, 2018).

\footnotetext{
${ }^{22}$ Deadheading refers to when a vehicle (e.g., public transit bus, TNC) operates without any passengers onboard.
} 
Pooled TNC users have been found to be younger, unmarried and do not own cars (Sarriera et al., 2017). A recent study of TNC users found that people who use TNCs frequently (i.e., more than three days per week) are more likely to take pooled trips, and these people are disproportionately young and low income (including students). This same study found that, in addition to taking trips for work or for social or recreational purposes, frequent TNC users are more likely to use TNCs to go grocery shopping than are less frequent users (Lazarus et al., 2021). These findings helped inform the premise of this study. A study of TNC users in Austin, Texas found that individuals who were employed, highly educated, and lived in higher density urban environments were more likely to take pooled trips. This same study found that women, older adults, and non-Hispanic white users were less likely to choose the pooled option over private (Kang et al., 2020).

From the literature one might infer that, while the typical private TNC user is young, middle-income, nonHispanic white and an even split between male and female. The typical pooled TNC user appears to be young, lower-income student that is more likely male and a minority.

\section{Reasons for Not Pooling}

Based on the existing literature, there appear to be three primary reasons why TNC users decide not to pool: 1) the extra time that taking a pooled TNC trip adds on to their existing trip, 2) safety as it relates to the other users in the pooled TNC ride as well as the pick-up environment, and 3) economically disadvantaged people and people with physical or cognitive disabilities (i.e., the people who stand the most to gain with TNC service) do not have equitable access to them in certain cities (Jiang et al., 2018; Jin et al., 2019; Young and Farber, 2019a; Young and Farber, 2019b). These barriers are discussed below.

\section{Trip Length}

Pooled TNC trips generally take longer than private trips due to the detours taken to pick up additional riders. A study of TNC trips in Toronto found that shared TNC trips took on average 3.6 minutes longer than comparable private trips (Young et al., 2020). Survey results of TNC users have found that they will only select pooling if the price is cheaper than the private option and if the travel time is considered faster than walking or public transit (Sarriera et al., 2017). These sentiments are corroborated in an analysis of Twitter posts made by pooled TNC users, who overwhelmingly tweeted negative comments about routing and travel time, even so far as tweeting positively when no other passengers were picked up because of the time savings (Pratt et al., 2019).

\section{Safety}

Safety is another common concern of pooled TNC users. Trust of fellow riders and the driver have been found to be one of the strongest influences on whether or not a person chooses to use a TNC (Amirkiaee \& Evangelopoulos, 2018; Aw et al., 2019). Female riders prefer being matched with other female riders for this reason (Sarriera et al., 2017). Additionally, some riders may be prejudiced and prefer having more information about who they are sharing a ride (Sarriera et al., 2017), with discriminatory attitudes are strongly negatively predictive of a rider's willingness to pool (Moody et al., 2019). Privacy concerns related to other riders knowing the area where a rider lives were also identified as a barrier. This concern is strongest among the wealthiest segment of riders and non-Hispanic white riders (Lavieri \& Bhat, 2019). Evidence has shown that riders and drivers are concerned about the safety of pick-up and drop-off locations when an indirect pooled option is selected. This concern is caused by drivers having to pick up riders at potentially busy intersections or in unsafe or unfamiliar areas (Bhuiyan, 2018; Lippke \& Noyce, 2020). 
Accessibility

A final aspect of TNCs that impacts a users' decision to pool is a lack of accessibility to TNC services for economically disadvantaged users as well as users with a physical or cognitive disability. The high direct cost of private TNC trips (as well as the indirect cost of requiring a smartphone, Internet access, and a credit card or banking service) can be a barrier to certain populations accessing TNC service (Shaheen et al., 2017). Although pooled TNC trips often have more economical fares, shared mobility availability is often not distributed equitably. In the case of New York City, TNC availability is concentrated in wealthy areas of the city, which incidentally also have strong public transit service. However, areas with low-income communities and people of color tend to live in transit deserts that lack shared mobility (Jiao \& Wang, 2019). TNC accessibility for people with physical disabilities can also be limited, as only a small number of vehicles per fleet are wheelchair accessible with drivers who will assist them (Sartori Do Amaral et al., 2019). Additionally, TNC use can be extremely difficult for the elderly and persons with cognitive disabilities (Shaheen et al., 2017). Pooled TNC options are especially limiting, as a person must be able to follow a navigation to a pick-up location, identify that a car is correct, and, if an indirect pool, follow navigation from the drop off to their destination. These activities must also occur while using a smartphone app with limited accessibility features such as voice activation or turn-by-turn walking directions (Livingstone-Lee et al., 2014). An otherwise willing person may select a private trip over a pooled trip because of these accessibility limitations.

The literature shows that there are a number of barriers to pooling including: the time/cost trade-off of taking a pooled trip, rider concern about their safety both with other passengers and while waiting for the shared vehicle, inequitable distribution of TNCs, and challenges related to identifying and physically accessing pickup/drop-off locations.

\section{Curb Management and the Built Environment}

Curb management and built environment strategies are potential areas to increase TNC users' willingness to pool. Literature shows curb management strategies and built environment changes can address each of the core existing limitations with pooling (time, safety, and access).

A study on TNC users found that people perceive their commute travel time as being valued more highly than their leisure travel time, but are also less sensitive to sharing rides for commutes. One of the study's key conclusions is that people would be more willing to share if there was a way to ensure no/low added time (Kang et al., 2020). The idea of using indirect pooling complements these results, as walking to a pick-up location allows for a faster, more direct route to the destination (Lo \& Morsemann, 2018). Encouraging commuters to select the indirect pooling option for their trips to and from work, and walking to their pick-up locations, would increase the occupancy of previously private TNC trips and would address the issue of pooling adding trip delay (Sarriera et al., 2017; Lippke \& Noyce, 2020).

One issue related to indirect pooling, however, is locating a suitable pick-up location at which it is both safe for drivers to park and for riders to wait (Bhuiyan, 2018; Lippke \& Noyce, 2020). Research has found that TNC users think that the responsibility is on policymakers to provide a mechanism to ensure riders are in a safe environment (Amirkiaee \& Evangelopoulos, 2018). In another study, users suggested that individualizing TNC service based on user preferences and geographic location, such as the ideal pick-up location based on neighborhood characteristics, would help riders gain trust in rideshare services (Aw et al., 2019). Public agencies have also identified the need for safe TNC loading zones in order to ensure TNC passenger safety and mitigate congestion between modes sharing the curb (Shaheen et al., 2019). Redeveloping existing curb 
management practices could provide an opportunity for addressing several of the key safety issues related to TNC pick-up and drop-off locations.

Although there is limited literature about developing specific standalone TNC pick-up and drop-off locations, many of the tenets of public transit center, mobility hub, and airport curb management design can be applied to create a safe and accessible experience. Table 2 below presents a summary of strategies that can be implemented to help improve the experience of a pooled TNC rider.

Table 2. Built Environment Improvement Strategies

\begin{tabular}{|c|c|c|c|}
\hline Category & Strategy & Change & Source \\
\hline \multirow{5}{*}{ Location } & $\begin{array}{l}\text { Locate pick-up and drop-off zones } \\
\text { in areas with adequate capacity }\end{array}$ & $\begin{array}{l}\text { Prevents vehicles from blocking } \\
\text { roadways and pedestrian paths, } \\
\text { maintain Americans with Disability } \\
\text { Act (ADA) compliance }\end{array}$ & LADCP (2016) \\
\hline & $\begin{array}{l}\text { Locate zones in proximity to public } \\
\text { transit, other forms of mobility } \\
\text { (docked bikeshare, scooter } \\
\text { sharing) }\end{array}$ & $\begin{array}{l}\text { Encourages multimodal transport } \\
\text { and makes mode transfers more } \\
\text { convenient }\end{array}$ & Aono (2019) \\
\hline & $\begin{array}{l}\text { Choose areas for zones with a } \\
\text { visual connection to nearby points } \\
\text { of interest }\end{array}$ & $\begin{array}{l}\text { Allows for waiting drivers to quickly } \\
\text { locate passengers }\end{array}$ & LADCP (2016) \\
\hline & $\begin{array}{l}\text { Build zones in densely populated, } \\
\text { walkable neighborhoods near } \\
\text { mixed-use development }\end{array}$ & $\begin{array}{l}\text { Maintains comfort and safety of } \\
\text { users on their approach }\end{array}$ & $\begin{array}{l}\text { Ewing and Handy } \\
\text { (2009), Aono } \\
\text { (2019), Lippke and } \\
\text { Noyce (2020) }\end{array}$ \\
\hline & $\begin{array}{l}\text { Build pick-up and drop-off zones } \\
\text { on streets abutting major } \\
\text { thoroughfares }\end{array}$ & $\begin{array}{l}\text { Ensures pick ups and drop offs are } \\
\text { conducted in a place that is safe for } \\
\text { both passengers and drivers and } \\
\text { does not restrict capacity of } \\
\text { occupied streets }\end{array}$ & LeighFisher (2010) \\
\hline \multirow{4}{*}{$\begin{array}{c}\text { Curb } \\
\text { Management }\end{array}$} & $\begin{array}{l}\text { Restrict curbside use to authorized } \\
\text { vehicles only }\end{array}$ & Ensures unwanted parked cars & $\begin{array}{l}\text { LeighFisher (2010), } \\
\text { SFMTA (2020) }\end{array}$ \\
\hline & $\begin{array}{l}\text { Use geofencing to regularize TNC } \\
\text { pick-up and drop-off locations }\end{array}$ & $\begin{array}{l}\text { Ensures consistency and safety for } \\
\text { all trips }\end{array}$ & SFMTA (2020) \\
\hline & $\begin{array}{l}\text { Designate curbspace that is large } \\
\text { enough to accommodate one to } \\
\text { five vehicles }\end{array}$ & $\begin{array}{l}\text { Maintains ample capacity for high- } \\
\text { demand locations while ensuring no } \\
\text { vehicle spill-over into travel lane(s) }\end{array}$ & $\begin{array}{l}\text { Mandle and Box } \\
\text { (2017) }\end{array}$ \\
\hline & $\begin{array}{l}\text { Provide a vehicle staging area off- } \\
\text { site but nearby for the egress of } \\
\text { large, planned events }\end{array}$ & $\begin{array}{l}\text { Decreases congestion related to } \\
\text { approaching vehicles and maintains } \\
\text { capacity during potential high- } \\
\text { volume events }\end{array}$ & $\begin{array}{l}\text { Mandle and Box } \\
\text { (2017), SFMTA } \\
(2020)\end{array}$ \\
\hline $\begin{array}{l}\text { Built } \\
\text { Environment }\end{array}$ & $\begin{array}{l}\text { Use consistent lighting at a } \\
\text { minimum of one to two foot- } \\
\text { candles (lumen per sq ft) }\end{array}$ & $\begin{array}{l}\text { Enhances feeling of safety, reduce } \\
\text { crime }\end{array}$ & $\begin{array}{l}\text { La Vigne (1997), } \\
\text { Aono (2019) }\end{array}$ \\
\hline
\end{tabular}




\begin{tabular}{|c|l|l|l|}
\hline Category & \multicolumn{1}{|c|}{ Strategy } & \multicolumn{1}{c|}{ Change } & \multicolumn{1}{c|}{ Source } \\
\hline \multirow{5}{*}{ Amenities } & $\begin{array}{l}\text { Place clear signage and labeling } \\
\text { around pick-up spot }\end{array}$ & $\begin{array}{l}\text { Reduces rider confusion by directing } \\
\text { and orienting them }\end{array}$ & $\begin{array}{l}\text { La Vigne (1997), } \\
\text { LeighFisher (2010), } \\
\text { APTA (2012), } \\
\text { Mandle and Box } \\
(2017)\end{array}$ \\
\cline { 2 - 4 } & \begin{tabular}{l} 
Include attentively designed \\
shelters at stops \\
\cline { 2 - 4 }
\end{tabular} & Signals high-quality service & APTA (2012) \\
\hline
\end{tabular}

Creating designated, physical pick-up and drop-off locations for pooled TNC users could also help to make the service more accessible, particularly for persons with physical and cognitive disabilities. Table 3 presents a summary of strategies related to the built environment that could be implemented to improve the accessibility of pooled TNC services for users with disabilities. 
Table 3. Strategies for Pooled TNC Availability

\begin{tabular}{|c|l|l|l|}
\hline Strategy & \multicolumn{1}{|c|}{ Description } & \multicolumn{1}{|c|}{ Improvement } & \multicolumn{1}{|c|}{ Source } \\
\hline Curb Ramps & $\begin{array}{l}\text { Build curb ramps and loading pads at } \\
\text { passenger loading zones }\end{array}$ & $\begin{array}{l}\text { Simplifies loading and makes pick-up } \\
\text { and drop-off zones more accessible } \\
\text { for passengers using WAV }\end{array}$ & SFMTA (2020) \\
\hline Distance & $\begin{array}{l}\text { Minimize the distance between zones } \\
\text { and nearby modes of transport }\end{array}$ & $\begin{array}{l}\text { Increases accessibility and simplicity } \\
\text { of mode transfers }\end{array}$ & Aono (2019) \\
\hline Loading Zones & $\begin{array}{l}\text { Designate and clearly mark curbspace } \\
\text { for passenger loading }\end{array}$ & $\begin{array}{l}\text { Improves ADA access along public } \\
\text { right-of-way and reduces modal } \\
\text { conflicts }\end{array}$ & $\begin{array}{l}\text { Cohen and } \\
\text { Shaheen (2018), } \\
\text { Shaheen et al. } \\
\text { (2019) }\end{array}$ \\
\hline Signage & $\begin{array}{l}\text { Employ signage at pick-up locations } \\
\text { including a map of surroundings }\end{array}$ & $\begin{array}{l}\text { Helps riders orient themselves and } \\
\text { provides additional information about } \\
\text { the area }\end{array}$ & Leven (2006) \\
\hline Tactile Markers & $\begin{array}{l}\text { Use tactile markers to construct } \\
\text { "landing pad" for waiting passengers }\end{array}$ & $\begin{array}{l}\text { Helps passengers alight the vehicle } \\
\text { and identify the correct pick-up zone }\end{array}$ & $\begin{array}{l}\text { Leven (2006), } \\
\text { APTA (2012) }\end{array}$ \\
\hline Wayfinding & $\begin{array}{l}\text { Enhance in-app wayfinding by } \\
\text { referencing landmarks and specific } \\
\text { physical features near pick-up and } \\
\text { drop-off zone }\end{array}$ & $\begin{array}{l}\text { Helps direct users to the waiting } \\
\text { location more clearly than just turn- } \\
\text { by-turn directions }\end{array}$ & $\begin{array}{l}\text { Livingstone-Lee et } \\
\text { al. (2014) }\end{array}$ \\
\hline
\end{tabular}

\section{Taxi Stands}

A review of the current literature on taxi stands and designated passenger loading zones (PLZ) shows that most studies focus on the operation and optimization of such facilities, but there are minimal discussions on the built environment or amenities at the facilities. Recent literature on taxi stands has primarily focused on the service acting as a set of operational research challenges, including optimizing which stand a taxi should travel to (Moreira-Matias et al., 2012), comparing the operational cost and level of service for customers when taxi stand versus curbside hailing operations are used (Salanova \& Romeu, 2018), and determining optimal passenger groupings for shared taxi services using clustering analysis (Zhang \& Ukkusuri, 2021). Key findings from these studies can help inform future changes to TNC pick-up and drop-off locations.

One applicable operations research paper evaluated how taxi stands should optimally be located by using Global Positioning System (GPS) data on pick ups and drop offs and locating stands to minimize the distance between any given taxi and stand (Qu et al., 2019). No evaluation of the built environment at these optimal locations, nor the infrastructure or amenities, is provided. However, that is reasonable given it is beyond the scope of the paper. That said, it can likely be assumed that because the taxi stands are located based on actual user data, their optimal locations are in areas where passengers would feel comfortable waiting for their ride.

The most relevant recent paper on taxi stands explored how taxi service and stands should be designed for autonomous services, with a focus on the user experience when interacting with these services (Kim et al., 2020). The researchers used the "Wizard of Oz" methodology to allow chauffeured vehicles to simulate the experience of using an automated taxi service. While the emphasis of this study was on user interaction with the "automated" taxi itself, the researchers did have participants use a "virtual taxi stand" for pick up and drop off. However, only one of each type was used throughout the experiment, with the pick-up stand being a repurposed public transit shelter and the drop-off stand being a painted concrete pad outside of a café. Though specific built environment aspects were naturally included as part of the virtual taxi stands (e.g., shelter, 
painted concrete, nearby amenities), it is unclear whether these were intentional features. Additionally, there were minimal survey and interview results pertaining to the experience of waiting at the stand itself, with the main focus of the paper being on the in-vehicle user experience. One participant did mention foreseeing challenges related to identifying the correct taxi, where it is a more complex scenario. Similarly, there were minimal results related to the drop-off location, though passengers did mention conflicting vehicles parked at the drop-off and being unsure of where to exit the vehicle.

\section{TNC Pick-Up and Drop-Off Zones}

Taxi stand design and location findings can help inform pick-up and drop-off locations for TNCs. These locations have grown in importance as the demand for curbspace for passenger pick up and drop off has increased since the arrival of TNCs in the mid-2010s while the available supply of curbspace has remained largely unchanged (Schaller Consulting, 2019). This has led cities to begin evaluating innovative strategies to help their curb management systems match the rapidly changing transportation landscape (Fehr and Peers, 2018; Goodchild et al., 2019). A series of reports by the National Association of City Transportation Officials, International Transport Forum, and Institute of Transportation Engineers share the collected wisdom of city administrators and transportation professionals. The reports suggest strategically converting parking lanes in peak pick-up and drop-off areas into "flex zones" that can be utilized for passenger and freight access (National Association of City Transportation Officials, 2017; International Transport Forum, 2018; Institute of Transportation Engineers, 2018). The reports suggest making these zones dynamic so the availability can change according to need and time of day. They also encourage expanding the use of flex zones to include non-automobile-based uses, such as bikesharing docking stations, food trucks and other amenities, or parklets (Institute of Transportation Engineers, 2018). The reports also suggest moving flex zones away from main thoroughfares and onto slower, side streets to allow for safer vehicular access and passenger loading. An additional suggestion recommends that TNCs use geofencing to alert drivers and riders of restricted loading areas (Institute of Transportation Engineers, 2018).

Studies on passenger loading have explored the impacts of TNC loading on traffic as well as the potential benefits of using designated passenger loading zones. A 2018 study involved the observation of two nightlifeheavy corridors with no designated PLZ in the city of Los Angeles during evening hours. The study found that, at the observed locations, TNC vehicles double parked for an average 37 minutes per hour per block face, and were estimated to reduce hourly traffic flow by $58 \%$ (Lu, 2018). To address these challenges cities can convert street parking in areas with heavy TNC volumes into short-term loading zones, and charge for vehicles that dwell for longer than a prescribed time. A 2018 report by Fehr and Peers, completed in conjunction with Uber, evaluated five case study locations in the San Francisco to address double parking and passenger loading concerns (Fehr and Peers, 2018). The report outlined similar recommendations as those in previous industry reports. The report additionally suggested converting street parking adjacent to driveways or intersections into PLZ, as this would allow for easier and more efficient TNC vehicle access than mid-block locations. The report only outlined recommendations for the case study locations; however, thus, the lack of implementation means there are limited results as to the efficacy of such conversions. That said, discussions held with city transportation administrators in Washington, DC and Boston, MA for a 2019 report found pilot PLZ conversions in nightlife areas and other trip generators (e.g., Massachusetts Institute of Technology in Cambridge, MA) to be successful (Schaller Consulting, 2019). The administrators in Washington, DC outlined challenges related to TNC driver compliance though, which was most likely attributed to cars parked in the PLZ. Washington, DC opted for a dynamic PLZ strategy and vehicle owners' lack of familiarity with the changing parking rules could be an explanation for the lack of their compliance. 
A final, relevant study conducted in 2019 quantified the effects of converting parking to PLZs by monitoring the before and after curb activity on three block-faces in Seattle, WA (Goodchild et al., 2019). The researchers found that using the PLZs with geofencing in the TNC apps reduced in-lane stopping from $20 \%$ to $14 \%$ for pick ups and from $16 \%$ to $15 \%$ for drop off. The PLZs also led to a reduction in the amount of loading time, with PLZ loadings being on average 42 seconds faster than those without PLZ. The study also identified several takeaways related to TNC riders who used the PLZs based on survey data. The researchers found that $30 \%$ to $40 \%$ of TNC riders crossed the street to or from the PLZ in an area with no sidewalk. This provides some insight behind where future PLZs should be located to allow for safe pedestrian access to and from the PLZ. The researchers also found that the number of riders using pooled TNC increased from $40 \%$ to $47 \%$ after the PLZ were constructed. Finally, the researchers found an overall increase in rider satisfaction from $72 \%$ to $79 \%$ satisfaction for pick ups and from $89 \%$ to $100 \%$ for drop offs. The researchers note several street design issues at the study PLZs, which could contribute to the lower satisfaction associated with waiting for pick up, including nearby construction sites, low lighting around the blocks, and minimal formal infrastructure (e.g., hand-formed asphalt curbs instead of concrete, no street paint, sandwich boards instead of permanent signage). Safety while waiting at the PLZ was not evaluated as part of the study, though the researchers did investigate potential conflicts related to pick up and drop off at the PLZ.

\section{Safety and Security}

Limited literature exists on the safety of waiting for a TNC at pick-up locations. However, there have been relevant studies conducted in the adjacent fields of safety at public transit stops and the safety of TNCs in general. Safety at public transit stops, and potentially more importantly the passengers' perception of safety at public transit stops, is an important consideration, as it has been suggested that the perceived worsening of safety of public transit has led to lower transit ridership (Manville et al., 2018). One potential implication of this is that the safety of TNC pick-up locations could have an impact on where users choose to be picked up and what types of TNC trips they will select.

\section{Safety at Public Transit Stops}

An explanation for crimes at public transit stops being committed is described as the junction of three criminological theories:

1. Routine Activity Theory: Potential targets and potential offenders can be inadvertently placed in close proximity when following routine, daily activities (Cohen \& Felson, 1979);

2. Crime Pattern Theory: Crime will occur if an area provides opportunities and is within the criminal's "awareness space," or area that the criminal frequents and is familiar with (Brantingham \& Brantingham, 1993); and

3. Rational Choice Theory: Crime-committing is the cost-benefit analysis wherein a criminal will choose their targets by internally calculating which will maximize the payoff of the crime while minimizing the likelihood of apprehension (Cornish \& Clarke, 1986).

These theories suggest public transit stops can frequently be crime generators because they experience a large, regular flow of people and are crime attractors because of low levels of guardianship (e.g., low surveillance, minimal staff, peripatetic fellow passengers), and thus create ample opportunities for crime (Newton \& Ceccato, 2015). While the flows of travelers cannot be affected, approaches have been taken to "design out crime" at certain public transit stops and stations. These designs focus on increasing the risk of getting caught through "natural surveillance" improvements and limiting the opportunity for crimes to be committed by making public transit stops into more "defensible spaces." Examples of improving natural surveillance include improving lighting, increasing pedestrian foot traffic so that there are more "eyes on the street" (Jacobs, 1961), 
placing stops in locations with storefronts and shopkeepers, and installing closed-circuit television cameras (Newton \& Ceccato, 2015). Locations can be more defensible against crime opportunities by improving visibility, reducing escape routes, and eliminating entrapment spots and hiding places (Newman, 1972). Safety concerns that can potentially be "designed out" typically fall into three categories: 1) location and time of day, 2) gender differences, and 3) homelessness. The following subsections discuss these considerations.

\section{Location and Time of Day}

A research area of particular interest is how crime rates at public transit stops vary based on location and time of day. Several studies have identified that most transit systems have a few "hot spots" where a large percentage of crimes in the system are committed. A 1999 study involving inventorying the surrounding land uses and stop-level attributes of the 10 most high-crime bus stops in Los Angeles, as well as surveying the riders who use them, found several characteristics shared by most or all high-crime bus stops (Loukaitou-Sideris, 1999). Hot spots were located near negative land uses that can be considered as "crime generators," including liquor stores, bars/taverns, check cashing establishments, single room occupancy hotels, pawn shops, and adult bookstores. High-crime bus stops were also located in areas with minimal natural surveillance, like surface parking lots and parking structures. Given their seclusion from guardianship and surveillance, the hot spots tended to house a high number of "public incivilities," like drinking, loitering, panhandling, and drug exchanging. The unfettered presence of these illicit activities and nearby vacant and dilapidated buildings strewn with trash gave the perception that there was minimal community guardianship and authority, which could lead criminals to believe the risk of being caught is low, lending some credence to the "broken windows" theory (Wilson \& Kelling, 1982). Interestingly, Loukaitou-Sideris (1999) found that stops crowded with heavy pedestrian traffic, while high in informal surveillance, can also be high-crime because the crowds make it easier for purse-snatchers and pickpockets to disappear.

Loukaitou-Sideris (1999) suggested that the key to maintaining bus stop safety was to carefully site and design the stops. The potential for crime could be lessened by shifting stops away from negative land uses or increasing policing or monitoring at stops that cannot be moved. Additionally, regularly maintaining bus stops by cleaning up trash and vandalism and placing bus stops near well-maintained businesses helps demonstrate that the area is regulated and under natural surveillance. Similarly, moving stops away from isolating locations like surface parking lots and increasing lighting and removing obstructed sightlines at stops can help reduce the likelihood of criminals trapping victims or escaping unseen.

More recent quantitative studies evaluating the relationship between crime and land use near bus stops have found very similar results. A 2017 study employing geocoded crime and bus stop data for the city of Indianapolis found that bus stops were associated with higher violent and property crime counts in areas with commercial and industrial land use, but that bus stops located near high-density housing had reduced crime counts (Stucky \& Smith, 2017). Though this study relied on crime data that aggregated crimes committed both on the bus and at the bus stop and did not consider built environment factors at the bus stops or proximity of stops to alcohol establishments, the findings of this study do suggest that stops in commercial areas should receive special attention as they are more highly susceptible to being loci of crime. A 2018 study used risk terrain modeling (i.e., combining spatial risk factors to calculate a risk score of a certain location) to determine how the environments surrounding bus stops in Malmo, Sweden impact the crime risk of those stops (Gerell, 2018). The research found that stops near restaurants, bars or nightclubs, and ATMs were at a higher risk of experiencing violent crime. Additionally, the study found that stops located in neighborhoods with low collective efficiency (i.e., residents have a lower trust in their neighbors and a lower expectation that, should something occur, their neighbors would intervene) were also at an increased risk of experiencing violent crime. 
These findings highlight the importance of location and community ownership when it comes to reducing potential crimes at bus stops.

Multiple recent studies have combined smart card data from public transit agencies with location-specific crime incidents to determine spatiotemporal patterns related to crime and transit. A 2018 report that evaluated smart card data in Seattle, Washington found that regarding waiting at public transit stops, more riders at the stop deterred crime as they provided more natural surveillance in one area. However, regarding walking to or around the transit stop, more riders increased the crime rate as larger crowds potentially provide anonymity to would-be offenders (Moudon et al., 2018). The study also found that stops in proximity to alcohol or marijuana outlets had an increased crime rate. One finding of note from the study was that locations with lighting and shelters were found to have more crime. This could be due to these stops having an increased propensity toward loiterers. However, it could also be attributed to the crime dataset used in the study being aggregated and mostly non-violent crimes (e.g., vandalism) occurring at sheltered stops, while violent crimes were more likely to occur at unsheltered stops.

A 2019 study using public transit smart card data analyzed patterns of bus stop crime in Brisbane, Australia, and found that bus stops had higher rates of theft during periods with more riders, corroborating Loukaitou-Sideris (1999)'s finding regarding crimes with crowds: that greater passenger flows at stops often indicates more viable targets for crime as opposed to more informal guardians that could reduce crime (Zahnow \& Corcoran, 2019). The study also found that locations near alcohol establishments and in neighborhoods that experience higher residential turnover experienced more theft, likely because these communities may have lower community guardianship. Finally, the authors found that bus stops located near large carparks have an increased likelihood of theft on weekdays, likely due to the flow of commuters in a sparse and isolated location.

\section{Gender Differences}

In addition to land use, time of day, and built environment factors, the gender of the transit rider plays an important role in the rider's perception of safety when walking to and waiting at the transit stop. Surveys on fear of crime have found that women are much more fearful than men, both of serious crimes of rape or violence, and of public nuisance crimes with sexual undertones (e.g., harassment, intimidation, unwanted comments) (Gordon \& Riger, 1989; Stanko, 1990). Studies have found that older, lower-income women, and nonwhite women tend to exhibit higher levels of fear of public settings than their younger, higher-income, or white counterparts (Brownson et al., 2001; Ross, 2000). This fear of personal safety has impacted how women travel and led to some women preferring to drive or take a taxi rather than walk or take public transit (Lynch \& Atkins, 1988; Stanko, 1990; Wekerkle \& Whitzman, 1995). Women are also more likely to avoid walking after dark for personal safety reasons. Additionally, women may avoid certain public spaces, or visit public spaces only if accompanied by a significant other or friends (Ross, 2000; Loukaitou-Sideris, 2005).

A 1990 interview-based study of women in Reading, England found that specific environments cause women to feel more afraid. The predominant environments included enclosed areas like an underground transit station or parking garage where could be entrapped and deserted, open spaces with visible signs of social disorder (e.g., litter, vandalism) and minimal surveillance where someone could hide and attack (Valentine, 1990). A 2005 study of transit riders in Los Angeles found that twice as many people reported feeling unsafe at the bus stop versus on the bus itself. The study found that $59 \%$ of the women surveyed felt unsafe waiting for their bus while only $41 \%$ of the men felt unsafe (Loukaitou-Sideris, 2005). The same study found that the women surveyed felt less safe at bus stops located in desolated areas and were more worried about public drunkenness, verbal threats, and groping than their male counterparts. However, these studies do suggest 
multiple solutions for creating public spaces that reduce women's fear and promote safety. These strategies include: moving bus stops from negative land uses to areas with buildings with windows, shops, and regular maintenance; improving lighting on the streets and shelters; and cleaning up litter. Loukaitou-Sideris (2005) also suggests complementing natural surveillance with increased policing, closed circuit television cameras, and emergency phones and buttons at stops and stations.

\section{Homelessness}

A final factor affecting rider perceptions of safety at transit stops, particularly in recent years, is the presence of homeless individuals at transit stops and in transit facilities. Though past studies have mentioned loitering and other incivilities often associated with homelessness as being factors affecting safety, only been recently has homelessness has been cited specifically (Loukaitou-Sideris, 2005). One reason for the recent interest in the effects of homelessness on safety and transit has been the steady decline in transit ridership, especially since the COVID-19 pandemic. A 2016 survey of former LA Metro riders found that 28\% said that the main reason they stopped using transit was because they felt unsafe or uncomfortable. This has led some researchers to posit that the dramatic increase in homelessness (a 46.5\% increase in Los Angeles County from 2013 to 2017) has potentially contributed to worsening perceptions of safety (Manville et al., 2018). Some homeless people may use transit stops and vehicles as shelters, which may make certain riders uncomfortable and thus detract from their perceived safety. A 2018 study based around interviews with transit operators found that $73 \%$ of agencies believe homelessness impacts their ridership, as it can make other riders uncomfortable and deter choice riders (Bell et al., 2018). Approximately $37 \%$ of the agencies interviewed also have seen an increase in crime attributed to homelessness including increases in assault, property damage, theft, drug sales and use, and vandalism. These agencies believe that the increase in homelessness creates safety concerns for other members of the public. That said, a 2020 causal analysis of factors affecting ridership of the Bay Area Rapid Transit system found that the number of homeless people in a transit station, police presence in a station, and perception of cleanliness at a station had an insignificant effect on ridership, or were inseparable from other factors' effects (such as general crowding) (Wasserman et al., 2020). Though transit operators believe the increase in homelessness is affecting ridership, and some riders are uncomfortable around homeless people or at least some of the activities they partake in, it is still highly speculative that the increase in homelessness in contributing to the decrease in transit ridership. The true effect of homelessness on transit is an area of active research.

\section{Safety at TNC Pick-Up and Drop-Off Locations}

The safety while waiting at TNC pick-up locations is an additional area of active research, with most prior research being associated with perceptions of safety in-vehicle, relating to the other passengers and the driver. In fact, one 2019 academic periodical simply recommended that all TNC users request their ride and wait indoors until the driver arrives, to minimize time outside with phone in hand (Miles, 2019). Another 2019 study tried to explore Uber's impact on crime in 18 different U.S. cities. The study found that, after Uber's arrival in the different cities, crimes against people (namely, assaults) reduced by 5\% (Weber, 2019). The author presumes that this is because TNCs increase the natural surveillance of an area, can be used to take victims away from potentially dangerous areas, and isolates potential criminals instead of them taking a crowded bus or rail line that would allow for opportunistic crimes to take place. The author asserted that Uber's entry into cities likely reduced bar and alcohol-related crime. However, the crime data used in the study was spatially aggregated at the city-level and no TNC pick-up location data was used in the analysis, so it is unclear where the reductions in assaults were actually taking place. The author's conclusion is that simply the presence of TNC drivers reduces city crime, with no built environment or land use factors incorporated. Despite these findings, 
there is currently a knowledge gap regarding which factors impact the safety and security of TNC users while waiting for pick up.

\section{Pricing Policies}

Modifying the existing TNC trip (both pooled and private) pricing is another potential strategy to increase TNC users' willingness to pool. Existing literature shows that changes to pricing could address the time and accessibility limitations that pooling currently has.

It is established that travel cost (i.e., the fact that pooled trips are generally a lower fare price than private trips) is a major motivator for users selecting the pooled trip option (Sarriera et al., 2017; Lavieri \& Bhat, 2019; Moody \& Zhao, 2020). Thus, changing pricing policy can be an effective tool for incentivizing more private users to shift to pooling. Research has found that users value commuting travel time twice as highly as leisure travel time, but that users are much more willing to share during commutes than during other times (Kang et al., 2020). This provides an opportunity for TNCs to alter their pooled service pricing to incentivize commute trips and offset any time delay costs, potentially by giving pricing discounts to users who take pooled trips that start or end near major employment centers.

Changing pricing policies of pooled rides also gives TNCs the opportunity to make pooling more economically accessible for users who do not have access to a car or for users who cannot drive (which are frequently lowincome individuals) (Lavieri \& Bhat, 2019). Subsidies for low-income users and reduced fare for users in transit deserts using pooled TNC as a link to transit can help address existing equity issues (e.g., high price of vehicle ownership, inequitable distribution of high-quality public transit service) (Shaheen, 2018). It is important, though, that policy materials be created to market to and ensure that low income and minority communities are not excluded from access to pooling (Shaheen et al., 2017).

There is also evidence that altering the existing pricing policies of private TNC trips could incentivize users to switch to pooled options. A discrete choice analysis model using stated-preference survey data found that, under the Random Utility Maximization framework, increasing the price of private trips would increase rider willingness to share. This suggests that putting a premium on private trips (either through the TNC increasing the price or through a local government imposing a tax on private rides) could lead to higher pooled vehicle occupancy (Alonso-Gonzalez, et al., 2020). Additionally, a survey study of residents of Austin, TX found that pooled TNC users are likely to make more monthly trips than a user with no experience with pooling. This suggests that if a TNC could get an individual to try pooling one time, it could have a lasting impact on the frequency of pooled TNC trips in the long run (Lavieri \& Bhat, 2019). A potential policy extension of this finding would be for a TNC to provide an offer where an existing user's first pooled ride is free, or that one part of their roundtrip is free if pooling is selected for the entire journey.

\section{Photovoice Methodology}

It is important for the researchers to experience how TNC users view the pooled trip experience by involving them as an integral part of the research process. However, most studies on pooling users are from stated preference surveys (International Transport Forum, 2017; Sarriera et al., 2017; Amirkiaee and Evangelopoulos, 2018; Aw et al., 2019; Lavieri and Bhat, 2019; Moody et al., 2019; Kang et al., 2020; Moody and Zhao, 2020; Alonso-Gonzalez et al., 2020; Lippke and Noyce, 2020) or expert interviews and literature review (Shaheen et al., 2017; Shaheen \& Cohen, 2018; Shaheen et al., 2020). Only two studies identified contained a focus group component: the simulation study run by the International Transport Forum (2018)used a focus group to 
develop stated-preference survey questions, the results from which were used to create the simulated population used in the travel behavior model (International Transport Forum, 2017). This focus group was held in Finland and because Uber and Lyft have not offered pooled services in Finland, the mode of transport was referred to as a "shared taxi." This connotes a different type of shared mobility experience that may have led to different responses than would have been expressed had a pooled TNC service been available. The second study with a focus group component was administered by Lippke and Noyce (2020) and used to complement the results of a stated-preference survey they administered to learn about riders' "willingness to pool" in 10 metropolitan areas (Lippke \& Noyce, 2020). The focus group was conducted with eight TNC users from the Metro Detroit area, although only $25 \%$ of the focus group had taken a pooled TNC before, and no participants had used indirect, pooled TNC trips. While the results provided insights about private TNC users' perception of pooling, the sample size of actual pooled TNC users was too limited to determine broader findings on pooled TNC users' actual experiences. Thus, there appears to be a gap in the existing literature on shared mobility, TNCs, and pooled TNC users that focused on gaining direct, qualitative input from actual pooled TNC users.

One type of social science research emphasizes the importance of involving community members in the development of the research findings themselves is Community-Based Participatory Research (CBPR). The goals of CBPR are to equalize power differences between the members of the community and the researchers, build trust between the two parties, and create a sense of ownership in an effort to bring about change. This type of research aims to minimize researcher bias as much as possible by having the community participants have an equal footing in the design, development, and implementation of the research process (Reason \& Bradbury, 2001). Although there are many different methodologies that fall into the category of CBPR, the one with the greatest potential to allow TNC users to reflect on their personal experiences with pooling and to allow outsiders (i.e., researchers and stakeholders) to view life through their eyes is the photovoice methodology.

The photovoice methodology was developed initially for the field of public health and was founded on the principles of feminist theory, constructivism (i.e., learning through the process of developing meaning through experiences), and documentary photography (Hergenrather et al., 2009). Photovoice study participants are able to document the strengths and needs of their community by using cameras and then meet for focus group discussions to share the photos and stories behind the images that they captured (Wang \& Burris, 1997). Individual interviews with participants have also been utilized to communicate with participants that may be unable to meet communally (Castleden et al., 2008; True, Rigg, \& Butler, 2014). From the interviews and focus group discussions, themes about community needs can be codified and representative images and stories collected. The culmination of most photovoice studies is a presentation or public display to which community leaders and decision makers are invited, allowing the participants' voices and images to be heard and seen, ideally leading to policy change and a strengthened dialogue between community leaders and the people who live in it (Wang \& Burris, 1997).

Although there are many public health examples of the photovoice methodology's implementation, many of the past studies most relevant to a transportation engineering application of the study, particularly in terms of improving access to a transportation service, involve giving cameras to the members of a community and examining the photos that they took of the built environment. One such study investigated the way the built environment affected Latina teens' ability/willingness to exercise. The photos taken showed that, while many of the participants were interested in walking or running in their communities, the participants were drvien not to exercise because the areas in which they lived were unsafe or were located very near to freeways (Hannay et al., 2013). Another photovoice study examined paratransit users, and the photos they captured and stories they told helped the researchers identify that long wait times, difficulties navigating pick-up and drop-off areas, 
and the steep price of subsidized accessible cabs all led to the users being stressed about transportation and instead actively choosing not to travel (Sitter \& Mitchell, 2020). Using photovoice with TNC users can help to identify what factors of the pooled TNC experience (including built environment factors) affect their decision to pool and will help inspire discussions on policy change.

\section{Key Takeaways}

- Shared Mobility: A variety of shared mobility options (e.g., ridesharing, TNCs) can increase mobility and vehicle occupancy while decreasing congestion and associated negative impacts.

- Ridesplitting Users: Ridesplitting can include direct and indirect trips and the demographic groups that tend to use ridesplitting services typically deviate from other TNC users.

- Ridesplitting Challenges: A variety of challenges need to be addressed to increase ridesplitting including trip length, safety concerns, and accessibility.

- Curb Management: Improved curb management and the development of physical pick-up and drop-off location infrastructure can potentially increase ridesplitting.

- Taxi Stands and TNC Locations: Lessons can be learned from existing research on taxi stands and TNC pick-up and drop-off sites including location selection (e.g., off of main thoroughfares), built environment features (e.g., lighting, proximity to other individuals), and management strategies (e.g., geofencing).

- Safety and Security: As TNC pick-up and drop-off locations are developed it is critical that safety and security concerns are addressed. These concerns are primarily on location and time of day considerations, gender differences, and the presence of homeless individuals.

- Pricing Strategies: Pooled rides can be encouraged through pricing strategies can. Lowered prices may increase the appeal of shared rides and increase TNC accessibility for low-income households.

- Inclusive Research: CBPR research, including the photovoice methodology, can help gain further insight on potential TNC pick-up and drop-off location considerations. 


\section{Expert Interviews}

Researchers conducted a series of expert interviews with key stakeholders to understand pooled mobility services prior to and during the COVID-19 pandemic. The expert interviews helped inform the development of the photovoice group protocol and the potential programs and incentives to increase pooling discussed in the groups. The interview questions were tailored to each individual expert's specific background in relation to pooling, but all interviewees were generally asked about:

- Current State of the Industry: What is the expert's experience with pooled mobility services?

- Pooling Opportunities: As the use of pooling increases, what potential opportunities exist for pooling, both generally and with respect to stakeholder organizations?

- Pooling Challenges: What are key challenges that pooling faces, and what challenges unique to the stakeholder organization does pooling create?

- Strategies and Key Considerations: How can pooling be improved from both the perspective of the stakeholder organization and pooling users? Specific strategies including built environment and curb management improvements at pick-up and drop-off (PUDO) locations and pricing promotion and incentive programs for users were a key focus of the discussions.

The findings from the expert interviews are summarized in the following sections.

\section{Current State of the Industry}

Generally, the experts have a positive perception of pooling, though there have been some challenges integrating pooling with other transportation services. Pooling adds another mobility option for consumers and helps expand "the continuum of available transportation services." One public transit expert stated that in some situations pooling complements fixed route public transit (e.g., as a first- and last-mile connection). TNC benefits are evidenced by the increase in TNC PUDO activities at public transit rail stations in recent years. However, another expert agreed that while pooling adds a mobility option it may compete with existing modes. The public transit experts, in particular, cited examples of pooling replacing potential trips by bus or metro, particularly during off-peak hours.

In addition to potentially complementing or competing with public transit, several experts mentioned that TNC PUDO activities can cause conflicts (e.g., at bus stops, in parking spaces, in bike lanes). High curbspace demand and low management can lead to these challenges. Additionally, two public sector experts noted that data sharing limitations (e.g., receiving information form TNCs) can make planning PUDO locations difficult. However, there have been examples where public agencies have successfully worked with TNCs to create geofenced PUDO areas for large public events.

The growth of pooling in recent years has increased its prominence for different mobility providers. Two of the experts from private mobility providers viewed pooling as integral to their core business model, while two experts from a different private mobility provider saw it as another available mobility service similar to the organization's single-occupancy option. However, experts from all three of the private mobility providers have been experimenting with several different types of pooling products to increase vehicle occupancy for people who travel along similar routes.

\section{Pooling Opportunities}

The experts agreed that pooling provides opportunities including: 
- Increased Mobility: Pooled rides can provide an additional transportation option that allows travelers to reach destinations previously only accessible by vehicle. Pooling can also decrease vehicle miles traveled and greenhouse gas emissions.

- First- and Last-Mile Connections: Pooled rides can help fill public transit service gaps, such as first- and last-mile connections to transit stops or stations.

- Commuter Benefits: Commuter benefits could be expanded to include and incentivize pooled TNC rides.

- Managed Road Lanes: Pooled rides can allow users to take advantage of managed lanes (e.g., highoccupancy vehicle lanes) to shorten their travel time and bypass congested single-occupancy vehicle lanes.

These potential opportunities are discussed in further detail below.

\section{Increased Mobility}

Several experts mentioned the potential for pooled modes to increase access to opportunities that were previously only available to those with a vehicle (e.g., timely, reliable access to job centers and healthcare services). As pooling services increase, there may be opportunities for stakeholders to develop different pooling options for different trip types (e.g., pooled TNC rides for first- and last-mile trips, microtransit ${ }^{3}$ options for trips to common destinations not well served by public transit). Pooling can also result in including reduced congestion (from increased vehicle occupancy), vehicle miles traveled, and greenhouse gas emissions.

\section{First- and Last-Mile Connections}

Multiple experts cited pooling's opportunity to provide first- and last-mile connections to public transit, particularly in low-density areas and where accessing longer distance, fixed-route public transit (e.g., BART, Caltrain, Transbay bus service) requires multiple transfers. Two of the private mobility providers described an opportunity for increased partnerships between private mobility services and public transportation agencies to help fill this gap. For example, private mobility providers' proprietary technology is flexible and scalable, which may be used to provide on-demand, dynamic routing technology for individuals in areas with low-density or limited mobility options. In this example, public-private partnerships could vary in degrees of involvement and financial capacity, from using a private company's drivers, vehicles, and technology to just using a private company's technology with a public agency's own drivers and vehicles.

\section{Commuter Benefits}

Experts also mentioned the potential for employee provided commuter benefits to support more pooling options. Currently the Bay Area Air Quality Management District (BAAQMD) only allows commuter benefits to be used for pooling in vehicles with six or more passengers (BAAQMD, 2014). However, this rule does not capture the current availability of pooled modes. Private mobility provider experts suggested that by expanding commuter benefits to include pooling in lower occupancy, electric, or hybrid vehicles, commuters would have more available pools to join while achieving the requisite emissions reduction benefits. A public sector expert also mentioned the opportunity for pooled mobility services to leverage existing vanpool permits by allowing their drivers to drive for company vanpools before starting their shift driving for dynamically-matched pooled rides.

\footnotetext{
${ }^{3}$ Microtransit is a privately or publicly operated, technology-enabled transit service that typically uses multi-passenger/pooled shuttles or vans to provide on-demand or fixed-schedule services with either dynamic or fixed routing.
} 
Managed Road Lanes

Pooling provides customers the opportunity to take advantage of infrastructure dedicated to high occupancy modes (e.g., managed lanes). Experts from the private and non-profit sectors mentioned managed lanes could allow customers in pooled vehicles to be able to travel faster than they would in single-occupancy vehicles. This opportunity to decrease travel times and encourage travelers to pool.

\section{Pooling Challenges}

Though there are many opportunities for pooling to grow, the experts also mentioned the challenges that pooling faces including:

- Public-Private Partnerships: Existing public transit agency limitations and misconceptions make it difficult to develop partnerships between different transportation stakeholders.

- Regulatory Definitions: Current regulations do not differentiate between services which can impact permitting and other processes.

- Trip Changes: Since pooled rides can change in trip length and time depending on the origin, destination, and order of the additional passengers picked up, the trip variability can be undesirable for riders.

- Indirect Trips: Drivers and riders may face difficulties identifying each other when taking indirect trips.

The pooling challenges are described in further detail below.

\section{Public-Private Partnerships}

Many of the challenges the experts discussed pertained to pooling service limitations. Three experts referenced existing partnership challenges between public transportation administrators and private mobility providers. Due to requirements from some public transit operator labor unions (e.g., wage minimums, worker compensation) and public funding restrictions (e.g., inability to use public funds to pay private companies for similar services) some public transportation administrators are hesitant or unable to work with private mobility providers. In part because of these limitations, some private mobility providers believe city and public transportation administrators view pooled services solely as a direct competitor to public transit instead of as a complementary service. This misconception is a reason why public-private partnerships are not materializing.

\section{Regulatory Definitions}

The public sector experts focused on the challenge of the potentially limiting regulatory definition of "transportation network company." The experts discussed how, while TNCs and their associated services have evolved, they are limited by their initial definitions (i.e., prearranged transportation services for compensation using an online-enabled app to connect drivers using their personal vehicles with passengers (CPUC, 2021)). Should TNCs want to explore services that expand upon this definition (e.g., using larger vehicles like vans, implementing fixed stops), they would need to branch out of their existing regulatory category for new types of permitting.

Additionally, the regulatory definition of TNCs results in an inability to tailor regulations for various services (e.g., different permitting for pooled TNCs versus private TNCs). The lack of clear distinctions between services can also impact users. One expert provided the example of explaining a publicly run microtransit service to potential riders. The riders incorrectly thought of service either as private TNC service or traditional fixed-route public transit service instead of a combination between the two. An expert from a non-profit organization 
shared a similar example where the lack of distinction between the direct and indirect pooled modes led to additional difficulties for individuals with mobility impairments.

\section{Trip Changes}

Several experts also raised the challenge of trip length uncertainty that is intrinsic to the pooled experience. Discounts for taking a pooled trip are applied upfront and the user learns about potential matches or deviations from the initial estimated time of arrival (ETA) after ordering the ride. Any change to these trip characteristics is viewed as undesirable by the user. Additionally, the potential variance in ETA from the initial to one including route matches has led some users to not be able to depend on pooled services for time-sensitive appointments or to connect to public transit for fear of missing a transfer.

\section{Indirect Trips}

The final set of challenges discussed pertain to those specifically of indirect (corner-to-corner) pooling. Indirect trips may be less desirable in low-density areas as riders may have to walk further than if they were in denser areas. Riders may also have difficulties identifying which side of the street to be on for pick up or walking to the location in a short time frame (as pooled trips are often cancelled by the operator if the passenger does not meet the vehicle in time for pick up). Fixed PUDO locations may help address these challenges, but they could also limit the flexibility of pooled services for users if no PUDO locations are near them. Fixed PUDO locations may also create equity challenges if fixed locations are placed in areas that are perceived as less desirable to drivers.

\section{Strategies and Key Considerations}

Experts provided strategies for a variety of elements of pooled TNC rides from curbspace management to incentives. Experts also identified key considerations to keep in mind as these strategies are developed and deployed. Table 4 summarizes the strategies and considerations, and they are further discussed in the subsections following the table. 
Table 4. Expert Recommended Strategies

\begin{tabular}{|c|c|c|}
\hline Subject Area & Strategy & Description \\
\hline \multirow{3}{*}{$\begin{array}{l}\text { General } \\
\text { Strategies }\end{array}$} & $\begin{array}{l}\text { Service Distinction and } \\
\text { Taxation }\end{array}$ & $\begin{array}{l}\text { Clearly distinguish pooled and private services and leverage these } \\
\text { differences to encourage the shift to pooled rides }\end{array}$ \\
\hline & Information Provision & $\begin{array}{l}\text { Provide riders with the most robust, accurate information possible } \\
\text { to encourage pooled ride use }\end{array}$ \\
\hline & $\begin{array}{l}\text { Available Service } \\
\text { Education }\end{array}$ & Educate users on the available services and their distinctions \\
\hline \multirow{2}{*}{$\begin{array}{l}\text { Curbspace } \\
\text { Management } \\
\text { and Built } \\
\text { Environment } \\
\text { Strategies }\end{array}$} & $\begin{array}{l}\text { Curbspace } \\
\text { Management and TNC } \\
\text { Data Sharing }\end{array}$ & $\begin{array}{l}\text { Improve data sharing between public agencies and TNCs to } \\
\text { manage where PUDO locations are and how to improve them }\end{array}$ \\
\hline & $\begin{array}{l}\text { Location Information } \\
\text { Provision }\end{array}$ & $\begin{array}{l}\text { Provide enhanced PUDO stop location information for riders and } \\
\text { drivers to increase ride efficiency }\end{array}$ \\
\hline \multirow{3}{*}{$\begin{array}{l}\text { Incentives and } \\
\text { Pricing } \\
\text { Promotions }\end{array}$} & $\begin{array}{l}\text { Managed Lanes } \\
\text { Access }\end{array}$ & $\begin{array}{l}\text { Allow pooled TNC rides to access managed lanes to save on trip } \\
\text { costs and time }\end{array}$ \\
\hline & $\begin{array}{l}\text { Single-Occupancy Trip } \\
\text { Costs Increases }\end{array}$ & $\begin{array}{l}\text { Increase single-occupancy vehicle costs and/or offering incentives } \\
\text { exclusively for pooled rides }\end{array}$ \\
\hline & $\begin{array}{l}\text { Mobility as a Service } \\
\text { Offerings }\end{array}$ & $\begin{array}{l}\text { Bundle transportation services and fees together for decreased } \\
\text { prices and increased mobility }\end{array}$ \\
\hline \multirow{3}{*}{$\begin{array}{l}\text { Important } \\
\text { Considerations }\end{array}$} & $\begin{array}{l}\text { Communication } \\
\text { Improvements }\end{array}$ & $\begin{array}{l}\text { Enhance communication between stakeholders (e.g., public transit } \\
\text { agencies, private mobility providers) to bridge relationship gaps }\end{array}$ \\
\hline & COVID-19 Impacts & $\begin{array}{l}\text { Gain a better understanding of COVID-19 impacts on ridership and } \\
\text { what factors would encourage pooling }\end{array}$ \\
\hline & Equity Impacts & $\begin{array}{l}\text { Understand how potential pooling strategies, curbspace } \\
\text { management policies, and pricing incentives impact different } \\
\text { demographic groups }\end{array}$ \\
\hline
\end{tabular}

\section{General Strategies}

Experts recommended three general strategies to help address potential challenges including:

1. Service Distinction and Taxation: Regulations should provide a greater distinction between different types of pooled and private services. These more narrowly defined services should then be taxed in a way that is equitable but also supports higher occupancy modes (e.g., percentage of the user's fare as opposed to a flat fee so pooled rides are less expensive than single-occupancy options).

2. Information Provision: Private mobility providers should give riders as much upfront information as possible when they are booking their trips (e.g., trip time, number of possible passengers). One expert also suggested offering a tier of pooled service that, for an extra fee, would guarantee the rider that they would be the first picked up and the first dropped off. Two different experts also recommended integrating public transit schedules into pooled trip planning and using geolocating features to time drop offs with public transit arrival. This increased reliability could support the use of pooling to connect to public transit.

3. Available Service Education: Organizations should educate potential users on available services. This could be accomplished by private operators or as part of a public agency's transit services. Especially if tiers of pooling service are added (e.g., direct pooling, indirect pooling, microtransit pooling), the distinction between services for users rises in importance. Outreach must be catered to the specific communities being served. For example, a smartphone notification or email advertisement may be appropriate for some riders while other riders may be better targeted by fliers and physical promotional ride coupons. 
In addition to these strategies, experts offered more specific strategies for the built environment and curb management and incentives and pricing promotions. These strategies are discussed in further detail in the following subsections.

\section{Curbspace Management and Built Environment Strategies}

Experts discussed the built environment and curb management in regard to pooled trips. The experts recommended two predominant strategies including:

1. Curbspace Management and TNC Data Sharing: The primary strategy experts suggested to improve curbspace management was to increase communication between TNCs and public officials. Increased communication would allow stakeholders to work together to create a more robust, dynamic curb management system for communities. Ideally, communication would include a data sharing agreement between TNCs and public agencies. However, TNC data contains proprietary information which makes sharing difficult, so a reasonable compromise would be a line of communication between the organizations to identify areas where the existing curb regulation does not reflect its use. For example, these may be areas with limited public transit services and high PUDO volumes. Additionally, multiple experts noted the simplicity and adaptability of geofencing technology. Geofencing could be leveraged to allow public agencies to work with TNCs to

\section{Curbspace Management: Service Improvements Through Local Feedback}

One private mobility expert described their company's use of local community organizations to provide feedback on where PUDO activities should be located (e.g., away from construction zones and busy intersections). By incorporating local knowledge into the route matching algorithm, the operator helps locate PUDO activities in ideal locations (e.g., safe, low traffic volume). This strategy has helped improve the PUDO experience for the service's riders. geofence PUDO zones at popular origins/destinations, or to restrict PUDO in unsafe or highly congested areas.

2. Location Information Provision: Experts from every sector suggested demarcating and marking fixed PUDO locations with a physical sign and in-app digital marker. Public agencies could work with private mobility providers to identify commonly used PUDO locations, especially in areas without passenger loading zones. The PUDO locations could be marked with a generic, public agency approved "pooled PUDO" sign to be used by all pooled mobility providers. These locations could be regulated to enforce passenger loading only and geofenced in-app for drivers. A network of fixed stops could increase routing efficiency as riders could select their closest PUDO location ahead of ordering a pooled ride. However, the non-profit expert cited the challenge of potential public backlash related to lost parking and public curbspace. The expert suggested addressing this concern by offering amenities at PUDO locations (e.g., Wi-Fi, benches, lighting).

Similarly, PUDO locations could be clarified in smartphone applications. Currently, there is a disconnect with how the physical world is presented digitally in-app, resulting in challenges such as vagueness regarding which side of a street a user should be picked up on. This disconnect can lead to safety concerns for both riders and drivers. Stakeholders could present fixed stops in-app, which could clarify walking directions by providing riders with in-app information and a physical landmark to walk toward. This change could improve passenger safety and improve loading efficiency. 


\section{Incentives and Pricing Promotion Strategies}

Experts also discussed leveraging incentives and pricing promotions to encouraged pooled rides, such as:

1. Managed Lanes: In the past, pooled services relied on pricing promotions and discounts to lower the cost of pooled services to incentivize riders, even if matching riders likely increased travel time. A new approach to incentivizing riders to take pooled trips could be using managed lanes that allow for higher-occupancy modes to travel faster and without having to pay a toll. These cost and time savings could be presented to riders to dissuade using a private alternative. However, the difficulty of pooled vehicles congesting high occupancy lanes for bus transit remains. This may be addressed by shifting the existing managed lanes system from a two to three passenger minimum (a strategy currently being explored by the expert at a non-profit organization) to help mitigate some of this traffic congestion.

2. Single-Occupancy Trip Costs: Pooled rides could be supported by de-incentivizing single occupancy modes. This could be accomplished by increasing the price of private TNC trips. However, this strategy is dependent on decreasing ETA changes caused by route matching so that riders who select the pooled option for cost related reasons do not feel as if they are forced into using an inferior service.

3. Mobility as a Service: Mobility services (e.g., public transit, shared micromobility ${ }^{4}$ ) and fare payments can be integrated into apps that can then offer bundles of transportation services for a reduced price. This is typically referred to as Mobility as a Service ${ }^{5}$ (MaaS) and is being trialed in select locations throughout Europe and the U.S. Bundling fares could promote pooling as a first- and last-mile connection to public transit and lead to an increase in public transit ridership. The non-profit experts supported this strategy by suggesting incorporating pooled ride credits into rider subsidy programs. Low-income transit riders sometimes have the option to receive credits for discounted transit fare, but by broadening these reduced fare programs to include other mobility options, including pooled rides, more equitable access to transportation could be provided.

\section{Important Considerations}

As these strategies are developed and trialed experts also offered areas of consideration and key lessons learned, including:

1. Communication Improvements: Many experts highlighted the need for improved communication between public and private sector organizations. Private mobility experts wanted to know what information they need to share with public officials to change their perception of pooling, and how private organizations can best leverage their technology to help improve existing public transportation systems. Public sector experts highlighted the need for a system to hold stakeholders accountable. Moving forward, bridging the gap between public and private organizations will be necessary to support pooling.

2. COVID-19 Impacts: Another rapidly developing area of interest for public and private organizations is the degree to which the COVID-19 pandemic will impact riders' decisions to share rides in the future. Experts are interested in knowing what precautions are necessary to make riders comfortable with sharing rides again, and how long it may take riders to use pooling at a level comparable with prepandemic levels. The potential hesitance of riders to move back to pooling could result in the need for private mobility providers to pivot from some of the strategies suggested toward ones focused on their single-occupancy services.

\footnotetext{
${ }^{4}$ Shared micromobility is the shared use of a bicycle, scooter, or other low-speed mode.

${ }^{5}$ Mobility as a Service (MaaS) is defined a digital platform that integrates end-to-end trip planning, booking, electronic ticketing, and payment services across all modes of transportation, public or private.
}

41 
3. Equity Impacts: Experts highlighted the need to evaluate the equity impacts of the different proposed strategies. Equity considerations include the impacts of high-occupancy tolling on drivers and what degree of subsidization would be necessary to shift low-income users, many of whom live in lowdensity areas with limited access to public transit, to pooled mobility. It is thus important moving forward that all products and service changes be evaluated through the lens of equity.

\section{Key Takeaways}

- Service Distinction: A greater distinction between pooled services is necessary and could support altered rates.

- Information Provision: Riders and other transportation stakeholders could benefit from TNCs improving the available upfront information for riders (including ETA, route taken, and additional riders) before discounts are applied.

- Service Information: Information on available services needs to be clarified and how this information is distributed should be tailored to different communities.

- Curb Management: Public agencies and TNCs can work together to create more robust, dynamic curb management systems that can be geofenced as needed for large, planned events or unexpected traffic congestion.

- Pick-Up and Drop-Off (PUDO) Locations: TNCs can work with local community organizations to identify appropriate PUDO locations and to identify unsafe or ambiguous locations.

- Pick-Up and Drop-off (PUDO) Network: TNCs and public officials can work together to create a network of fixed PUDO locations with a physical sign and in-app marker to better help identify surroundings.

- User Incentives: Managed lanes can be leveraged to incentivize users to select pooled modes for time and cost savings.

- Commuter Benefits: Commuter benefits programs can be expanded to encourage pooling.

- Service Integration: Pooling can be increased through multimodal and fare payment integration, MaaS, and subsidy programs.

- COVID-19 Impacts: COVID-19 impacts will alter how pooling operates in the future. 


\section{Photovoice Groups}

A modified version of the photovoice methodology was employed to better understand TNC user's travel decisions. Photovoice typically involves participants in the data-collection and analysis process of communitybased research through the use of photography and small group discussions (Wang \& Burris, 1997). However, due to shelter-in-place and social distancing measures from the COVID-19 pandemic, an altered version of the traditional photovoice methodology was used. Rather than meeting with group participants in person and exploring and analyzing an area, participants were asked to submit their own photos of places they had or would be willing to meet TNC drivers. The submitted photos were then discussed in a small group over Zoom. Participant engagement with their surrounding built environment helped to facilitate conversations about built environment, service, and incentive preferences and provide information for future improvements.

\section{Demographics}

Respondents to the screener survey were deemed eligible to participate in photovoice if they met the following requirements:

- Were age 18 years or older,

- Lived in the San Francisco Bay Area,

- Had previous experience using TNCs (private or pooled),

- Had access to a smartphone or cell phone with a camera and Internet capabilities, and

- Were able to use the Zoom teleconferencing application.

Eligible participants were selected, in part, based on the frequency which they had used TNCs (private or pooled) prior to the COVID-19 pandemic (i.e., March 2020). The photovoice groups had a total of 15 TNC users, with eight non-heavy TNC and seven heavy TNC users. During the photovoice sessions differences in travel patterns and pooling preferences were revealed between male and female participants. As a result, demographic characteristics (e.g., vehicle ownership) were explored by gender. The group of 15 TNC users had eight male and seven female participants.

\section{Participant Demographics}

Participant demographic information was collected in the travel behavior survey including gender, age, race/ethnicity, educational attainment, and household income. The survey can be found in Appendix D Photovoice Participant Demographic Survey. The demographic information was then compared to the 2019 American Community Survey (ACS) for the study region (i.e., the San Francisco Bay Area) (United States Census Bureau, 2019). Key participant demographic findings include:

- Age: Participants' ages ranged from 26 to 60 , with $40 \%$ of participants between the ages of 35 and 44 . The demographics reflected a slight under-representation of young adults and the elderly compared to the San Francisco Bay Area's statistics. However, the distribution was fairly even among the ages represented.

- Race/Ethnicity: Participants' races/ethnicities aligned very closely with the San Francisco Bay Area data, with an underrepresentation of Hispanic/Latino photovoice participants.

- Educational Attainment: The photovoice participants had higher levels of educational attainment than the San Francisco Bay Area demographics. Approximately 93\% of the photovoice participants had a bachelor's degree or higher, compared to $51 \%$ of Bay Area residents.

- Income: The participant demographics also had an overrepresentation of middle and upper-middle incomes. Most of the photovoice participants had an income between $\$ 50,000$ and $\$ 199,999$. However 
only $24 \%$ of the San Francisco Bay Area population has a household income less than $\$ 50,000$, and $26 \%$ of the population has an income of $\$ 200,000$ or more.

The data from the participant survey and ACS are located in Table 5. 
Table 5. Photovoice Group Demographics

\begin{tabular}{|c|c|c|c|c|c|}
\hline & Characteristic & $\begin{array}{c}\text { Non-Heavy } \\
\text { TNC Users } \\
(n=8)\end{array}$ & $\begin{array}{c}\text { Heavy TNC } \\
\text { Users } \\
(n=7) \\
\end{array}$ & $\begin{array}{l}\text { Full Group } \\
\qquad(n=15)\end{array}$ & $\begin{array}{c}\text { San Francisco Bay Area } \\
(\mathrm{n}=4.73 \text { million) }\end{array}$ \\
\hline \multirow{2}{*}{$\begin{array}{l}\grave{d} \\
\frac{1}{0} \\
\text { ป } \\
\end{array}$} & Male & $50 \%$ & $57 \%$ & $53 \%$ & $49 \%$ \\
\hline & Female & $50 \%$ & $43 \%$ & $47 \%$ & $51 \%$ \\
\hline & & & & & \\
\hline \multirow{8}{*}{ 品 } & Under age 20 years & $0 \%$ & $0 \%$ & $0 \%$ & $22 \%$ \\
\hline & Age 20 to 24 years & $0 \%$ & $0 \%$ & $0 \%$ & $6 \%$ \\
\hline & Age 25 to 34 years & $13 \%$ & $43 \%$ & $27 \%$ & $16 \%$ \\
\hline & Age 35 to 44 years & $38 \%$ & $43 \%$ & $40 \%$ & $15 \%$ \\
\hline & Age 45 to 54 years & $25 \%$ & $0 \%$ & $13 \%$ & $13 \%$ \\
\hline & Age 55 to 59 years & $13 \%$ & $14 \%$ & $13 \%$ & $7 \%$ \\
\hline & Age 60 to 64 years & $13 \%$ & $0 \%$ & $7 \%$ & $6 \%$ \\
\hline & Age 65 years and over & $0 \%$ & $0 \%$ & $0 \%$ & $16 \%$ \\
\hline & & & & & \\
\hline \multirow{6}{*}{ 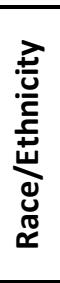 } & Asian/Pacific Islander & $13 \%$ & $57 \%$ & $33 \%$ & $27 \%$ \\
\hline & Black/African-American & $13 \%$ & $0 \%$ & $7 \%$ & $7 \%$ \\
\hline & Caucasian & $38 \%$ & $43 \%$ & $40 \%$ & $39 \%$ \\
\hline & Hispanic/Latino & $25 \%$ & $0 \%$ & $13 \%$ & $22 \%$ \\
\hline & Two or more races & $0 \%$ & $0 \%$ & $0 \%$ & $4 \%$ \\
\hline & Other & $0 \%$ & $0 \%$ & $0 \%$ & $1 \%$ \\
\hline \multirow{7}{*}{ 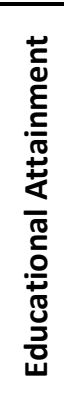 } & Less than high school & $0 \%$ & $0 \%$ & $0 \%$ & $6 \%$ \\
\hline & Some high school & $0 \%$ & $0 \%$ & $0 \%$ & $5 \%$ \\
\hline & $\begin{array}{l}\text { Graduated high school or } \\
\text { equivalent (GED) }\end{array}$ & $0 \%$ & $0 \%$ & $0 \%$ & $16 \%$ \\
\hline & Some college, no degree & $13 \%$ & $0 \%$ & $7 \%$ & $16 \%$ \\
\hline & Associate's degree & $0 \%$ & $0 \%$ & $0 \%$ & $7 \%$ \\
\hline & Bachelor's Degree & $50 \%$ & $86 \%$ & $67 \%$ & $30 \%$ \\
\hline & $\begin{array}{l}\text { Graduate or professional } \\
\text { degree }\end{array}$ & $38 \%$ & $14 \%$ & $27 \%$ & $21 \%$ \\
\hline & & & & & \\
\hline \multirow{10}{*}{ 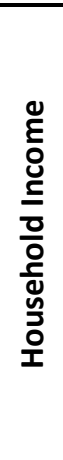 } & Less than $\$ 10,000$ & $0 \%$ & $0 \%$ & $0 \%$ & $4 \%$ \\
\hline & $\$ 10,000$ to $\$ 14,999$ & $0 \%$ & $0 \%$ & $0 \%$ & $3 \%$ \\
\hline & $\$ 15,000$ to $\$ 24,999$ & $0 \%$ & $0 \%$ & $0 \%$ & $5 \%$ \\
\hline & $\$ 25,000$ to $\$ 34,999$ & $0 \%$ & $0 \%$ & $0 \%$ & $5 \%$ \\
\hline & $\$ 35,000$ to $\$ 49,999$ & $0 \%$ & $0 \%$ & $0 \%$ & $7 \%$ \\
\hline & $\$ 50,000$ to $\$ 74,999$ & $25 \%$ & $14 \%$ & $20 \%$ & $11 \%$ \\
\hline & $\$ 75,000$ to $\$ 99,999$ & $38 \%$ & $29 \%$ & $33 \%$ & $10 \%$ \\
\hline & $\$ 100,000$ to $\$ 149,999$ & $38 \%$ & $0 \%$ & $20 \%$ & $18 \%$ \\
\hline & $\$ 150,000$ to $\$ 199,999$ & $0 \%$ & $43 \%$ & $20 \%$ & $12 \%$ \\
\hline & $\$ 200,000$ or more & $0 \%$ & $14 \%$ & $7 \%$ & $26 \%$ \\
\hline
\end{tabular}




\section{Household Vehicle Ownership}

In addition to demographic information, the photovoice participants were asked to provide basic household information including the number of vehicles per household. Most participants had high vehicle ownership or leasing rates, with the female participants having a higher average vehicle ownership than the male participants. However, heavy TNC users had fewer participants with zero vehicle households than the nonheavy users, with an average of 1.14 to one vehicle per household. This ownership rate can likely be attributed to higher average household incomes for heavy TNC users. Table 6 summarizes household vehicle ownership rates.

Table 6. Vehicles per Household

\begin{tabular}{|c|c|c|c|c|c|}
\hline $\begin{array}{c}\text { Number of Vehicles per } \\
\text { Household }\end{array}$ & $\begin{array}{c}\text { Non-Heavy } \\
\text { TNC Users } \\
(n=8)\end{array}$ & $\begin{array}{c}\text { Heavy TNC } \\
\text { Users } \\
(n=7)\end{array}$ & $\begin{array}{c}\text { Male Users } \\
(n=8)\end{array}$ & $\begin{array}{c}\text { Female Users } \\
(n=7)\end{array}$ & $\begin{array}{c}\text { Full Group } \\
(n=15)\end{array}$ \\
\hline Zero & $25 \%$ & $14 \%$ & $25 \%$ & $14 \%$ & $20 \%$ \\
\hline One & $63 \%$ & $57 \%$ & $63 \%$ & $57 \%$ & $60 \%$ \\
\hline Two & $0 \%$ & $29 \%$ & $13 \%$ & $14 \%$ & $13 \%$ \\
\hline Three & $13 \%$ & $0 \%$ & $0 \%$ & $14 \%$ & $7 \%$ \\
\hline Average & 1 & 1.14 & 0.88 & 1.29 & 1.07 \\
\hline
\end{tabular}

\section{TNC Use Frequency}

TNC use ranged across participants, with most heavy TNC users taking TNCs four to six days per week and most non-heavy TNC users taking TNCs one to three days per week. TNC use by males ranged from once every three months to two to four times per day, while most female participants took TNCs at least once a month to four to six days per week. Table 7 presents the frequency of TNC use (private and pooled) of the photovoice participants.

Table 7. TNC Use Frequency

\begin{tabular}{|l|c|c|c|c|c|}
\hline $\begin{array}{c}\text { Frequency of TNC use } \\
\text { (private and pooled) }\end{array}$ & $\begin{array}{c}\text { Non-Heavy TNC } \\
\text { Users } \\
(\mathrm{n}=8)\end{array}$ & $\begin{array}{c}\text { Heavy TNC } \\
\text { Users } \\
(\mathrm{n}=7)\end{array}$ & $\begin{array}{c}\text { Male Users } \\
(\mathrm{n}=8)\end{array}$ & $\begin{array}{c}\text { Female Users } \\
(\mathrm{n}=7)\end{array}$ & $\begin{array}{c}\text { Full Group } \\
(\mathrm{n}=15)\end{array}$ \\
\hline Once a year & $0 \%$ & $0 \%$ & $0 \%$ & $0 \%$ & $0 \%$ \\
\hline Once every 6 months & $0 \%$ & $0 \%$ & $0 \%$ & $0 \%$ & $0 \%$ \\
\hline Once every 3 months & $13 \%$ & $0 \%$ & $13 \%$ & $0 \%$ & $7 \%$ \\
\hline Once a month & $25 \%$ & $0 \%$ & $0 \%$ & $29 \%$ & $13 \%$ \\
\hline Every other week & $25 \%$ & $0 \%$ & $25 \%$ & $0 \%$ & $13 \%$ \\
\hline 1 to 3 days per week & $38 \%$ & $0 \%$ & $13 \%$ & $29 \%$ & $20 \%$ \\
\hline 4 to 6 days per week & $0 \%$ & $57 \%$ & $25 \%$ & $29 \%$ & $27 \%$ \\
\hline Once a day & $0 \%$ & $14 \%$ & $0 \%$ & $14 \%$ & $7 \%$ \\
\hline 2 to 4 times a day & $0 \%$ & $29 \%$ & $25 \%$ & $0 \%$ & $13 \%$ \\
\hline More than 4 times a day & $0 \%$ & $0 \%$ & $0 \%$ & $0 \%$ & $0 \%$ \\
\hline
\end{tabular}

\section{Pooling Frequency}

Previous research has found that more frequent TNC users are more likely to select pooled options (Lazarus et al., 2021). As a result, the survey of the photovoice participants explored their frequency to select the pooled 
trip option. This revealed that $86 \%$ of the heavy TNC users select the pooled option more than half of the time, while only $26 \%$ of the non-heavy users select pooled more than half of the time. These findings are further detailed in Table 8.

Table 8. Pooled Ride Frequency

\begin{tabular}{|l|c|c|c|c|c|}
\hline \multicolumn{1}{|c|}{ Frequency of selecting the "pooled" option } & $\begin{array}{c}\text { Non-Heavy } \\
\text { TNC Users } \\
(n=8)\end{array}$ & $\begin{array}{c}\text { Heavy TNC } \\
\text { Users } \\
(n=7)\end{array}$ & $\begin{array}{c}\text { Male } \\
\text { Users } \\
(n=8)\end{array}$ & $\begin{array}{c}\text { Female } \\
\text { Users } \\
(n=7)\end{array}$ & $\begin{array}{c}\text { Full } \\
\text { Group } \\
(n=15)\end{array}$ \\
\hline Never & $25 \%$ & $0 \%$ & $0 \%$ & $29 \%$ & $13 \%$ \\
\hline Some of the time (less than 50\%) & $25 \%$ & $0 \%$ & $13 \%$ & $14 \%$ & $13 \%$ \\
\hline Half of the time (50\%) & $25 \%$ & $14 \%$ & $38 \%$ & $0 \%$ & $20 \%$ \\
\hline Most of the time (more than 50\%) & $13 \%$ & $43 \%$ & $25 \%$ & $29 \%$ & $27 \%$ \\
\hline Almost always & $13 \%$ & $43 \%$ & $25 \%$ & $29 \%$ & $27 \%$ \\
\hline
\end{tabular}

\section{Demographic Key Findings}

- The 15 TNC users who participated in the photovoice groups were evenly distributed by gender and age, and the distribution of their reported races/ethnicities aligned closely with that of the general population of the study area (i.e., the San Francisco Bay Area).

- Photovoice participants had higher levels of educational attainment and income levels closer to the median (i.e., fewer high- and low-income levels represented) of that of the general population.

- Participants had high vehicle ownership or leasing rates, with female users and heavy TNC users exhibiting higher ownership rates than the full group average.

- Most heavy TNC users took TNCs four to six days per week and most non-heavy TNC users took TNCs one to three days per week, with heavy TNC users taking pooled TNCs more frequently than non-heavy TNC users, as is reflected in the literature.

\section{Photovoice Discussion}

The photovoice groups revealed considerations that influenced travel behavior and decision making. Safety and security concerns were at the forefront of these considerations. These concerns included trip types (e.g., private versus pooled rides, direct versus indirect trips) and built environment features. The surrounding environment (e.g., built environment features, neighborhoods) greatly informed safety and security concerns when waiting for and meeting TNC drivers. Safety concerns were particularly prevalent for females, and some of the males in the groups stated that they made different trip choices when deciding for or traveling with a female. The following subsections discuss safety and other TNC ridership considerations including:

- Private and Pooled TNC Trips: Previous experience using TNCs including private and pooled rides and direct and indirect trips;

- Heavy and Non-Heavy User Differences: Different perspectives on multimodal trips, incentives, and waiting locations from heavy and non-heavy TNC users;

- Current Pick-Up and Drop-Off Locations: Descriptions of existing locations where participants get picked up and dropped off by TNC drivers;

- Potential Designated TNC Stops: Desired built environment features, amenities, and locations for designated TNC stops; and

- COVID-19 Impacts: Travel changes due to the COVID-19 pandemic and potential long-term impacts. 


\section{Private and Pooled TNC Trips}

The photovoice sessions began with questions about experiences using private and pooled (both direct and indirect) TNC trips and public transit connections. The following subsections discuss:

- Private TNC Trips: TNC trips where there were no additional passenger pick ups or drop offs along a single route (e.g., UberX, Uber $\mathrm{XL}$, Lyft),

- Pooled TNC Trips: TNC trips where additional passengers were picked up and dropped off along a shared route (e.g., Uber Pool, Lyft Shared),

- TNCs and Public Transit Connections: A TNC trip (either private or pooled) that acted as a first- or lastmile connection to a mode or between modes of public transit, and

- Differences Between TNC Users: Characteristics and preferences of heavy and non-heavy TNC users.

\section{Private TNC Trips}

Over $65 \%$ of participants stated that their primary reason for selecting private over pooled TNC rides was to avoid the added time from picking up and dropping off additional passengers on pooled trips. This consideration was particularly critical for time sensitive trips (e.g., job interview, flight) and trips where privacy was preferred (e.g., on a date, to a doctor's appointment). Participants also shared that they typically select private rides when traveling with companions. Private TNC rides also offered riders more control over their environment (e.g., not being subjected to passengers with strong perfumes, the ability to take a phone call in private).

\section{Pooled TNC Trips}

Over $85 \%$ of participants had taken pooled TNC trips before, predominantly due to price incentives. A few participants cited avoiding surge pricing as a factor for choosing pooled trips. Participants also selected pooled trips based on trip distance, since longer trips would cost more, and feelings of safety and security (e.g., sharing a ride with other passengers rather than just the driver). One participant mentioned selecting pooled trips in order to use the high-occupancy vehicle lane and avoid freeway congestion.

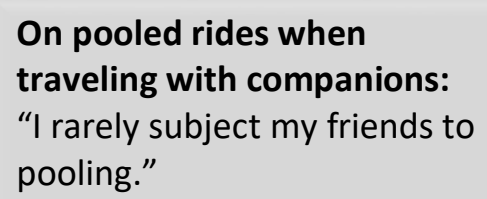
traveling with companions: "I rarely subject my friends to pooling."

\section{Direct Pooled Trips}

Eight participants stated that direct pooling was the best mode of transportation during inclement weather. This preference is likely because the rider's willingness to wait for public transit outside decreases in worse weather, as does the rider's interest in walking to an indirect pick-up location.

\section{Indirect Pooled Trips}

Participants also had experience taking indirect pooled trips. Participants expressed a high willingness to take indirect pooled trips, especially within short walking distances (i.e., five to seven minutes) and if a discount to the trip cost would be applied. Approximately $40 \%$ of participants were hesitant to take indirect pooled trips if they had to walk in an unsafe area and/or if the walking distance was too long (i.e., more than 10 minutes). Other reservations noted included walking in the evening/nighttime, in hilly areas, and when traveling with companions. Multiple participants expressed dissatisfaction with the service due to difficulties locating the TNC at the assigned pick-up spot. 


\section{TNCs and Public Transit Connections}

Approximately $60 \%$ of participants had used TNCs to connect to public transit. The top reasons for the multimodal trips included:

1. Inaccessibility of public transit via walking,

2. Difficulty with carrying luggage or other items,

3. Lack of connection to the final destination,

4. Time constraints, and

5. Traveling outside of public transit operating hours.

The primary reason individuals did not use TNCs to connect to public transit was a preference to use a single mode (i.e., public transit) for the entire trip duration. However, $60 \%$ of participants stated that they would call a TNC if the wait time for public transit increased by a large amount (e.g., more than 20 to 30 minutes), such as in the case of an unforeseen delay or a bus that was too crowded for additional passengers to board.

\section{Public Transit}

When compared to public transit, pooling was the more attractive option due to the appeal of shorter trip times and ability to avoid complicated transfers. Participants also found pooled rides more attractive than crowded or unsafe public transit options. Additionally, participants selected pooled rides when they were in locations with limited public transit access or were traveling outside of public transit operating hours. However, several passengers shared reasons for preferring public transit over TNCs (private or pooled), with the top reason being price. Public transit modes are generally cheaper than either type of TNC trip. For example, one participant stated that they could buy a monthly public transit pass that included all rides, instead of paying for individual TNC rides. Another participant preferred public transit because of the ability to take their bike onboard if they used it as a first- or last-mile connection.

\section{Private and Pooled TNC Trip Key Findings}

- TNC users took private TNC trips when trip time, purpose, and discretion were important. However, TNC users took pooled TNC trips when trip cost was important and public transit was not available.

- Participants preferred direct trips in inclement weather, at night, and in unfamiliar areas, but were interested in the indirect option when they received a discount on the trip cost and the walking distance was not too far.

- Group participants connected TNCs to public transit when transit was inaccessible by walking, they had luggage, or the wait time for public transit had increased due to unforeseen circumstances.

Heavy and Non-Heavy TNC User Differences

From the small group discussions, several differences between the heavy and the non-heavy TNC users were identified. These differences are described in Table 9 and discussed in further detail below the table. 
Table 9. Heavy and Non-Heavy TNC User Differences

\begin{tabular}{|c|c|c|c|}
\hline Difference & Description & Heavy TNC Users & Non-Heavy TNC Users \\
\hline $\begin{array}{l}\text { Multimodal } \\
\text { Trips }\end{array}$ & $\begin{array}{l}\text { Frequency in } \\
\text { which TNC users } \\
\text { take TNCs to } \\
\text { connect to other } \\
\text { modes (e.g., } \\
\text { public transit, } \\
\text { walking) }\end{array}$ & $\begin{array}{l}\text { Over } 85 \% \text { of users have } \\
\text { connected to public } \\
\text { transit } \\
\text { Over } 85 \% \text { have taken } \\
\text { indirect trips } \\
\text { Over } 71 \% \text { used indirect } \\
\text { trips for at least half of } \\
\text { their TNC trips }\end{array}$ & $\begin{array}{l}\text { - Less than } 28 \% \text { of users have } \\
\text { connected to public transit } \\
\text { - Less than } 63 \% \text { have taken indirect } \\
\text { trips } \\
\text { - Less than } 38 \% \text { used indirect trips for } \\
\text { at least half of their TNC trips } \\
\text { Approximately } 38 \% \text { did not know } \\
\text { indirect trip options existed }\end{array}$ \\
\hline Incentives & $\begin{array}{l}\text { Preferences for } \\
\text { different } \\
\text { incentive types }\end{array}$ & $\begin{array}{l}\text { - Preferred "frequent ride } \\
\text { promotion" discounts } \\
\text { - } \quad \text { Preferred discounts for } \\
\text { indirect trips }\end{array}$ & $\begin{array}{l}\text { - } \quad \text { Preferred individual trip discounts } \\
\text { - } \quad \text { Preferred discounts for indirect trips }\end{array}$ \\
\hline $\begin{array}{l}\text { Waiting } \\
\text { Locations }\end{array}$ & $\begin{array}{l}\text { Ideal waiting } \\
\text { location } \\
\text { characteristics }\end{array}$ & $\begin{array}{l}\text { - Less concerned with } \\
\text { physical space and } \\
\text { amenities } \\
\text { More concerned with } \\
\text { space for drivers to pull } \\
\text { into } \\
\text { Desired large, highly } \\
\text { visible signage }\end{array}$ & $\begin{array}{l}\text { - Strong desire for select built } \\
\text { environment features (e.g., wide } \\
\text { sidewalks, lighting) } \\
\text { - More selective with location (e.g., in } \\
\text { locations that were not crowded, not } \\
\text { on one-way streets) } \\
\text { Desired more subtle, discreet } \\
\text { signage }\end{array}$ \\
\hline
\end{tabular}

\section{Multimodal Trips}

The discrepancy in multimodal trip preferences can most likely be attributed to heavy TNC users taking TNCS for multiple trip types (e.g., commutes, errands, recreational activities) and wanting to minimize their per-trip cost. Since non-heavy TNC users take TNCs predominantly for recreational purposes or to travel to the airport they are incentivized to minimize the overall number of TNC trips taken.

\section{Incentives}

When discussing incentives for higher occupancy vehicles heavy TNC users were more interested in frequencybased incentives. This could be due to the fact that these users would be taking a TNC trip regardless of if a discount were present or not. Alternatively, non-heavy TNC users were drawn to discount-based pooling incentives. This could be explained by the non-heavy users taking TNCs for "choice" trips and having other preferred options (like public transit or personal car) available. However, both groups expressed interest in incentives for indirect trips. This may be because shifting from direct pooling to indirect requires an additional behavioral change, even for heavy TNC users (i.e., a heavy TNC user might take pooled for all of their trips, but only for a percentage of them do they select the indirect option).

\section{Waiting Locations}

The differences in waiting area preferences between heavy and non-heavy TNC users can be attributed to different levels of comfort associated with pick up in busy areas. The heavy TNC users showed fewer preferences for specific built environment features at pick-up locations - caring more about where the TNC driver would pull over. However, non-heavy TNC users exhibited strong preferences for wide sidewalks, lighting, and benches. The heavy TNC users may have been more experienced with waiting in a variety of environments because they had done so more frequently, whereas the non-heavy TNC users may have been 
less comfortable in areas where it was ambiguous where the TNC would pick them up. Heavy TNC users also preferred larger, more eye-catching signage to demark pick-up and drop-off locations, while non-heavy TNC users preferred smaller signs that were more subtle. This bifurcated response could have been because the heavy TNC users acknowledged the utility of having highly visible signage and shelters because they know it would be easier for drivers to spot them. Alternatively, since the non-heavy TNC users would likely use the spaces less frequently the corporate branding in public spaces was perceived as less useful and more visually unsettling. Similarly related to comfort, female heavy TNC users felt safer in pooled TNCs, while the female non-heavy TNC users felt safer in private TNCs.

\section{Heavy and Non-Heavy User Differences Key Findings}

- Heavy TNC users preferred multimodal trips while non-heavy users wanted to use one mode for the entirety of their trip duration.

- Likely because heavy TNC users take TNC trips more frequently, they were interested in frequencybased incentives. Alternatively, non-heavy TNC users preferred discount-based pooling incentives.

- Heavy TNC users had less built environment preferences for waiting locations but did prefer visible signage. However, non-heavy users wanted areas that facilitated easy connections to drivers (e.g., wider sidewalks) but with more subtle signage.

\section{Current Pick-Up and Drop-Off Locations}

When discussing the locations participants had experience getting picked up or dropped off by TNCs at, the most prevalent concern was regarding their safety and security. The concerns included walking to and waiting at the locations, as well as once the participants got into the TNC. Virtually all participants mentioned safety as an issue or consideration when deciding where to take TNC trips from and whether to take a direct or indirect trip. Personal security was the primary concern, seconded by traffic/roadway safety concerns (e.g., crossing streets with no crosswalks, entering/exiting a TNC on roadways with many lanes of fast traffic). This section provides further information on personal safety and security at and around TNC PUDO locations including:

- Walking to Pick-Up Locations: How do TNC users factor the safety of the area surrounding a pick-up location into their decision to walk (e.g., for an indirect pooled trip)?

- Waiting at Pick-Up Locations: What characteristics of pick-up locations do TNC users find make them feel safer when waiting and what aspects need to be improved?

- In-Vehicle Safety: What safety concerns do users have about the in-vehicle experience of a TNC trip and what features could help address them?

- Gender Differences: What aspects of TNC trip safety do male and female TNC users view differently and what strategies do they use to improve feelings of security? 
Walking to Pick-Up Locations

\section{On waiting in unsafe locations:} "They've gotten robbed in front of this bench by just, you know, people, and are harassed by the homeless people in the park across the street, and then there's also like homeless encampments just everywhere. It's not safe at all."
In discussions with participants, there was a general high level of concern regarding walking to or waiting at pick-up locations due to the perceived lack of safety of waiting areas, particularly at night. Several participants mentioned not wanting to walk through or wait in neighborhoods that are wellknown as being high-crime neighborhoods (e.g., Tenderloin

and Hunter's Point in San Francisco). Common fears included being approached on the street, robbed, or encountering a homeless person facing mental health challenges. Participants avoided waiting on certain streets because of alleyways that could provide hiding places for unsavory individuals but were also hesitant to wait in crowded areas due to concerns about theft (e.g., of mobile phones).

Figure 1. Unsafe Waiting Location Example

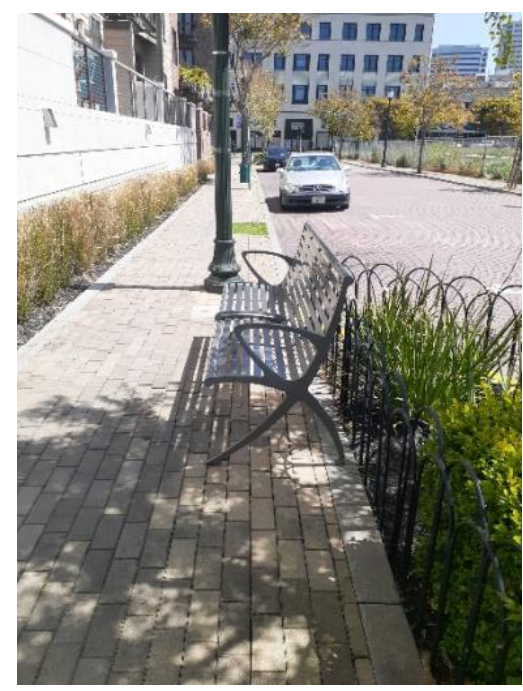

Source: Photovoice Participant, 2021

\section{Waiting at Pick-Up Locations}

Safety and security concerns were also deciding factors when choosing a location to meet TNC drivers. The overwhelming majority of participants preferred areas that were well lit and maintained and had clear sightlines that helped them monitor their surroundings. Table 10 summarizes the preferred characteristics, location, and included amenities in potential PUDO locations. Figure 2 illustrates some of these considerations.

Table 10. Ideal PUDO Location Considerations

\begin{tabular}{|c|c|c|}
\hline Characteristics & Location & Amenities \\
\hline $\begin{array}{ll}\text { - } & \text { Clean } \\
\text { - } & \text { Well-lit } \\
\text { - } & \text { Quiet } \\
\text { - } & \text { Low foot traffic but not isolated } \\
\text { (e.g., to have "eyes on the street" } \\
\text { but not make it difficult for the } \\
\text { driver and passenger to identify } \\
\text { each other) } \\
\text { - Nearby crosswalks and/or } \\
\text { pedestrian signals }\end{array}$ & $\begin{array}{l}\text { - } \quad \text { Safe or familiar areas } \\
\text { Open space and good site lines } \\
\text { (to identify the approaching TNC } \\
\text { more easily and monitor the } \\
\text { surroundings) } \\
\text { Near stores, shopping centers, } \\
\text { or cafes (especially during poor } \\
\text { weather conditions) } \\
\text { Not in areas with narrow or one- } \\
\text { way streets }\end{array}$ & $\begin{array}{l}\text { Benches or other types of seating } \\
\text { that could be used while waiting } \\
\text { that faced the street to identify } \\
\text { the TNC driver more easily }\end{array}$ \\
\hline
\end{tabular}


Figure 2. PUDO Location in San Francisco

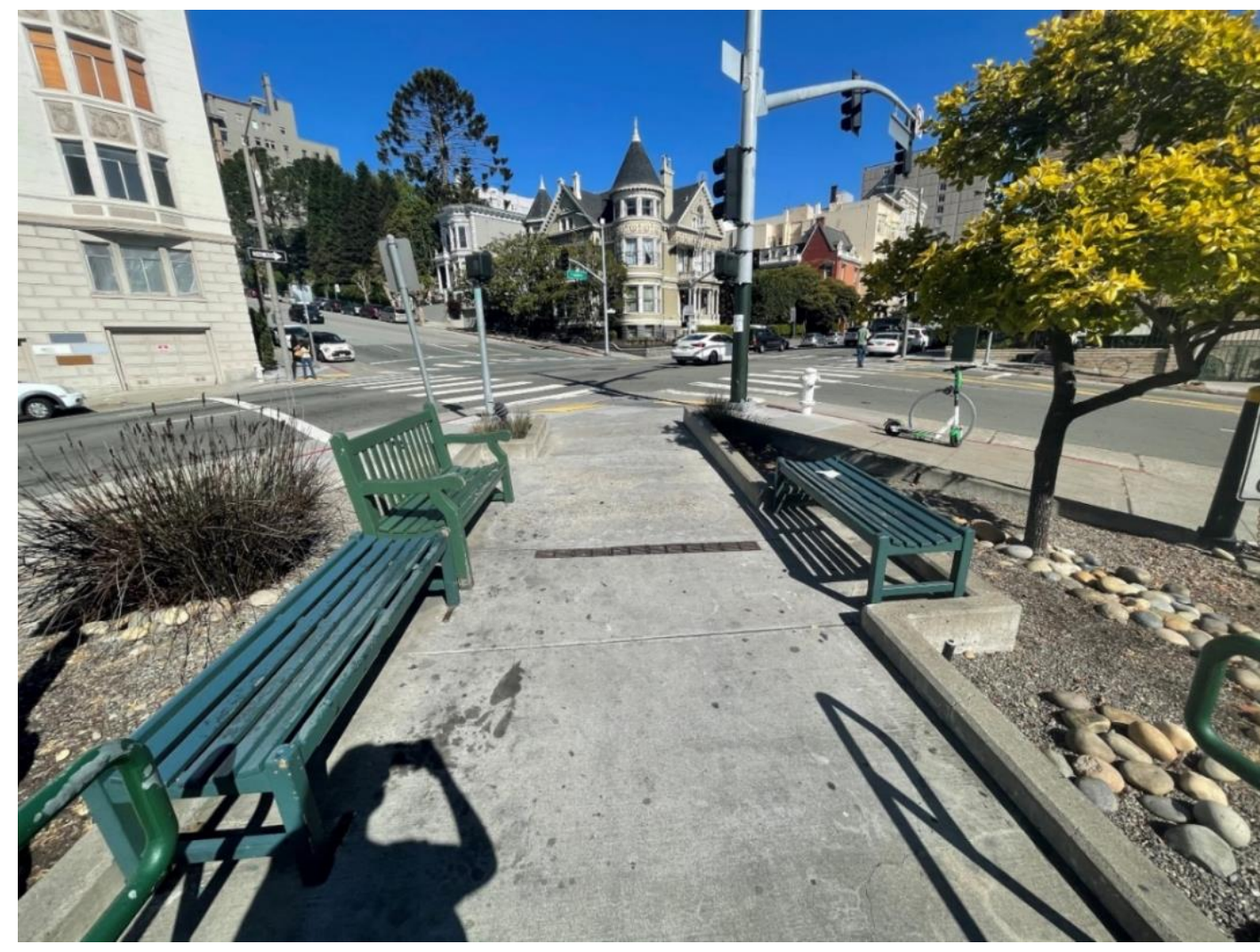

\section{Source: Photovoice Participant}

Homelessness was brought up by over half of the participants and on various occasions as a source of discomfort at potential waiting areas. Several participants specified a distinction between homeless individuals that were aggressive and could potentially attack or rob them, and homeless individuals that were simply "down on their luck." Though the former group were viewed as being more dangerous, participants generally said they would not feel comfortable walking by or waiting near either group.

Other aspects of waiting locations that contributed to participants' lack of feeling safe included a prevalence of trash, dirtiness, and "urban ugliness" (e.g., abandoned warehouses), as well as loitering and areas with low lighting. As a response to these concerns participants generally preferred to order direct trips and wait inside stores, other businesses, or their home until their TNC arrived and only then going outside to meet the vehicle. Waiting inside shops provided an activity (e.g., browsing) and ensured shelter from the weather, sufficient lighting, and other people.
On homeless individuals at pick-up locations:

"At that hour [11pm] downtown on Market Street, you won't see as much, I guess, regular people walking around, it's probably more like homeless people just hanging out and about and just, if I'm by myself, I just feel like it's my safety at risk." 


\section{In-Vehicle Safety}

When asked about improvements to the existing safety system for the in-vehicle aspect of TNC trips there were mixed responses. Several participants stated the features of the current system make it as safe as it can be. However, other participants recommended changes to improve in-vehicle safety including:

- Rating passengers in a pooled ride;

- Rating drivers on vehicle cleanliness, ride quality, safety, and "creepiness" (e.g., uncomfortable driver commentary);

- Automatically sending trip information (e.g., the route, other passenger and driver information, ETA) to other parties in pooled rides;

- Submitting emergency contact information; and

- Setting gender preferences for both the TNC driver and for the other passengers in pooled trips.

Participant concerns were based on the lack of background checking of new drivers on the services and from media stories they had seen regarding TNC drivers preying on passengers. Additionally, one participant cited discomfort with the potential racial prejudice of other passengers as being a motivating factor for her to take private trips. A variety of safety impacts varied by gender, and are discussed in further detail in the following section.

\section{On pooling with strangers:}

"Cost doesn't matter - it's about me being comfortable as a black woman and as a woman."

\section{Gender Differences}

The discussion of existing TNC PUDO locations revealed key differences between male and female TNC users on safety and security. Key differences include:

- Information Disclosure: Female participants were more concerned about the TNC drivers having their home address and were more willing to be picked up or dropped off down the block from their residence.

- Private versus Pooled Rides: Though the female participants had different preferences for private versus pooled rides, safety factored into arguments for both sides. Females that preferred private rides stated that it offered them more control over their environment while women who preferred pooled rides liked having passengers other than the driver.

- Pick-Up Locations: Female participants preferred waiting for TNCs near retail opportunities. This preference was in part due to the opportunity to run errands while waiting and the appeal of sheltered, but not isolated, well-lit, and safe locations.

- Waiting Activities: Female participants preferred to do things that did not involve having their phone out (e.g., shopping) while male participants were more likely to use their phone while waiting (e.g., to check emails, monitor the ETA). This difference is potentially because female participants viewed themselves at higher risk for robbery and preferred to not have their phones out so they could be more alert.

- Surrounding Crowds: Female participants preferred locations that were well-traveled, were not isolated, and, if there was a shelter, was open and/or transparent. Inversely, male participants were more concerned with crowds and waiting in areas with heavy foot traffic. This difference is likely due to a greater concern of assault for females and theft for males.

- Precautions: Female participants engaged in a variety of techniques to help ensure their safety including:

○ Having a male order the ride, 
- Being walked out by a male to the vehicle,

- Having a male wait outside for the ride,

- Waiting near a security guard or police officer,

- Changing the drop-off location if they feel unsafe,

- Sharing location information with a friend, and

- Sending ride information (e.g., origin and destination, license plate number) to an outside party.

\section{Driver Connections}

In addition to safety, a critical PUDO consideration for the majority of participants was the ease of Figure 3. Example PUDO Location connecting with TNC drivers. This consideration included waiting at a location where drivers could easily pull over (e.g., white painted curbs indicating passenger loading zones, ample or unused street parking, horseshoe-style driveways, large parking lots). Participants also preferred locations with clear landmarks that could make directing the driver to their locations simpler (e.g., large statues, recognizable storefronts with large signs). Figure 3 illustrates some of these features.

These preferences were likely informed by difficulties meeting TNC drivers, particularly in and around San Francisco. Participants faced challenges with TNCs picking up in busy locations, causing difficulty for drivers to stop, leading them to resort to double parking or loading or unloading passengers at a red-painted curb $(n=4)$, in a bus

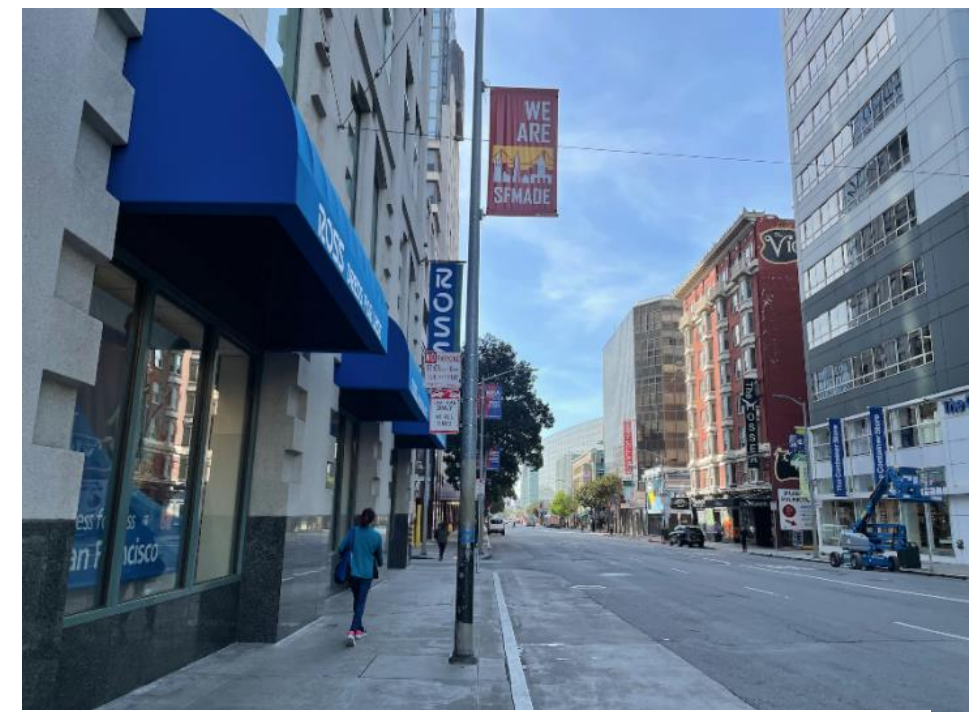

Source: Photovoice Participant, 2021 lane $(n=4)$, or in a bike lane $(n=2)$. Participants also identified crowded spaces $(n=5)$ as being difficult for drivers because it could make locating the correct passenger $(n=9)$ challenging and time-consuming.

\section{PUDO Location Key Findings}

- TNC users were concerned about walking to pick-up locations at night and through unsafe areas that put them at risk for being robbed, attacked, or approached by homeless individuals.

- TNC users preferred waiting in safe, well-lit, and open locations near shopping areas and away from homeless encampments.

- TNC users' in-vehicle safety concerns could be addressed by additional safety features, such as providing more detailed trip information to emergency contacts and allowing for specific driver/passenger preferences.

- Female TNC users preferred waiting in retail areas where there were other people around and often took additional safety precautions when waiting for and taking rides. Male TNC users' main safety concern was having their phone stolen while waiting in a crowded area.

- TNC users considered the ease of connecting with their driver when selecting pick-up locations and preferred locations with loading zones, parking lots, and clear landmarks to help avoid double parking or conflicts with other modes. 


\section{Potential Designated TNC Stops}

During the discussion of what participants liked and disliked about different TNC waiting locations, and their descriptions of the safety and security concerns they had regarding walking to and waiting at TNC pick-up locations, approximately half of the participants suggested designated TNC stops to address concerns with pick up and drop off. Participants were probed about this potential system and their responses included considerations, such as:

- Built Environment Features: Design and built environment features to increase the attractiveness of the location,

- Waiting Amenities: Amenities to improve the waiting experience,

- Stop Locations: Ideal geographic areas and neighborhoods for stops to be located, and

- Network of Stops: Design of a system of TNC stops.

\section{TNC Stop Location Interest}

Participants suggested that designated TNC stops would provide the desired space for a TNC driver to easily pull-over - even on busy, one-way roadways - and would be a place where the passenger knew they are supposed to wait, simplifying the driver-passenger location challenge.

\section{Skepticism and the Status Quo}

Despite the interest in a network of TNC stops throughout the discussion, many participants exhibited a strong sense of skepticism about whether improvements could be made, and if so, how long the improvements would exist before being dirtied or ruined. This general skepticism for improving upon the status quo was present in nearly all of the discussion groups and related to safety and security, built environment improvements at TNC stops, and even regarding the hypothetical designated TNC stop shelters.

\author{
On having greenery at TNC \\ stops: \\ "I guess I'm a bit cynical from \\ all that from living in San \\ Francisco, because trees means \\ dog poop...I don't know if I'd \\ like it surrounded by trees."
}

\section{On maintaining cleanliness at TNC stops: \\ "My concern is how are they going to stay safe and clean? Because I feel like there's no way those areas are gonna stay safe and clean." \\ "The cynic in me is worried that the minute that these shelters go up, it's going to be vandalized and gross and that kind of thing."}

For example, when the inclusion of greenery or street trees was suggested, one participant expressed disinterest, citing maintaining cleanliness as being an issue. When benches were mentioned, participants raised concerns about cleanliness as well as about homeless people sleeping on them. A similar concern was raised about including phone chargers at waiting areas.

When the concept of shelters at designated TNC stops was suggested to participants, participants immediately raised concerns over safety and cleanliness. Even when safety improvements were explored (e.g., providing emergency call buttons, adding surveillance cameras), several $(n=4)$ participants believed such improvements would be futile.

Two participants also expressed concerns about designated TNC stops actually improving the trip time of the pooled TNC ride. One participant expressed skepticism about whether she would use the system due to bad prior experiences with traditional pooled TNCs. 


\section{Built Environment Features}

Similar to the aspects of the pick-up location photographs that participants liked, the key built environment features participants wanted at designated TNC stops included:

Figure 4. Built Environment Features Example

Seating (80\%),
Lesignated wayfinding and signage (53\%),

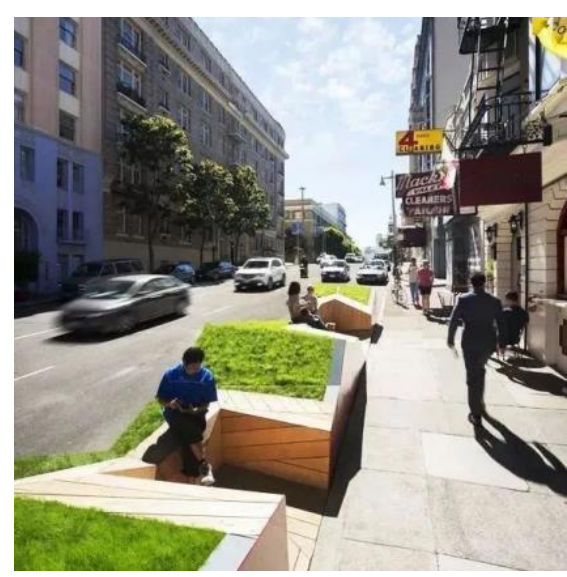

Source: Photovoice Participant, 2021
Two participants noted that benches, in particular, could be helpful when traveling and waiting with a mobility impairment (e.g., broken leg) or with a companion with a mobility need.

\section{On having benches at TNC stops:}

"And I thought to myself, it's all wood and it's so comfortable, a homeless person - not that I have anything against homeless people - but that's where they would stop and rest."

\section{Security Considerations}

Several participants had dissenting opinions relating to how shelters at TNC stops should be secured, given the safety concerns expressed regarding traditional ad-hoc TNC waiting locations. Two participants expressed interest in shelters being accessible only to TNC users with a unique access code that would be presented through the app and would change for every trip. The participants assumed that TNC users are generally responsible and restricting access of stop shelters exclusively to TNC users would keep those spaces safe and clean. A few other participants expressed concern related to such shelters being closed off and isolated, as it could pose a risk for TNC users, especially females, to be pushed inside and trapped. Instead, the participants suggested making the shelters an open design with transparent walls so that those outside of the shelter could see in and vice versa. Participants suggested incorporating other safety features into TNC shelters including surveillance cameras and emergency call buttons.

\section{Waiting Amenities}

Participants suggested several different types of amenities for inside the TNC stop shelters to help improve the waiting experience including providing real-time trip information. Some participants were interested in Wi-Fi to allow for multitasking (e.g., checking emails) while others said this was not necessary since their phones were equipped with data plans and they had good reception throughout the city. Participants recommended other 
waiting amenities including phone charging stations, bodega-like snack vending, water bottle refill stations, play areas/activities for children, and a community art pop-up.

\section{Stop Locations}

Figure 5. Residential Pick-Up Location

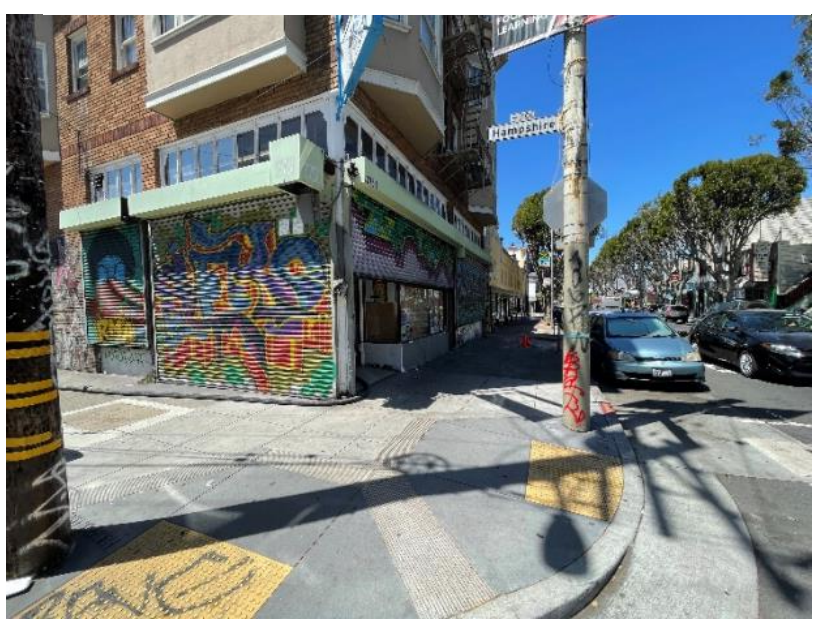

Source: Photovoice Participant, 2021
When asked about where the designated TNC stops should be located, most participants suggested they be placed in safe, centralized neighborhoods with good surrounding visibility. Participants specifically recommended that TNC stops be located in busy areas (e.g., downtown districts, event centers, tourist destinations), near retail or dining opportunities, and near parks. With the exception of one female participant, the consensus among the discussion groups was that participants generally felt comfortable waiting in residential areas and if TNC stops were located near their home, they would most likely not use them (illustrated in Figure 5). Finally, several participants suggested PUDO stops be strategically located to have minimal traffic flow impacts. For example, one participant recommended building them into parklets so that they do not take up sidewalk space.

On locating TNC stops in residential areas:

"I don't think I need that where I am in the Mission. I feel perfectly fine just getting a TNC from my apartment or the corner."

\section{Network of Stops}

Several participants provided feedback on a system of designated TNC stops. Three female participants said that they would use the system for every pooled trip with no additional discount or incentive needed, with one participant sharing that she even would not mind walking to a more inconvenient location so long as it was safe. Two male participants shared that their use of such a service would be location dependent, though one did share that he could see the service being useful for connecting users traveling in the same direction for their commutes. Regarding the pricing of the system, one participant shared that they would even pay more to use the system but would be interested in being able to donate the difference between the typical indirect trip cost and the additional cost to use a TNC stop to a charity or a social program that would support the homeless. Another participant expressed interest in a flat fee structure to connect from any one TNC stop to another throughout the city. However, a participant in the same discussion group shared that she was not sure she would use the system enough to warrant paying a flat fee and would probably just use the typical indirect trip option instead.

\section{Designated TNC Stop Key Findings}

- There was interest in a network of TNC stops providing designated areas for drivers to pull over and a safe place for TNC users to wait, though users were skeptical of how the safety and cleanliness of these stops would be maintained. 
- Users were interested in seating, shelter, and lighting at stops, as well as wayfinding and safety features like cameras and emergency call buttons. Some users were also interested in waiting amenities like screens with real time trip information and Wi-Fi.

- Users preferred to use TNC stops located in busy areas that were safe, centralized, and near shopping and dining establishments. Some users were willing to pay a higher trip cost or walk to more inconvenient locations to make use of a network of TNC stops.

\section{Incentives}

In addition to designated TNC stops, several different types of incentives to shift participants toward higher occupancy (i.e., pooled TNCs) trips were explored. Participants were asked about both discounts and promotions to incentivize them to change mode choice including:

- Private to pooled TNC trips,

- $\quad$ Direct pooled to indirect pooled TNC trips, and

- $\quad$ TNC trips connecting to public transit.

Discounts were presented as a dollar or percentage amount off of the base cost as bundled services (e.g., MaaS) and "frequent rider" programs (i.e., participants would receive reward points or credits after taking $\mathrm{X}$ number of TNC trips).

\section{Private to Pooled TNC Trips}

Over $90 \%$ of participants expressed an interest in the incentives shifting them from using private to pooled TNC trips, with a preference for individual trip cost discounts over promotions. The preferred discount percentage varied amongst participants from $20 \%$ to $50 \%$ off the base cost. One participant expressed interest in the cost of pooled trips being split evenly between the number of riders taking the pooled TNC ride.

\section{Indirect Trips}

Additionally, 53\% of participants showed an interest in receiving a discounted cost for taking an indirect pooled trip, with preferences ranging from a few dollars off of the base pooled cost to a $20 \%$ to $50 \%$ discount off the base pooled cost. Participants with no experience using the indirect pooled trip feature in the past also expressed willingness to try the service in the future if such a discount were in place. Participants did state that their interest in receiving a discount to take an indirect trip

On how time of day trumps indirect trip incentives: "If I need to go like four blocks at 2 am, then that's not worth it...walking is quite dependent on the time frame." was dependent on the time of day and the area in which the TNC app asked them to walk through, saying that they would only use the discount if it was during the day and they were in a safe area.

\section{Public Transit Connections}

However, participants were less interested in programs incentivizing connecting TNC trips to public transit. Participants generally fell into one of three perspectives:

1. Those that do not connect TNC trips to public transit or do so with such infrequency that a discount would not impact their behavior,

2. Those that are required to connect TNC trips to public transit due to transit gaps in their commute and would accept the discount but would continue to connect TNCs to public transit regardless of whether the incentive existed, and 
3. Those that would be more likely to connect TNCs to public transit if there was an incentive.

The cost of the TNC connection and the convenience of the mode currently used to connect to public transit (e.g., walking, driving a personal vehicle) may contribute to these perspectives. For example, one participant that typically commuted by driving their personal vehicle to connect to CalTrain stated that they could be incentivized to connect to CalTrain via a TNC if the price for CalTrain station parking increased to more than the price of the equivalent TNC trip (i.e., about \$7). However, taking a personal vehicle was also appealing because of the convenience it afforded for running errands: "If I want to stop at the grocery store on the way back, I just have my car with me."

Though there was some interest in a "frequent rider" rewards program, it was primarily viewed as something participants wanted as a passive feature to run in the background (e.g., similar to credit card points) that would not influence trip making decisions. One participant also cited concerns over the value of the redeemable rewards, stating that they needed to be valuable enough to be incentivizing to participate.

\section{Incentives Key Findings}

- Most TNC users would switch from private to pooled trips for a price discount, and about half of users would switch from direct pooled trips to indirect pooled trips for an additional discount, depending on time of day and walking area.

- There was less interest in incentives to connect TNC to public transit as most users who already do it either do so infrequently or were required to do it (e.g., for their commute) and would continue doing so with or without a discount. Disincentivizing the use of personal cars to connect to public transit (e.g., by raising station parking prices) could shift more users to using pooled TNC for this purpose.

\section{COVID-19 Impacts}

In addition to personal safety and security concerns, the risk of spreading or contracting the COVID-19 virus greatly altered TNC users' travel patterns. Participants were asked about how their travel will continue to be changed as the pandemic continues and is contained. The following subsections detail these responses.

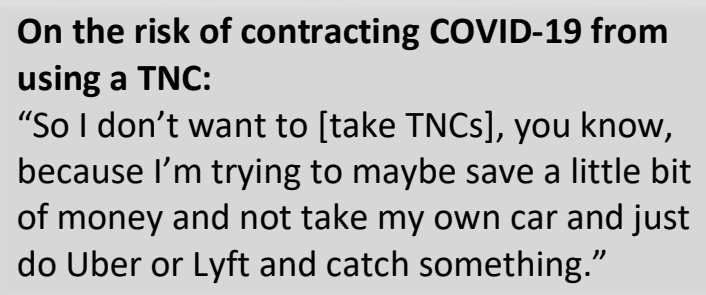
using a TNC: "So I don't want to [take TNCs], you know, because I'm trying to maybe save a little bit of money and not take my own car and just do Uber or Lyft and catch something."

\section{During the Pandemic}

Collectively, participants used TNCs less during the pandemic, though for different reasons. The reasons for reduced TNC use, from most to least commonly stated by participants, include:

- Cleanliness: Concerns related to the cleanliness of TNC vehicles and whether or not the driver was sick or has been vaccinated,

- Business Closures: Lack of open businesses/destinations, and

- Containment Concerns: Reduction of risk for vulnerable family members.

Participants' TNC use during the pandemic decreased from $60 \%$ to $90 \%$ for the most frequent heavy TNC users to stopping use altogether. Instead of taking TNCs, users shifted to riding bikes, using electric scooters, walking, and taking private vehicles. One heavy TNC user began taking public transit more because the pandemic reduced onboard crowds and increased available time for the participant to learn the transit systems. 


\section{After the Pandemic}

Participants had mixed responses regarding TNC use, and in particular taking pooled trips, in the future. Three participants shared that they would likely take pooled TNCs about the same amount as before, with one describing no difference between a private or pooled TNC ride from a cleanliness perspective because the ride was already shared with the driver. Six participants, however, shared that they would likely take TNCs and especially pooled TNCs less frequently, with the most common reasons including:

- Social Distancing: Lingering uncertainty with sharing close spaces with potentially infected strangers,

- Vaccination Status: Discomfort regarding not knowing the vaccine status of the driver or other passengers, and

- Changed Travel Patterns: New preferences for travel modes during the pandemic (e.g., personal micromobility devices).

When asked about what changes could be made to make them feel more comfortable with taking pooled TNC rides again, participants mentioned features like having passenger and driver vaccine requirements, maintaining plastic dividers between passengers and the driver, offering a "Proof of Sanitization" between rides, and providing hand sanitizer.

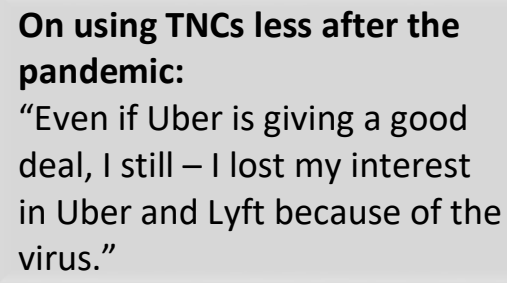
deal, I still - I lost my interest in Uber and Lyft because of the virus."

\section{COVID-19 Key Findings}

- All TNC users (heavy and non-heavy) have decreased their use of TNC services during the pandemic, mostly due to health concerns and a lack of open destinations.

- TNC users were mixed about how they will use TNCs after the pandemic, with some planning to pool similarly to as much as before and others foreseeing a permanent decrease in their use, due to continued health concerns and changes to their travel patterns.

\section{Key Takeaways}

- Demographics: The 15 TNC users who participated in the photovoice groups were evenly distributed by gender and age, and the distribution of their reported races/ethnicities aligned closely with that of the general population of the study area (i.e., the San Francisco Bay Area) with high levels of educational attainment, income, and vehicle ownership and leasing rates. TNC use ranged from one to six days per week.

- Private and Pooled Trips: Factors that dictated the use of private and pooled trips included trip time, purpose, privacy, cost, public transit availability, weather, time of day, and accessibility.

- Heavy and Non-Heavy TNC Use: Heavy and non-heavy TNC users differed in multimodal trip use, incentives, and preferred waiting locations.

- Current PUDO Locations: TNC users were concerned about walking to pick-up locations at night and through unsafe areas that put them at risk for being robbed, attacked, or approached by homeless individuals and preferred waiting in safe, well-lit, and open locations near shopping areas and away from homeless encampments. There were further differences between female and male TNC drivers females were more concerned with individual risk while males were concerned with robbery.

- Potential Designated TNC Stops: There was interest in a network of designated TNC stops especially if these stops were well maintained; had seating, shelter, lighting, wayfinding, and safety features and were located in safe, centralized areas. 
- Incentives: Most TNC users would switch from private to pooled rides for a price discount although there was less of an incentive to connect TNCs to public transit.

- COVID-19 Impacts: All TNC users (heavy and non-heavy) have decreased their use of TNC services during the pandemic and mixed responses to how they will use TNCs with the containment of COVID19. 


\section{Workshop}

A two-hour Zoom workshop was held where the TNC user participants from the photovoice activity shared with key pooling stakeholders their perspectives on and relevant photos relating to pooling, pick-up and drop-off locations, and incentives. The researchers presented the TNC users and pooling stakeholders with a summary of key findings and images from the photovoice group discussions and allowed both parties to share their thoughts and opinions on each, leading to an improved mutual understanding. The researchers also shared several proposed strategies to improve pooling that were developed from the expert interviews and photovoice discussions. TNC users shared their opinions on the strategies, and pooling stakeholders provided feedback on the strategies' feasibility and areas for improvement. The workshop resulted in a series of key takeaways regarding TNC trip improvements, pooling incentives, and fruitful areas for future research.

\section{Workshop Demographics}

Workshop participants were recruited from the TNC users and transportation industry experts that participated in earlier portions of the study. The workshop meeting time was selected based on the shared availability of the stakeholders, and all interested TNC user participants were invited to attend if available. Twelve TNC users (seven male and five female, six heavy and six non-heavy users) and five transportation industry experts representing stakeholder organizations participated in the final workshop.

\section{TNC User Workshop Participant Demographics}

Because the TNC users that participated in the workshop were a subset of the TNC users that participated in the photovoice discussion groups, the demographics of the two groups are similar. The TNC users in the workshop had an over-representation of male users in comparison to that of the larger San Francisco Bay Area population, particularly those that were non-heavy TNC users. The workshop participants were evenly distributed by age, although there was a slight over-representation of young adult and middle-aged TNC users and lower proportions of very old or very young individuals than makeup the general area population. The TNC users had an over-representation of Asian/Pacific Islander and Caucasian individuals and had no representation of Black/African-American users, which differs from the racial/ethnic makeup of that of the study region. Approximately $92 \%$ of the workshop participants had at least a bachelor's degree, compared to $51 \%$ of that of the larger San Francisco Bay Area population. Lastly, the workshop participants generally over-represented middle- and high-income ranges for household income when compared to the general population. The demographic data of the TNC user workshop participants, as well as that of the study area, are presented in Table 11. 
Table 11. Demographics of TNC User Workshop Participants

\begin{tabular}{|c|c|c|c|c|c|}
\hline & Characteristic & $\begin{array}{c}\text { Non-heavy } \\
(n=6)\end{array}$ & $\begin{array}{l}\text { Heavy TNC } \\
\text { Users }(n=6)\end{array}$ & Full Group ( $n=12)$ & $\begin{array}{c}\text { San Francisco Bay Area } \\
(\mathrm{n}=4.73 \text { million) }\end{array}$ \\
\hline \multirow{2}{*}{ 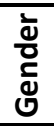 } & Male & $67 \%$ & $50 \%$ & $58 \%$ & $49 \%$ \\
\hline & Female & $33 \%$ & $50 \%$ & $42 \%$ & $51 \%$ \\
\hline \multirow{9}{*}{$\stackrel{\text { 嵒 }}{\alpha}$} & & & & & \\
\hline & Under age 20 years & $0 \%$ & $0 \%$ & $0 \%$ & $22 \%$ \\
\hline & Age 20 to 24 years & $0 \%$ & $0 \%$ & $0 \%$ & $6 \%$ \\
\hline & Age 25 to 34 years & $17 \%$ & $50 \%$ & $33 \%$ & $16 \%$ \\
\hline & Age 35 to 44 years & $17 \%$ & $33 \%$ & $25 \%$ & $15 \%$ \\
\hline & Age 45 to 54 years & $33 \%$ & $0 \%$ & $17 \%$ & $13 \%$ \\
\hline & Age 55 to 59 years & $17 \%$ & $17 \%$ & $17 \%$ & $7 \%$ \\
\hline & Age 60 to 64 years & $17 \%$ & $0 \%$ & $8 \%$ & $6 \%$ \\
\hline & Age 65 years and over & $0 \%$ & $0 \%$ & $0 \%$ & $16 \%$ \\
\hline & & & & & \\
\hline \multirow{6}{*}{ 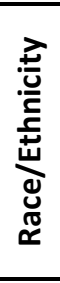 } & Asian/Pacific Islander & $17 \%$ & $67 \%$ & $42 \%$ & $27 \%$ \\
\hline & Black/African-American & $0 \%$ & $0 \%$ & $0 \%$ & $7 \%$ \\
\hline & Caucasian & $50 \%$ & $33 \%$ & $42 \%$ & $39 \%$ \\
\hline & Hispanic/Latino & $33 \%$ & $0 \%$ & $16 \%$ & $22 \%$ \\
\hline & Two or more races & $0 \%$ & $0 \%$ & $0 \%$ & $4 \%$ \\
\hline & Other & $0 \%$ & $0 \%$ & $0 \%$ & $1 \%$ \\
\hline & & & & & \\
\hline \multirow{7}{*}{ 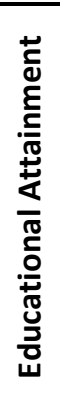 } & Less than high school & $0 \%$ & $0 \%$ & $0 \%$ & $6 \%$ \\
\hline & Some high school & $0 \%$ & $0 \%$ & $0 \%$ & $5 \%$ \\
\hline & $\begin{array}{l}\text { Graduated high school } \\
\text { or equivalent (GED) }\end{array}$ & $0 \%$ & $0 \%$ & $0 \%$ & $16 \%$ \\
\hline & Some college, no degree & $17 \%$ & $0 \%$ & $8 \%$ & $16 \%$ \\
\hline & Associate's degree & $0 \%$ & $0 \%$ & $0 \%$ & $7 \%$ \\
\hline & Bachelor's Degree & $50 \%$ & $83 \%$ & $67 \%$ & $30 \%$ \\
\hline & $\begin{array}{l}\text { Graduate or professional } \\
\text { degree }\end{array}$ & $33 \%$ & $17 \%$ & $25 \%$ & $21 \%$ \\
\hline & & & & & \\
\hline \multirow{10}{*}{ 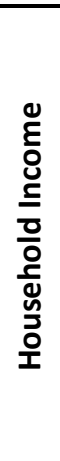 } & Less than $\$ 10,000$ & $0 \%$ & $0 \%$ & $0 \%$ & $4 \%$ \\
\hline & $\$ 10,000$ to $\$ 14,999$ & $0 \%$ & $0 \%$ & $0 \%$ & $3 \%$ \\
\hline & $\$ 15,000$ to $\$ 24,999$ & $0 \%$ & $0 \%$ & $0 \%$ & $5 \%$ \\
\hline & $\$ 25,000$ to $\$ 34,999$ & $0 \%$ & $0 \%$ & $0 \%$ & $5 \%$ \\
\hline & $\$ 35,000$ to $\$ 49,999$ & $0 \%$ & $0 \%$ & $0 \%$ & $7 \%$ \\
\hline & $\$ 50,000$ to $\$ 74,999$ & $33 \%$ & $17 \%$ & $25 \%$ & $11 \%$ \\
\hline & $\$ 75,000$ to $\$ 99,999$ & $17 \%$ & $17 \%$ & $17 \%$ & $10 \%$ \\
\hline & $\$ 100,000$ to $\$ 149,999$ & $50 \%$ & $0 \%$ & $25 \%$ & $18 \%$ \\
\hline & $\$ 150,000$ to $\$ 199,999$ & $0 \%$ & $50 \%$ & $25 \%$ & $12 \%$ \\
\hline & $\$ 200,000$ or more & $0 \%$ & $17 \%$ & $8 \%$ & $26 \%$ \\
\hline
\end{tabular}




\section{Household Vehicle Ownership for TNC Users in Workshop}

The TNC users who participated in the workshop owned on average 1.08 vehicles per household. The heavy TNC users in the workshop generally owned more vehicles than the non-heavy TNC users. Additionally, on average, the male TNC users in the workshop owned nearly half the average number of vehicles owned by the female TNC users in the workshop. Table 12 presents the vehicle ownership rates for the TNC users who participated in the workshop.

Table 12. Vehicles per Household for TNC User Workshop Participants

\begin{tabular}{|l|c|c|c|c|c|}
\hline $\begin{array}{c}\text { Number of Vehicles per } \\
\text { Household }\end{array}$ & $\begin{array}{c}\text { Non-Heavy } \\
\text { TNC Users } \\
(n=6)\end{array}$ & $\begin{array}{c}\text { Heavy TNC } \\
\text { Users } \\
(n=6)\end{array}$ & $\begin{array}{c}\text { Male Users } \\
(n=7)\end{array}$ & $\begin{array}{c}\text { Female Users } \\
(n=5)\end{array}$ & $\begin{array}{c}\text { Full Group } \\
(n=12)\end{array}$ \\
\hline Zero & $33 \%$ & $17 \%$ & $29 \%$ & $20 \%$ & $25 \%$ \\
\hline One & $50 \%$ & $50 \%$ & $57 \%$ & $40 \%$ & $50 \%$ \\
\hline Two & $0 \%$ & $33 \%$ & $14 \%$ & $20 \%$ & $17 \%$ \\
\hline Three & $17 \%$ & $0 \%$ & $0 \%$ & $20 \%$ & $8 \%$ \\
\hline Average & 1 & 1.17 & 0.85 & 1.4 & 1.08 \\
\hline
\end{tabular}

\section{TNC User Frequency of TNC Users in Workshop}

The TNC users in the workshop exhibited a range of TNC use, though most of the participants used private and pooled TNCs with a frequency between every other week and four to six days per week. The female users generally used TNC with greater frequency than the male users in the workshop. Most non-heavy TNC users in the workshop took TNC either every other week or one to three days per week, while most heavy TNC users in the workshop took TNC four to six days per week. The frequency of TNC use of the TNC users that participated in the workshop is summarized in Table 13.

Table 13. TNC Use Frequency of TNC User Workshop Participants

\begin{tabular}{|l|c|c|c|c|c|}
\hline $\begin{array}{c}\text { Frequency of TNC use } \\
\text { (private and pooled) }\end{array}$ & $\begin{array}{c}\text { Non-Heavy TNC } \\
\text { Users } \\
(n=6)\end{array}$ & $\begin{array}{c}\text { Heavy TNC } \\
\text { Users } \\
(n=6)\end{array}$ & $\begin{array}{c}\text { Male Users } \\
(n=7)\end{array}$ & $\begin{array}{c}\text { Female Users } \\
(n=5)\end{array}$ & $\begin{array}{c}\text { Full Group } \\
(n=12)\end{array}$ \\
\hline Once a year & $0 \%$ & $0 \%$ & $0 \%$ & $0 \%$ & $0 \%$ \\
\hline Once every 6 months & $0 \%$ & $0 \%$ & $0 \%$ & $0 \%$ & $0 \%$ \\
\hline Once every 3 months & $17 \%$ & $0 \%$ & $14 \%$ & $0 \%$ & $8 \%$ \\
\hline Once a month & $17 \%$ & $0 \%$ & $0 \%$ & $20 \%$ & $8 \%$ \\
\hline Every other week & $33 \%$ & $0 \%$ & $29 \%$ & $0 \%$ & $17 \%$ \\
\hline 1 to 3 days per week & $33 \%$ & $0 \%$ & $14 \%$ & $20 \%$ & $17 \%$ \\
\hline 4 to 6 days per week & $0 \%$ & $67 \%$ & $29 \%$ & $40 \%$ & $33 \%$ \\
\hline Once a day & $0 \%$ & $17 \%$ & $0 \%$ & $20 \%$ & $8 \%$ \\
\hline 2 to 4 times a day & $0 \%$ & $17 \%$ & $14 \%$ & $0 \%$ & $8 \%$ \\
\hline More than 4 times a day & $0 \%$ & $0 \%$ & $0 \%$ & $0 \%$ & $0 \%$ \\
\hline
\end{tabular}

\section{Pooling Frequency of TNC Users in Workshop}

Nearly all of the TNC users in the workshop had used the pooled option for their TNC trips, with only one of the 12 participants never selecting to pool. Approximately $75 \%$ of the TNC users in the workshop pooled $50 \%$ or more of their TNC trips, with 33\% of the full group pooling almost always. The female users in the workshop tended to pool more frequently than the male users, and the heavy TNC users chose to pool more often than 
the non-heavy users. Table 14 summarizes the frequency with which the TNC users in the workshop selected the pooled option for their TNC trips.

Table 14. Pooled Ride Frequency of TNC User Workshop Participants

\begin{tabular}{|l|c|c|c|c|c|}
\hline $\begin{array}{c}\text { Frequency of selecting } \\
\text { the "pooled" option }\end{array}$ & $\begin{array}{c}\text { Non-Heavy TNC } \\
\text { Users } \\
(n=6)\end{array}$ & $\begin{array}{c}\text { Heavy TNC } \\
\text { Users } \\
(n=6)\end{array}$ & $\begin{array}{c}\text { Male Users } \\
(n=7)\end{array}$ & $\begin{array}{c}\text { Female Users } \\
(n=5)\end{array}$ & $\begin{array}{c}\text { Full Group } \\
(n=12)\end{array}$ \\
\hline Never & $17 \%$ & $0 \%$ & $0 \%$ & $20 \%$ & $8 \%$ \\
\hline $\begin{array}{l}\text { Some of the time (less } \\
\text { than 50\%) }\end{array}$ & $33 \%$ & $0 \%$ & $14 \%$ & $20 \%$ & $17 \%$ \\
\hline Half of the time (50\%) & $33 \%$ & $17 \%$ & $43 \%$ & $0 \%$ & $25 \%$ \\
\hline $\begin{array}{l}\text { Most of the time (more } \\
\text { than 50\%) }\end{array}$ & $0 \%$ & $33 \%$ & $14 \%$ & $20 \%$ & $17 \%$ \\
\hline Almost always & $17 \%$ & $50 \%$ & $29 \%$ & $40 \%$ & $33 \%$ \\
\hline
\end{tabular}

\section{Expert Stakeholder Organizations Represented in Workshop}

Five transportation industry experts representing pooling stakeholder organizations attended the workshop and provided their thoughts and opinions on the key takeaways from the photovoice discussion groups and their feedback and recommendations on the potential pooling strategies. Three of the experts represented public sector organizations, one expert represented a non-profit transportation advocacy organization, and one expert represented a private mobility provider. Table 15 presents the stakeholder organizations represented in the workshop.

Table 15. Stakeholder Organizations Represented in Workshop

\begin{tabular}{|l|c|c|c|}
\hline \multicolumn{1}{|c|}{ Organization } & \multicolumn{2}{c|}{ Sector } \\
\cline { 2 - 4 } & $\begin{array}{c}\text { Non-Profit } \\
(\mathrm{n}=1)\end{array}$ & $\begin{array}{c}\text { Private } \\
(\mathrm{n}=1)\end{array}$ & $\begin{array}{c}\text { Public } \\
(\mathrm{n}=3)\end{array}$ \\
\hline $\begin{array}{l}\text { Alameda-Contra Costa Transit District (AC } \\
\text { Transit) }\end{array}$ & & & $\mathrm{X}$ \\
\hline California Public Utilities Commission & & & $\mathrm{X}$ \\
\hline City of Oakland & & & $\mathrm{X}$ \\
\hline TransForm & $\mathrm{X}$ & & \\
\hline Via & & $\mathrm{X}$ & \\
\hline
\end{tabular}

\section{Workshop Demographic Key Findings}

- The 12 TNC users who participated in the final workshop were evenly distributed by age, but there was an over-representation of male participants and participants whose race/ethnicity was Asian/Pacific Islander or Caucasian. TNC user participants in the workshop also had higher levels of educational attainment and household income levels closer to the median (i.e., fewer high- and low-income levels represented) than that of the general population of the study area (i.e., the San Francisco Bay Area).

- Female users and heavy TNC users in the workshop had higher ownership rates than the full group average, which was slightly more than one vehicle per household.

- Most heavy TNC users in the workshop took TNCs four to six days per week, and the non-heavy TNC users in the workshop took TNCs either every other week or one to three days per week. The female 
users and heavy TNC users in the workshop chose to pool their TNC rides more often than the male or non-heavy TNC users.

- Five experts representing stakeholder organizations attended the workshop, with three representing public sector organizations, one representing a non-profit transportation advocacy organization, and one representing a private mobility provider.

\section{Workshop Discussion}

The workshop discussion enabled participants to identify potential strategies to improve walking to and waiting at pick-up locations, taking pooled trips, connecting TNC trips to public transit, and incentivizing pooled trips and public transit connections. The following topics were discussed in the workshop:

- TNC Trip Improvements: TNC users discussed their desire for designated TNC PUDO locations, including what built environment features they would like to see implemented. In exchange, expert stakeholders offered insight on the feasibility of these developments and potential challenges. TNC users and experts also discussed improving TNC rides by enhancing in-app safety features and discussing how they could be developed.

- Pooling Incentives: TNC users and expert stakeholders discussed different incentives to increase TNC vehicle occupancy and connections to public transit. These discussions also included the potential for innovative partnerships with stakeholders, such as retailers.

- Future Research: Both the TNC users and expert stakeholders provided insight on future areas of research that could help increase pooling, first- and last-mile public transit connections, and equity impacts.

The discussions on each of these topics are summarized in the following sections.

\section{TNC Trip Improvements}

Workshop participants discussed two predominant ways to improve TNC trips: 1) creating designated TNC stops and 2) increasing in-app safety features. These improvements are discussed below.

\section{Designated TNC Stops}

Multiple TNC users brought up the idea of designated TNC stops and it was presented as one of the recommendations to improve pooling. Designated TNC stops could help address driver connection, trip time, and safety challenges. Multiple users shared stories about having difficulty finding or communicating with the driver about a safe and accessible pick-up location. Designated TNC stops could help address this problem. One user also posited that designated stops could allow TNC users to congregate at them, which could help with ride matching and potentially decrease travel time by reducing the number of pick ups. Designated TNC stops also had an added safety appeal. Multiple female users expressed interest in having designated stops, as they could use them for PUDO instead of providing a home address. The designated location could help protect the riders' privacy from the driver or other passengers.

Designated TNC stops could also increase individuals' willingness to take pool rides. Users shared that, depending on neighborhood, time of day, and weather, they would be interested in walking five to 10 minutes to reach a more desirable pick-up point for a $25 \%$ to $30 \%$ discount on the base trip cost. The TNC users suggested using location data of frequent TNC trip requests to identify where potential stops could be located. These stops could also help lower the barrier to entry for people hesitant to try pooling by giving them easier, safer access to the service. 
Although users and stakeholders were supportive of the idea of having designated stops for TNC PUDO, they were less supportive of the idea of including shelters and seating at the locations. In a poll, users confirmed that their preferred built environment features at waiting locations include shelter, seating, and lighting. However, the TNC users immediately voiced concerns about the cleanliness and maintenance of public spaces and how homeless individuals could be deterred from loitering at the locations. One user also expressed concern about the size and appearance of the shelters taking up public space, particularly if they had TNC branding on them.

The stakeholders' concerns mirrored those of the users. The department of transportation representative noted the difficulties with paying for the upfront and maintenance costs of sheltered stops. Advertisers typically fill this role but, in this case, it could risk creating community backlash due to advertisements occupying public space. The same stakeholder also described how these maintenance concerns related to the larger discussion on how to make people feel safe in public spaces. The stakeholder cited recent examples of a nearby public transit agency debating continuing their bus shelter program and another nearby city discussing whether to add surveillance cameras to publicly accessible digital kiosks. The expert recommended that instead of building shelters at designated TNC stops, resources may be better invested in providing good lighting at these locations and making sure there are designated spots on the curb for the TNC drivers to pull into that are clearly marked in-app.

\section{Increased In-App Safety Features}

In addition to designated TNC locations, users also pointed to enhanced in-app safety features to improve TNC rides. Throughout the discussion of key findings from the photovoice groups, users reiterated their safety concerns related to different pooling aspects. When the identified differences between male and female TNC users were presented, the female TNC users restated their discomfort with the driver or other passengers knowing their home address. Several male TNC users also shared this sentiment and one male TNC user explained that he never puts his home address in the app and instead puts the address of a nearby bar. Most of the users shared that they generally felt more comfortable in pooled rides (as opposed to private rides) because they were not alone with the driver. However, multiple users supported the idea of rating their fellow passengers (similar to how drivers are currently rated and reviewed). Users also shared that they would like to be able to select the gender of their driver, and that it would make them feel safer at night or in private trips. To help address these safety concerns that were voiced in the photovoice groups, two key recommendations to improve pooling safety were presented:

1. In-App Safety Information: Increase in-app safety information by providing riders with upfront information, allowing for increased trip preferences (e.g., select gender or vaccine status of driver and other passengers), providing the option to share trip information with an emergency contact, and offering the option to select specific pick-up locations for indirect trips.

2. Geofencing and Location Information: Leverage geofencing and location features to address different safety preferences of male and female TNC users, such as geofencing pick-up areas based on userselected waiting preferences and suggesting nearby safe public waiting areas.

TNC users generally liked the idea of the first safety recommendation (i.e., in-app safety information), particularly the option to select the driver gender and to share trip information. However, one female user shared that she would likely not use the gender preference option, as she was usually either taking a pooled trip (where she felt safe due to the presence of other passengers), or she was taking a private trip (which she would use when in a rush and would thus likely not care about the gender of her driver). 
The pooling stakeholders were also supportive of the first recommendation. The department of transportation representative stated that their organization is ready to work with pooled mobility service providers to help source the information needed to facilitate such a system. Additionally, the private mobility provider shared that, from a non-technical standpoint, the in-app safety features did not seem too difficult to integrate. Future user surveys could support these efforts by identifying which safety features are most important to people. The users and stakeholders had less positive feedback for the second safety recommendation (i.e., geofencing and location information). Users were concerned with how the additional filtering of drivers and locations would affect the trip time since the driver might have to travel further off the optimal path to reach a passenger's pick-up zone. One user also noted that drivers could ignore the recommendations if they were in a hurry. As a result, the location filtering would need to be integrated into the ride matching system. The private mobility provider agreed with this concern and shared a secondary concern that restricting the number of pickup locations could also greatly increase the ride matching time, as it is a trade-off between having more versus better pick-up locations. Another expert stakeholder shared an equity challenge that location filtering could present: users geofencing off areas they perceive as being unsafe for pick-up could lead to issues related to providing equal service to these areas.

\section{Pooling Incentives}

Workshop participants also discussed different pooling incentives including:

- Pooling for Non-Urgent Trips: TNCs could partner with retailers to incentivize customers that would typically travel to their location (e.g., store, airport, tourist destination) by personal vehicle to pool by offering them retail-based incentives (e.g., discounts on products at the retailer).

- Pooling To and From High-Demand Locations: Particularly in areas with limited parking availability and where pooling may be more appealing, TNCs could work with venues to support pooling by providing users who pool with vouchers for food or drinks at the venues.

- Pooling To and From Employment and Education Locations: Based on user interest in receiving a discount to bulk purchase multiple, regular pooled trips ahead of time (e.g., commuting to school or work), employers or schools could incentivize employees and students traveling in the same direction to pool their trips by subsidizing the purchase of bundled trips.

Throughout the workshop TNC users reiterated their preference for waiting in or near retail spaces and to use pooling for trips that were not time sensitive (e.g., to retail locations, social activities). As a result, workshop participants discussed using existing retail locations to wait for TNCs. The department of transportation representative proposed the idea of TNCs developing partnerships with retailers to allow TNC users to wait for their ride in their space. The partnership could provide users with a safe location to wait inside of, drivers with a clear and recognizable landmark to drive toward, and retailers with potential customers.

\section{Incentives to Connect TNCs to Public Transit}

During conversations about incentives TNC users expressed interest in incentives to pool and take indirect trips. During the workshop TNC users showed an interest in using TNCs to connect to public transit, particularly when the concept of timed transfers between TNCs and public transit was discussed. One user shared an anecdote of how he had two transit-based options to travel to and from the airport: one longer journey by bus and one much-shorter journey by rail. However, the rail service's infrequency could result in a missed transfer that led to a longer trip time than the bus option. The user shared how he would not mind scheduling a TNC trip in advance if there was a way to guarantee that he could make the timed transfer. Other users expressed interest in transferring between modes, particularly if a discount were applied and if fare payment for both systems 
could be integrated. One user described an example of this system working well as in the case of bus passes. When polled, users ranked the discount to transfer modes as their most preferred incentive (with a fixed dollar discount ranked first and a fixed percentage discount ranked second), then integrated fare payment.

When the stakeholders were asked about using incentives to connect TNCs to public transit, they were generally positive in their responses. The private mobility provider shared that connecting users to public transit is a key aspect of their existing service model and that multimodal service allows users to take longer trips when the bus goes places that are outside their service area and vice versa. While supportive, the public transit stakeholder expressed concern about multimodal incentives, and stressed that incentives should be developed in such a way that they are tied to modal efficiency and sustainability. The stakeholder encouraged incentivizing trips, from greatest to least discount, as follows: pooled TNC trips connecting to public transit, indirect pooled trips, and direct pooled trips. The private mobility provider shared that their largest challenge with facilitating transfers between modes is integrating fare payment, as people often use fare cards or other forms of payment which may not integrate well with their service's payment system.

\section{Future Research}

Although many conversations in the workshop were around developing strategies and recommendations to improve pooling, the stakeholders had several lingering questions which show that there are still many aspects of pooling that require further research. The future research areas include understanding how to best align TNC driver and rider goals and addressing potential gender-based equity challenges for TNC rides. Across many of the photovoice discussions and in the final workshop, users described issues related to TNC drivers including: rushing passengers during PUDO, canceling pooled rides after not being able to connect with the user, and operating their vehicles in unsafe manners as they hurry to fulfill trips. The driver behaviors reflect the driver experience and aim to meet their goals (e.g., completing trips, expediting pick ups and drop offs). The driver goals are often at odds with the user experience and the users' goals (e.g., safe and comfortable rides). Though the driver/user rating system is meant to balance the driver and users' goals, it is not as effective as perhaps it was intended. TNC users in the workshop discussion suggested mandatory driver training to familiarize them with local landmarks and loading zones so they know safe PUDO locations, and incentivizing drivers to be patient during and following app directions for passenger PUDO (e.g., adhering to the prescribed pick-up location). The recommendations are steps toward parity from the user perspective, but additional work will be necessary to develop realignment strategies from both perspectives.

Future research could also focus on the current gender-based equity challenges related to the TNC waiting experience. The gendered difference in safety perception of the TNC experience was a key result from the photovoice discussions and many of its finer points were reiterated throughout the workshop. While the recommended improvements to in-app safety features were viewed as a step in the right direction, they do not address the root problem that makes the waiting experience of certain users uncomfortable: perceptions of safety while being in public is inequitable between male and female users. The transportation equity stakeholder described how the time spent waiting in public for a TNC could be inequitable to female users as it puts them at a greater risk for being attacked, approached, or harassed. The stakeholder suggested potentially investigating the effects of this by giving female users a large discount to take pooled rides and investigating if they interact with pooling differently (i.e., take more pooled trips). The stakeholder suggested that if, even after being highly incentivized to pool, female users do not pool more, the environmental aspects of taking the pooled trip may be the driving factor in the female users' decision making and would need to be addressed to truly make pooling equitable for all users. 


\section{Key Takeaways}

- TNC Stops: Designated TNC stops with lighting and clearly marked pick-up areas (physically and in-app) can help address driver connection challenges and user safety concerns while mitigating the potential cost, cleanliness, and vagrancy issues building shelters with benches could create.

- Safety Concerns: In-app safety features like location sharing with emergency contacts, selecting driver gender preferences, and hiding user home addresses can easily be implemented to reduce many user safety concerns, though additional work on using geofencing and location features to filter preferred safe pick-up locations will be required to manage matching algorithm and service equity challenges.

- Pooling Incentives: Partnerships can be formed with employers, schools, and locations for non-urgent trips (e.g., retail, venues, airport departures) to develop incentivizes to encourage pooling to/from these locations. Partnerships between services and retailers can also be developed to incentivize riders to use their spaces as safe waiting locations.

- TNCs and Public Transit Connections: If stakeholders can address fare integration issues and incentive structures that prioritize multimodal trips, TNC users would be interested in connecting public transit to TNCs for a fixed dollar amount, mode transfer discounts, and when timed transfers were available.

- Future Research: Work related to pooling is still necessary, particularly to develop a system in which the goals of drivers and riders are no longer at odds, and to investigate how to address the inequity of safety relating to gender-based differences in waiting experiences. 


\section{Key Takeaways and Policy Recommendations}

The literature review, expert interviews, photovoice groups, and workshops resulted in a variety of key findings, which were then used to develop the policy recommendations. The key findings include: heavy-and non-heavy user references, pick-up location changes, pooling interested, and safety concerns. The findings are described below.

\section{Heavy and Non-Heavy User Preferences}

The research revealed differences between heavy and non-heavy TNC users. Heavy TNC users use TNCs for different trip types (e.g., commuting, errands, recreation) and with greater frequency. Therefore, heavy TNC users are incentivized to minimize their per-trip cost by taking more multimodal trips, including walking to pickup locations. Non-heavy TNC users, however, tend to take TNCs for "choice" trips and have other preferred options (e.g., public transit, personal car), so they try to minimize the overall number of TNC trips they take, preferring incentives that reduce the cost of these "one off" trips. Additionally, heavy TNC users exhibited fewer preferences for built environment features. The fewer built environment preferences are likely because heavy TNC users are more accustomed to waiting for TNCs at ad hoc pick-up locations and concerned about easy access to the driver. Inversely, non-heavy TNC users, likely because they are less comfortable with waiting and accessing TNCs, showed stronger preferences for built environment features at waiting locations to make the pick-up area less ambiguous.

\section{Pick-Up Location Changes}

Only about half of the TNC users in the study said that they would walk to their pick-up location even with a discount. TNC users' willingness to walk to pick-up locations was dependent on neighborhood, time of day, weather, topography, and how long they had to reach the pick-up location. Users were concerned about safety walking to and waiting at the pick-up location, even if there was only a short wait time. Users also wanted improved identification of pick-up locations to ensure they easily met the driver.

\section{Pooling Interest}

Nearly all of the TNC users in the study had used pooling in the past, with cost-savings as their primary reason for doing so. Most users expressed interest in pooling in the future, as long as a discount were involved. Although there were slight concerns regarding other passengers, the TNC users' predominant reason to not pool was because of the added time. However, TNC experts stated that time and cost savings could be used to shift users to pooling. For example, strategies that make pooling the cheaper option (e.g., discounts, Mobility as a Service bundles, increased private trip costs) and/or the faster option (e.g., managed lanes, more indirect trips taking advantage of straight-line routing) could continue to shift users to pooled modes. Stakeholders suggested pricing services in a manner that is tied to its efficiency and sustainability, with multimodal trips and indirect trips heavily discounted, direct pooling priced as the default service, and private trips priced as a much more expensive option.

\section{Safety Concerns}

Safety concerns were viewed as the top priority for TNC users when determining where to wait and whether or not to walk to pick-up locations. Users preferred built environment features that supported personal safety and security (e.g., waiting at well-lit areas, having open visibility of their surroundings). Users also preferred waiting in safe neighborhoods, near retail opportunities, and away from homeless encampments. Although users liked the idea of waiting under shelter and having benches or seating available, they were also wary that these built 
environment features invited loitering homeless individuals. Instead, users preferred to wait in their residence, stores, or cafes and then exit to meet the vehicle at the last moment instead of waiting out in the open.

Compared to male TNC users, who were primarily concerned with avoiding locations where their phone could be stolen, females factored safety into nearly every element of the TNC experience, including the in-vehicle portions. Female users exhibited stronger preferences for waiting in or near retail establishments and in locations that were well-traveled and not isolated or closed off. Female users also took additional precautions to ensure their safety including:

- Asking a male to call the ride,

- Having a male walk them to the vehicle,

- Sharing trip information with a third party,

- Using a different address to protect their privacy, and

- Waiting near a security guard or police officer.

\section{Policy Recommendations}

The study team developed policy recommendations based on findings from the literature review, expert interviews, photovoice groups, and workshop. The recommendations also help to support the opportunities and address the challenges identified in the key findings. The recommended policies include:

1. Data Sharing: Stakeholders can improve communication in order to share data and address challenges more efficiently.

2. Network of TNC Stops: The research found that a network of designated TNC stops can help address user safety concerns and other challenges associated with indirect trips.

3. Operational Improvements: Stakeholders will need to address logistical barriers (e.g., timed transfers, integrated fare payments) to encourage TNC users to connect to public transit in a meaningful way.

4. Partnership Programs: Partnerships between public agencies, TNCs, and retailers can help pooling tap into existing markets of users traveling in the same direction for non-urgent, high-demand, and/or routine trips.

5. Safety and Trip Information: Stakeholders improving safety and trip information communication with users can help address concerns of safety and security and lower the barrier to entry for new users.

Table 16 summarizes the policies and the respective key findings they address. The policy recommendations are further discussed following the table. 
Table 16. Key Findings and Associated Policy Recommendations

\begin{tabular}{|c|c|c|c|c|c|c|}
\hline \multirow[b]{2}{*}{ Key Finding } & \multirow[b]{2}{*}{ Description } & \multicolumn{5}{|c|}{ Policy Recommendations } \\
\hline & & $\begin{array}{l}\text { Data } \\
\text { Sharing }\end{array}$ & $\begin{array}{c}\text { Network } \\
\text { of TNC } \\
\text { Stops }\end{array}$ & $\begin{array}{c}\text { Operational } \\
\text { Improvements }\end{array}$ & $\begin{array}{c}\text { Partnership } \\
\text { Programs }\end{array}$ & $\begin{array}{l}\text { Safety and } \\
\text { Trip } \\
\text { Information }\end{array}$ \\
\hline $\begin{array}{l}\text { Heavy and } \\
\text { Non-Heavy } \\
\text { User } \\
\text { Preferences }\end{array}$ & $\begin{array}{l}\text { Heavy TNC users try to minimize } \\
\text { the cost of their TNC use on a per- } \\
\text { trip basis, while non-heavy TNC } \\
\text { users try to minimize the overall } \\
\text { number of TNC trips they take. }\end{array}$ & & $x$ & $x$ & $x$ & \\
\hline $\begin{array}{l}\text { Pick-Up } \\
\text { Location } \\
\text { Changes }\end{array}$ & $\begin{array}{l}\text { TNC users can be incentivized to } \\
\text { take more indirect trips if changes } \\
\text { to pick-up locations were made. }\end{array}$ & & $x$ & $x$ & $x$ & \\
\hline $\begin{array}{l}\text { Pooling } \\
\text { Interest }\end{array}$ & $\begin{array}{l}\text { Most TNC users are interested in } \\
\text { pooling, especially when trip cost is } \\
\text { discounted. }\end{array}$ & & & $x$ & & \\
\hline $\begin{array}{c}\text { Safety } \\
\text { Concerns }\end{array}$ & $\begin{array}{l}\text { Safety is a concern for all users, but } \\
\text { especially so for female users, who } \\
\text { often take additional precautions to } \\
\text { feel comfortable with TNC } \\
\text { experiences. }\end{array}$ & $x$ & & & $x$ & $x$ \\
\hline
\end{tabular}

\section{Data Sharing}

In the expert interviews and workshops public sector representatives stated that they want to work with TNCs, as they can see the important role pooling has in the transportation ecosystem. However, public agencies rely on sufficient data to solve problems effectively and they recognize that part of TNCs' competitive advantage is their data. As a result, sharing all data is infeasible. To address this challenge, public agency representative suggested forming agreements with TNCs to share select data. This data could include common pick-up and drop-off locations or where curb uses do not match their designation (e.g., towaway zones that are used as loading zones). These data sharing agreements could help improve curbspace use and transportation safety and efficiency for all stakeholders.

\section{Network of TNC Stops}

Stakeholders suggested developing a network of TNC stops to help address a variety of pooling and indirect trip challenges. TNC users preferred to wait in their residence, store, or café because they are well-lit, not isolated, and above all else, safe. Additionally, TNC users preferred features at waiting locations that were similar to that of retail locations - clean, well maintained, and where individuals did not run the risk of being robbed or approached by homeless individuals. Many users also stated they would be willing to walk out of their way or pay a higher trip cost to wait in these facilities. As a result of these considerations, workshop participants suggested developing a network of designated TNC stops with strong lighting and clear designations for where 
TNC vehicles could pull over, both on the curb and in-app. Stakeholders could also partner with retailers to leverage existing infrastructure for these locations. These partnerships would provide TNC users with safe waiting locations, drivers with a clear and recognizable landmark to drive toward, and retailers with potential customers.

\section{Operational Improvements}

In the photovoice discussions, TNC users appeared to be uninterested in using TNCs to connect to public transit because of concerns about a delayed TNC trip causing them to miss a public transit connection. However, the workshop revealed an interest in using modal transfers and integrated fare payment services to connect TNCs to public transit. These services are currently limited by two logistical barriers: 1 ) timing TNC routes for trip planning and 2) integrating different fare types into a compatible fare payment system. In order to make TNCs a viable first- and last-mile option, stakeholders must work to efficiently integrate these different modes. Service providers can learn from other MaaS implementations to develop operational strategies that best approach these existing roadblocks.

\section{Partnership Programs}

Though TNC users expressed interest in simple per-trip discounts for pooled rides, the users' interest in more varied types of incentives demonstrates that there may be currently untapped markets. For example, there are TNC users who are traveling in the same direction that could be incentivized to pool through innovative partnerships. The workshop discussed examples of innovative partners including: event venues (e.g., sporting venues, tourist attractions), schools, employers, retailers, and airports. Partnerships that target these locations could help streamline rides for users who take non-urgent trips, are traveling to or from high-demand destinations, or are making regular trips where very few of them are pooling. Mobility providers could more efficiently route these trips because people are traveling in the same direction. Users also expressed an interest in pooling for these trips, especially when incentives like retail discounts, food or drink vouchers, and bulk purchase discounts are involved.

\section{Safety and Trip Information}

Users currently find uncertainty in many aspects related to pooling including variables, such as: which service will be available where, where an indirect trip will make them walk/wait, who they will be sharing the ride with, how many other people will be picked up, how much it will extend their trip time, and whether the driver/other passengers been vaccinated for COVID-19. These unanswered questions can decrease users' interest in pooling. This may be particularly true for individuals with less frequent TNC use who may feel they cannot trust the service. If TNCs increase the amount of upfront trip information provided to users (e.g., ETA, number of pick ups and drop offs, where an indirect trip would pick them up), the users could then set their expectations accordingly. Additionally, if stakeholders give users the opportunity to share their trip information with others (e.g., emergency contacts), it could help hold the TNCs accountable and provide users with increased feelings of safety. TNCs allowing users to select a preferred driver gender could also improve feelings of safety, especially for female users taking trips at night or by themselves. Stakeholders working to make pooling easier and safer to use could lower the barrier to entry for new users and encourage non-heavy TNC users to take more pooled trips. 


\section{Conclusion}

This research was designed to answer two key questions:

1. How do infrastructure and built environment features at pooling pick-up locations impact a TNC user's decision to pool?

2. How can incentives be used to shift users to take pooled trips, walk to pick-up locations, and use TNCs to connect to public transit?

A multi-method research approach was designed to answer these questions. The approach included: 1) a literature review of shared mobility, key pooling information, curb management strategies, built environment features, safety and security considerations, pricing policies, and photovoice methodology information; 2) interviews with 10 pooling and four photovoice experts; 3) photovoice discussion groups with 15 TNC users; and 4) a workshop with 12 TNC users and five stakeholders.

The literature review identified that the main barriers to widespread pooling adoption include: time and cost trade-off, safety in and outside of the vehicle, and access to services. However, the literature stated that these barriers can potentially be addressed through two predominant strategies: 1) designated pick-up and drop-off zones with appropriate safety features and amenities and 2) changes to existing pricing policies that reduce costs for low-income individuals and raise costs for private trips. Despite these findings, a review of past research on taxi stands and passenger loading zones revealed two key literature gaps: 1) user perception of the built environment at waiting locations and 2 ) information on pick-up location features and amenities that would promote TNC use. Additionally, prior research on safety concerns while waiting for transportation modes was limited to safety at public transit stops. There has not been any research conducted on the factors that affect the safety and security of TNC users while waiting at pick-up locations.

Key findings from the literature review informed the development of the expert interview protocol. During these interviews, the experts stated that pooling could expand the continuum of transportation services and save users both time and money. These benefits could be supported through commuter benefit expansion and high-occupancy vehicle lane developments. However, experts also stated that pooling faces challenges including funding restrictions, administrative misconceptions that limit the success of public-private partnerships, a lack of clear regulatory distinction between types of pooled services, and issues with presenting users with complete upfront trip data. The experts suggested TNCs improve communication at all levels (e.g., with travelers, between public and private stakeholders) to ensure pooling's future success. Examples of these communication improvements include private mobility operators and public agencies creating a line of communication to support curbspace management and bridge information gaps, and communication with users to provide them with as much information as possible regarding upfront trip information and the differences between service types. Interviews were also conducted with four photovoice experts to better understand the opportunities and challenges of the photovoice methodology.

The findings from the expert interviews led to the development of a modified photovoice methodology. The photovoice methodology was successfully implemented with seven heavy and eight non-heavy TNC users from the San Francisco Bay Area. The TNC users shared that safety at pick-up locations is a primary concern and factors greatly into deciding to walk to pick up (i.e., only short distances through safe neighborhoods during the daytime) and where they will wait for pick up (i.e., predominantly inside their residence or a nearby store or café). Users expressed interest in designated TNC stops but shared that they want these stops to mimic the attributes of the stores and residences in which they would normally wait (i.e., safe, clean, well-lit, low foot 
traffic but not isolated, located in busy areas). Female TNC users, in particular, preferred waiting in locations that were open, not isolated, and had visibility of their surroundings. These findings confirm the literature review findings. However, male TNC users were more interested in waiting in locations where there was little to no concern that their phone would be stolen (e.g., not crowded). When discussing multimodal trips, it was revealed that heavy TNC users were more likely to connect TNCs with other modes and concerned about whether the driver could safely pull over. Inversely, the non-heavy TNC users were less likely to connect TNCs to other modes and preferred waiting in areas with wide sidewalks and good lighting. Nearly all TNC users were interested in discounts to take pooled trips, though only half were interested in indirect trips, and few were interested in discounts to connect to transit. Only heavy TNC users were interested in passive "frequent rider" promotional programs.

The results of the photovoice discussions were compiled and synthesized into a presentation of key findings and recommendations. These were shared and discussed in a workshop held with 12 returning photovoice participants and five pooling stakeholders. Photovoice participants agreed with many of the photovoice group findings, and the workshop participant suggestions led to the development of several strategies to improve and incentivize pooled trips.

Designated TNC stops were identified as a potential strategy to address driver connection, safety, and trip time challenges. The stakeholders recommended that these stops be equipped with strong lighting and clearly marked pick-up areas for TNC vehicles or developed in partnership with retailers to allow TNC users to wait for rides in their spaces. TNC users and stakeholders also pointed to enhancing in-app safety information features (e.g., selecting driver gender, sharing trip information with emergency contact, providing information about trip upfront) as to address many safety and security concerns shared by TNC users. These improvements could be particularly important for female users taking trips alone or at night.

To incentivize taking pooled trips, TNC users and stakeholders suggested developing partnerships, including with retailers to provide retail-based incentives to take pooling for non-urgent trips, venues to provide food or drink vouchers to take pooling to and from high-demand locations, and employers and schools to make subsidized bundled trips available to commuters who pool. The TNC users also shared that they would be interested in using TNCs to connect to public transit if a transfer discount was integrated into the fare payment system and timed transfers were available. However, the experts noted operational challenges with both of these improvements.

Finally, stakeholders in the workshop discussion suggested several areas for future research. Future research areas included: exploring how to address potential service-related equity challenges that can arise from allowing passengers to geofence specific PUDO locations, developing system changes and driver incentives to better realign TNC driver and user goals, and focusing on addressing the gendered inequity of waiting in public spaces for a TNC.

Through a mixed-methods approach this study revealed why users choose to pool and connect TNCs to public transit, the role that the built environment, and incentives play in shifting these behaviors. By engaging with both users and stakeholders of pooled mobility services, recommendations and strategies for improvement were formed based on a solid understanding of TNC users' underlying experiences and beliefs. Policymakers and private mobility providers can use the strategies as a starting point to develop a network of partnerships, incentives, and safe waiting locations to support pooling. By building a community around the idea of pooling, 
many user challenges and stakeholder concerns could be addressed, leading to a potential increase in pooling and the development of new positive externalities. 


\section{References}

(@MCO), O. I. (2017). You can now pick up UberX and Lyft from MCO! Retrieved from Twitter: https://twitter.com/mco/status/910595720603979776

Alonso-Gonzalez, M., Cats, O., van Oort, N., Hoogendoorn-Lanser, S., \& Hoogendoorn, a. (2020). What are the determinants of the willingness to share rides in pooled on-demand services? Transportation .

American Public Transportation Association. (2012). Design of On-Street Transit Stops and Access from Surrounding Areas. Washington, D.C.: American Public Transportation Association.

Amirkiaee, S., \& Evangelopoulos, N. (2018). Why do people rideshare? An experimental study. Transportation Research Part F: Traffic Psychology and Behavior, 55.

Anair, D., Martin, J., Pinto de Moura, M., \& Gouldman, J. (2020). Ride-Hailing's Climate Risks. Oakland: Union of Concerned Scientists.

Aono, S. (2019). Identifying Best Practices for Mobility Hubs. Vancouver: University of British Columbia.

Aw, E., Basha, N., Ng, S., \& Sambasivan, M. (2019). To grab or not to grab? The role of trust and perceived value in on-demand ridesharing services. Asia Pacific Journal of Marketing and Logistics, 31.

BAAQMD. (2014). Regulation 14 Mobile Source Emissions Reduction Measures Rule 1: Bay Area Commuter Benefits Program. San Francisco, California.

Bell, L., Beltran, G., Berry, E., Calhoun, D., Hankins, T., \& Hester, L. (2018). Public Transit and Social Responsibility: Homelessness. Washington, D.C.: American Public Transportation Association.

Bhuiyan, J. (2018). Uber's new 'Express Pool' is all about getting more riders to share rides. Retrieved from Vox: https://www.vox.com/2018/2/21/17032598/uber-express-pool-transit-bus-cheaper

Brantingham, P., \& Brantingham, P. (1993). Environment, routine and situation: Toward a pattern theory of crime. In R. Clarke, \& M. Felson, Routine activity and rational choice: Advances in criminological theory (Vol. 5, pp. 259-294). Piscataway, NJ: Transaction.

Brownson, R., Baker, E., Houseman, R., Brennan, L., \& Bacak, S. (2001). Environmental and Policy Determinants of Physical Activity in the United States. American Journal of Public Health, 91(12), 995-2003.

Castleden, H., Garvin, T., \& First Nation, H. (2008). Modifying Photovoice for community-based Indigenous research. Social Science \& Medicine, 66.

Centers for Disease Control. (2021). People at Increased Risk And Other People Who Need to Take Extra Precautions. Retrieved from Centers for Disease Control and Prevention: https://www.cdc.gov/coronavirus/2019-ncov/need-extra-precautions/index.html

Chan, N., \& Shaheen, S. (2011). Ridesharing in North America: Past, Present, and Future. Transport Reviews, 32.

Clewlow, R., \& Mishra, G. (2017). Disruptive Transportation: The Adoption, Utilization, and Impacts of RideHailing in the United States. Institute of Transportation Studies.

Cohen, A., \& Shaheen, S. (2018). Planning for Shared Mobility.

Cohen, L., \& Felson, M. (1979). Social change and crime trends: A routine activity approach. American Sociological Review, 44, 588-698.

Conway, M., Salon, D., \& King, D. (2018). Trends in Taxi Use and the Advent of Ridehailing, 1995-2017: Evidence from teh US National Household Travel Survey. Urban Science.

Cornish, D., \& Clarke, R. (1986). The Reasoning Criminal. New York: Springer-Verlag.

CPUC. (2021). Transportation Network Companies Background. Retrieved from California Public Utilities Commission: https://www.cpuc.ca.gov/tncinfo/

Erhardt, G., Roy, S., Cooper, D., Sana, B., Chen, M., \& Castiglione, J. (2019). Do transportation network companies decrease or increase congestion? Science Advances. 
Etherington, D. (2018). Uber officially launches Uber Express POOL, a new twist on shared rides. Retrieved from TechCrunch: https://techcrunch.com/2018/02/21/uber-officially-launches-uber-express-pool-a-newtwist-on-shared-rides/

Ewing, R., \& Handy, S. (2009). Measuring the Unmeasurable: Urban Design Qualities Related to Walkability. Journal of Urban Design.

Fehr and Peers. (2018). San Francisco Curb Study. San Francisco: Fehr and Peers. Retrieved from https://www.fehrandpeers.com/curbs-of-the-future/

Gehrke, S., Felix, A., \& Reardon, T. (2018). A Survey of Ride-Hailing Passengers in Metro Boston. Boston: Metropolitan Area Planning Council.

Gerell, M. (2018). Bus Stops and Violence, Are Risky Places Really Risky? European Journal of Criminal Policy and Research, 24, 351-371.

Goodall, W., Fishman, T., Bornstein, J., \& Bonthron, B. (2017). The rise of mobility as a service. Deloitte Review.

Goodchild, A., MacKenzie, D., Ranjbari, A., Machado, J., \& Chiara, G. (2019). Curb Allocation Change Project: Final Report. Seattle: University of Washington.

Gordon, M., \& Riger, S. (1989). The Female Fear. New York: The Free Press.

Graehler, G., Mucci, A., \& Erhardt, G. (2019). Understanding the Recent Transit Ridership Decline in Major US Cities: Service Cuts or Emerging Modes? 2019 Transportation Research Board Annual Meeting.

Grahn, R., Harper, C., Hendrickson, C., Qian, Z., \& Matthew, H. (2019). Socioeconomic and usage characteristics of transportation network company (TNC) riders. Transportation, 47.

Hannay, J., Dudley, R., Milan, S., \& Leibovitz, P. (2013). Combining Photovoice and foucs groups: engaging Latina teens in community assessment. American Journal of Preventative Medicine.

Henao, A. (2017). Impacts of Ridesourcing - Lyft and Uber - on Transportation Including VMT, Mode Replacement, Parking, and Travel Behavior. Denver: University of Colorado.

Henao, A., \& Marshall, W. (2018). The impacts of ride-hailing on vehicle miles traveled. Transportation, 21732174.

Hergenrather, K., Rhodes, S., Cowan, C., Bardhoshi, G., \& Pula, S. (2009). Photovoice as community-based participatory research: a qualitative review. American Journal of Health and Behavior.

Institute of Transportation Engineers. (2018). Curbside Management Practitioners Guide. Washington, D.C.: Institute of Transportation Engineers. Retrieved from https://s23705.pcdn.co/wpcontent/uploads/2019/03/ITE-Kerbside-Curbside-Management-Guide.pdf

International Transport Forum. (2017). Shared Mobility Simulations for Helsinki. Paris: International Transport Forum.

International Transport Forum. (2018). The Shared-Use City: Managing the Curb. Paris: International Transport Forum. Retrieved from https://www.itf-oecd.org/sites/default/files/docs/shared-use-city-managingcurb_5.pdf

Jacobs, J. (1961). The Life and Death of Great American Cities. New York: Vintage Books.

Jiang, S., Chen, L., Mislove, A., \& Wilson, C. (2018). On Ridesharing Competition and Accessibility: Evidence from Uber, Lyft, and Taxi. 2018 World Wide Web Conference on World Wide Web.

Jiao, J., \& Wang, F. (2019). Shared mobility and transit-dependent population: A new equity opportunity or issue? International Journal of Sustainable Transportation.

Jin, S., Kong, H., \& Sui, D. (2019). Uber, Public Transit, and Urban Transportation Equity: A Case Study in New York. The Professional Geographer.

Kang, S., Mondal, A., Bhat, A., \& Bhat, C. (2020). Pooled Versus Private Ride-Hailing: A Joint Revealed and Stated Preference Analysis Recognizing Psycho-Social Factors. Austin: The University of Texas at Austin.

Kim, S., Chang, J., Park, H., Song, S., Cha, C., Kim, J., \& Kang, N. (2020). Autonomous Taxi Service Design and User Experience. International Journal of Human-Computer Interation, 36(5), 429-448. 
La Vigne, N. (1997). Visibility and Vigilance: Metro's Situational Approach to Preventing Subway Crime. Washington: National Institute of Justice.

Lavieri, P., \& Bhat, C. (2019). Investigating objective and subjective factors influencing the adoption, frequency, and characteristics of ride-hailing trips. Transportation Research Part C: Emerging Technologies.

Lavieri, P., Dias, F., Juri, N., Kuhr, J., \& Bhat, C. (2018). A Model of Ridesourcing Demand Generation and Distribution. Transportation Research Record.

Lazarus, J., Caicedo, J., Bayen, A., \& Shaheen, S. (2021). To Pool or Not to Pool? Understanding Opportunities and Challenges to Expand the Market for Pooling. Transportation Research Part A: Policy and Practice.

LeighFisher. (2010). Airport Curbside and Terminal Area Roadway Operations. Airport Cooperative Research Program.

Lekach, S. (2019). Lyft rolls out its own version of Uber Express Pool called 'Shared Saver'. Retrieved from Mashable: https://mashable.com/article/lyft-shared-saver-uber-express-pool/

Levin, D. (2006). Which way is up: towards accessible wayfinding in transit stations. Cambridge: Massachusetts Institute of Technology.

Lewis, E., \& MacKenzie, D. (2017). UberHOP in Seattle: Who, Why, and How? Transportation Research Record.

$\mathrm{Li}$, X., Hu, S., Fan, W., \& Deng, K. (2018). Modeling an enhanced ridesharing system with meet points and time windows. PloS ONE.

Li, Z., Hong, Y., \& Zhang, Z. (2016). An empirical analysis of on-demand ride-sharing and traffic congestion. International Conference of System Sciences. Dublin.

Lippke, K., \& Noyce, C. (2020). Public Acceptance and Adoption of Shared-ride Services in the Ride-hailing industry. University of Michigan.

Livingstone-Lee, S., Skelton, R., \& Livingston, L. (2014). Transit Apps for People with Brain Injury and Other Cognitive Disabilities: The State of the Art. Assistive Technology.

Lo, J., \& Morsemann, S. (2018). The Perfect uberPOOL: A Case Study on Trade-Offs. Ethnographic Praxis in Industry Conference.

Los Angeles Department of City Planning. (2016). Mobility Hubs: A Reader's Guide. Los Angeles: Los Angeles Department of City Planning.

Loukaitou-Sideris, A. (1999). Hot Spots of Bus Stop Crime: The Importance of Environmental Attributes. Journal of the American Planning Association, 65(4), 395-411.

Loukaitou-Sideris, A. (2005). Is It Safe to Walk Here? Design and Policy Responses to Women's Fear of Victimization in Public Places. Research on Women's Issues in Transportation, Report of a Conference, Volume 2: Technical Papers. Washington, D.C.: Transportation Research Board.

Lu, R. (2018). Pushed from the Curb: Optimizing Curb Space for Use by Ride-sourcing Vehicles. Los Angeles: University of California. Retrieved from https://escholarship.org/content/qt25p966dh/qt25p966dh_noSplash_970a2e35099554d365f630d9a1 7cc1d3.pdf.

Lynch, G., \& Atkins, S. (1988). The Influence of Personal Security Fears on Women's Travel Patterns. Transportation, 15, 255-277.

Mandle, P., \& Box, S. (2017). Transportation Network Companies: Challenges and Opportunities for Airport Operators. Washington: The National Academies Press.

Manville, M., Taylor, B., \& Blumenberg, E. (2018). Falling Transit Ridership: California and Southern California. Los Angeles: University of California Institute of Transportation Studies. Retrieved from https://www.its.ucla.edu/2018/01/31/new-report-its-scholars-on-the-cause-of-californias-fallingtransit-ridership/.

Miles, D. (2019). Help students, staff stay safe when using rideshare apps. Student Affairs Today, 22(5), 6. 
Moody, J., \& Zhao, J. (2020). Adoption of Exclusive and Pooled TNC Services in Singapore and the US. Journal of Transportation Engineering Part A: Systems.

Moody, J., Middleton, S., \& Zhao, J. (2019). Rider-to-rider discriminatory attitudes and ridesharing behavior. Transportation Research Part F: Traffic Psychology and Behavior, 62.

Moreira-Matias, L., Fernandes, R., Gama, J., Ferreira, M., Mendes-Moreira, J., \& Damas, L. (2012). An Online Recommendation System for the Taxi Stand choice Problem (Poster). IEEE Vehicular Networking Conference.

Moudon, A., Bassok, A., \& Kang, M. (2018). Safe from Crime at Location-Specific Transit Facilities: Final Project Report. Washington State Transportation Center. Retrieved from https://www.wsdot.wa.gov/research/reports/fullreports/882-1.pdf.

Murphy, C., \& Feigon, S. (2016). Shared Mobility ad the Transformation of Public Trust. American Public Transportation Association.

National Association of City Transportation Officials. (2017). Curb Appeal: Curbside Management Strategies for Improving Transit Reliability. National Association of City Transportation Officials. Retrieved from https://nacto.org/wp-content/uploads/2017/11/NACTO-Curb-Appeal-Curbside-Management.pdf.

Newman, O. (1972). Defensible Space: Crime Prevention through Urban Design. New York: MacMillan.

Newton, A., \& Ceccato, V. (2015). Theoretical perspectives of safety and security in transit environments. In V. Ceccato, \& A. Newton, Safety and Security in Transit Environments: An Interdisciplinary Approach (pp. 23-36). New York: Palgrave Macmillan.

Pew Research Center. (2021). Who owns cellphones and smartphones. Retrieved from Pew Research Center: https://www.pewresearch.org/internet/fact-sheet/mobile/

Pratt, A., Morris, E., Zhou, Y., Khan, S., \& Chowdhury, M. (2019). What do riders tweet abou the people they meet? Analyzing online commentary about UberPool and Lyft Shared/Lyft Line. Transportation Research Part F: Traffic Psychology and Behavior.

Qu, Z., Wang, X., Song, X., Pan, Z., \& Li, H. (2019). Location Optimization for Urban Taxi Stands Based on Taxi GPS Trajectory Big Data. IEEE Access, 7, 62273-62283.

Rayle, L., Dai, D., Chan, N., Cervero, R., \& Shaheen, S. (2016). Just a better taxi? A survey-based comparison of taxis, transit, and ridesourcing services in San Francisco. Transportation Policy.

Reason, P., \& Bradbury, H. (2001). Handbook of Action Research - Participative Inquiry and Practice. London: Sage.

Ross, C. (2000). Walking, Exercising, and Smoking: Does Neighborhood Matter? Social Science and Medicine, 15(2), 265-274.

SAE International. (2018). Taxonomy and Definitoins for Terms Related to Shared Mobility and Enabling Technologies. Detroit: SAE International .

Salanova, J., \& Romeu, M. (2018). Modeling framework for comparing taxi operational modes: Case study in Barcelona. Transportation Research Procedia, 33, 59-66.

Saldaña, J. (2013). The Coding Manual for Qualitative Researchers. Los Angeles: SAGE.

Sarriera, J., Alvarez, G., Blynn, K., Alesbury, A., Scully, T., \& Zhao, J. (2017). To Share or Not To Share: Investigating the Social Aspects of Dynamic Ridesharing. Transportation Research Record J.

Sartori Do Amaral, C., Chamorro-Koc, M., Beatson, A., \& Tuzovic, S. (2019). Enabling self-determination through transformative service design and digital technologies: studying mobility experiences of people with disability. International Association of Societities of Design Research Conference, (pp. 1-16).

Schaller Consulting . (2017). Unsustainable? The Growth of App-Based Ride Services and Traffic, Travel, and the Futrue of New York City. New York City: Schaller Consulting.

Schaller Consulting. (2018). The New Automobility: Lyft, Uber, and the Future of American Cities. New York City: Schaller Consulting. 
Schaller Consulting. (2019). Making the Most of the Curb: Managing passenger and parcel pick-up and drop-off on congested city streets. New York: Schaller Consulting.

SFMTA. (2020). Curb Management Strategy. San Francisco.

Shaheen, S. (2018). Chapter 4: Shared Mobility: The Potential of Ride Hailing and Pooling. Berkeley: University of California, Berkeley: Transportation Sustainability Research Center.

Shaheen, S., \& Cohen, A. (2018). Shared ride services in North America: definitions, impacts, and the future of pooling. Transport Reviews.

Shaheen, S., \& Cohen, A. (2019). Shared Micromobility Policy Toolkit: Docked and Dockless Bike and Scooter Sharing. Berkeley: University of California, Berkeley.

Shaheen, S., Bell, C., Cohen, A., \& Yelchuru, B. (2017). Travel Behavior: Shared Mobility and Transportation Equity. Washington: Federal Highway Administration.

Shaheen, S., Chan, N., \& Gaynor, T. (2016). Casual carpooling in the San Francisco Bay Area: Understanding user characteristics, behaviors, and motiviations. Transport Policy, 165-173.

Shaheen, S., Cohen, A., \& Bayen, A. (2018). The Benefits of Carpooling. Berkeley: University of California, Berkeley: Transportation Sustainability Research Center.

Shaheen, S., Cohen, A., \& Zohdy, I. (2016). Shared Mobility: Current Practices and Guiding Principles. Washington, D.C.: Federal Highway Administration.

Shaheen, S., Cohen, A., Chan, N., \& Bansal, A. (2020). Chapter 13: Sharing strategies: carsharing, shared micromobility (bikesharing and scooter sharing), transportation network companies, microtransit, and other innovative mobility modes. Transportation, Land Use, and Environmental Planning.

Shaheen, S., Cohen, A., Randolph, M., Farrar, E., Davis, R., \& Nichols, A. (2019). Shared Mobility Policy Playbook. California Department of Transportation.

Shaheen, S., Lazarus, J., Caicedo, J., \& Bayen, A. (2021). To Pool or Not to Pool Understanding the Time and Price Tradeoffs of On-Demand Ride Users - Opportunities, Challenges, and Social Equity Considerations for Policies to Promote Shared-Ride Services. UC Office of the President: University of California Institute of Transportation Studies.

Sitter, K., \& Mitchell, J. (2020). Perceptions of Paratransit Accessibility Among Persons with Disabilities: An Adapted Photovoice Study. Health Promotional Practice.

Stanko, E. (1990). Everyday Violence: Women's and Men's Experience of Personal Danger. London: Pandora.

Stucky, T., \& Smith, S. (2017). Exploring the conditional effects of bus stops on crime. Security Journal, 30, 290309.

True, G., Rigg, K., \& Butler, A. (2014). Understanding Barriers to Mental Health Care for Recent War Veterans Through Photovoice. Quality Healthy, 1-13.

United States Census Bureau. (2019, June 3). 2019: ACS 1-Year Estimates Data Profiles. Retrieved from United States Census Bureau: https://data.census.gov/cedsci/table?g=310M500US41860\&tid=ACSDP1Y2019.DP05

Valentine, G. (1990). Women's Fear and the Design of Public Space. Built Environment, 16(4), 288-303.

Van Audenhove, L. (2007). Expert Interviews and Interview Techniques for Policy Analysis. Vrije Universiteit Brussel.

Wang, C., \& Burris, M. (1997). Photovoice: concept, methodology, and use for participatory needs assessment. Health Educational Behavior.

Wasserman, J., Taylor, B., Blumenberg, E., Garrett, M., King, H., Paul, J., . . Schouten, A. (2020). What's Behind Recent Transit Ridership Trends in the Bay Area? Volume II: Trends among Major Transit Operators. University of California Institute of Transportation Studies. Retrieved from https://escholarship.org/uc/item/96w4g18f

Weber, B. (2019). Uber and urban crime. Transportation Research Part A Policy and Practice, 130, 496-506. 
Wekerkle, G., \& Whitzman, C. (1995). Safe Cities: Guidelines for Planning, Design and Management. New York: Van Nostrand Reinhold.

Wilson, J., \& Kelling, G. (1982). Broken Windows: The Police and Neighborhood Safety. Atlantic Monthly, 249(3), 29-38.

Young, M., \& Farber, S. (2019). Ride-hailing Platforms Are Shaping the Futrue of Mobility, but for Whom? OSF Preprints.

Young, M., \& Farber, S. (2019). The who, why, and when of Uber and other ride-hailing trips: An examination of a large sample household travel survey. Transportation Research Part A: Policy and Practice.

Young, M., Farber, S., \& Palm, M. (2020). The true cost of sharing: A detour penality analysis between UberPool and UberX trips in Toronto. Transportation Research Part D: Transport and Environment.

Zahnow, R., \& Corcoran, J. (2019). Crime and bus stops: An examination using transit smart card and crime data. Environment and Planning B: Urban Analytics and City Science, 1-18.

Zhang, W., \& Ukkusuri, S. (2021). Share-a-Cab: Scalable Clustering Taxi Group Ride Stand From Huge Geolocation Data. IEEE Access, 9, 9771-9776.

Zheng, H., Chen, X., \& Chen, X. (2019). How Does On-Demand Ridesplitting Influence Vehicle Use and Purchase Willingness? A Case Study in Hangzhou, China. IEEE Intellient Transportation Systems Magazine. 


\section{Appendix A - Pooling Expert Interview Protocol}

\section{Consent Form Review}

If you agree to be audio and video recorded, we will store it for up to three years in a secure data repository where it will only be accessed by the primary researchers. If we use a quotation from you in any publication, we will ask you for permission, and you will be given the opportunity to approve and edit any quotation used. If you approve a quotation, you will not be identified by name or any other identifiable information (e.g., job title, geographic area). If you decide you do not want to be recorded, we can stop the recording at any time.

- Do you consent to being recorded as a part of this study?

\section{Interview Purpose}

The purpose of this interview is to gain a better understanding of the successes and challenges that pooled mobility services and organizations that interact with them have faced. The interviews also will identify potential strategies that can be used to increase the use of pooled mobility options.

In this interview, when we refer to "pooling" and "pooled trips" we mean pooled Transportation Network Company (TNC) trips (e.g., UberPool, Lyft Shared rides) and shared microtransit trips (e.g., the services provided by Via and TransLoc). Pooled trips are when multiple passengers with different origins and destinations are picked up and dropped off by the same vehicle because the origins and destinations share a common route.

We will also refer to "direct" and "indirect" pooled trips. Direct pooled trips are those where each passenger is picked up and dropped off directly at their selected origin and destination points. Examples of direct pooled TNC services include UberPool and Lyft Shared. Microtransit providers frequently offer direct, door-to-door service to riders, usually for an additional fee. Indirect pooled trips are those that require passengers to walk a short distance (i.e., five to eight minutes) from their original origin and destination points to pick-up and dropoff locations set using an algorithm to make use of optimal straight-line routing. Examples of indirect pooled TNC services include Uber Express Pool and Lyft Shared Saver. Microtransit trips that involve the passenger meeting the on-demand vehicle at a nearby bus stop or assigned location are also considered indirect shared rides.

- Do you have any questions about any of these terms before we begin?

\section{Interview Questions}

1. Who do you work for and what is your current role?

2. How do you interact with TNCs (pooled and not pooled) and/or microtransit in your current role?

3. What has been your organization's experience with pooling (direct and indirect), including pooled TNCs and microtransit, and non-pooled TNCs?

4. What are opportunities for pooling (direct and indirect)?

5. What do you see as key pooling challenges (direct and indirect)?

6. Are there any unique challenges your organization encounters with direct and indirect pooling?

7. From your organization's perspective, how do you think direct and indirect pooling could be improved?

8. How could direct and indirect pooling be improved for users? 
9. How might the built environment at pick-up and drop-off locations impact a TNC or microtransit user's decision to pool? How might it impact TNC and/or microtransit pooling (direct and indirect)?

10. How might incentives impact pooling (direct and indirect)?

11. Do you have any other recommendations for strategies to increase the use of pooled TNCs (direct and indirect) and/or microtransit?

12. Do you have any final comments or areas that you think we should consider in the context of this study? 


\section{Appendix B - Photovoice Expert Interview Protocol}

1. What is your name and profession? Who do you work for?

2. What is your familiarity with the photovoice methodology?

3. From your experience, what are some general best practices for using the photovoice methodology in a study?

4. What unforeseen challenges or limitations have past implementations of the methodology encountered? These can be studies that you yourself have administered or studies in the photovoice literature that you are familiar with.

5. What challenges do you anticipate conducting a study using photovoice during the? Do you have any suggestions for mitigating these challenges?

6. Were you to conduct a photovoice study during the COVID-19 pandemic, what modifications would you make to the original methodology? Feel free to use a study you administered or are familiar with as an example.

7. Do you have any suggestions for maintaining a trusting and collaborative discussion environment despite all discussions being held virtually?

8. What do you think of the proposed photovoice methodology for this pooling study? 


\section{Appendix C - Photovoice Participant Screener Survey}

Thank you for expressing your interest in this research study. Should you be selected to take part in the study, we will email you with further instruction. We appreciate your time and effort in taking this survey. Before proceeding with the survey, please download and read the consent form for this survey.

This survey will take approximately five minutes. From the consent form, you do not have to answer all questions, you may skip any questions you do not wish to answer, and you may terminate participation at any time. Per UC Berkeley requirements, you must be 18 years of age or older to take this survey. By clicking [Agree] you confirm that you are 18 years of age or older and consent to participate in this research. If you have questions about the survey or the procedures, you may email poolingstudy@berkeley.edu.

1. I am 18 years or older, and I agree to take this survey.
a. Agree
b. Disagree

\section{Section 1: TNC and Pooling Usage}

1. Have you ever used Transportation Network Company (TNC) services, such as Uber or Lyft? Please consider both private rides and shared (or pooled) rides with strangers.
a. I have never heard of Uber/Lyft.
b. I have heard of Uber/Lyft, but I do not know how to use these services.
c. I have heard of Uber/Lyft and I know how to use these services, but I have never used them.
d. Yes, I have used Uber/Lyft.

2. Prior to COVID-19 (i.e., March 2020), how often did you use the TNC services Uber or Lyft? Please consider both private rides and shared (or pooled) rides with strangers.
a. Never in the last year
b. Once a year
c. Once every 6 months
d. Once every 3 months
e. Once a month
f. Every other week
g. 1 to 3 days per week
h. 4 to 6 days per week
i. Once a day
j. 2 to 4 times a day
k. More than 4 times a day

3. Prior to COVID-19 (i.e., March 2020), when you used Uber/Lyft, how often did you use the shared ride options (e.g., Uber Pool, Uber Express Pool, or Lyft Shared rides [formerly Lyft Line])?

When using Uber/Lyft, I used the shared ride, which pairs me with strangers traveling in a similar direction, option...
a. Almost always
b. Most of the time (more than $50 \%$ ) 
c. Half of the time $(50 \%)$

d. Some of the time (less than $50 \%$ )

e. Never

\section{Section 2: Screening Information}

This project involves participants going outside and traveling to three locations near their home by walking or by taking a convenient mode (e.g., biking, public transit, driving) and then taking photographs at these locations and uploading them to a secure data center. This should take a maximum of 20 minutes for each of the three trips. Please note they may be trips you were already taking.

1. Do you have access to either a smart phone or a cell phone with a camera and the ability to upload images to the Internet?
a. Yes
b. No

2. We ask that individuals that are more vulnerable to catching COVID-19 please abstain from participating in this study. A full list of vulnerable populations can be found here.

Given the current state of the COVID-19 pandemic, are you comfortable with going outside and taking pictures at three locations near your home?
a. Yes
b. No

3. Do you agree to follow all local COVID-19 guidelines (wear a mask, practice social distancing, etc.) during all parts of this study?
a. Yes
b. No

4. Once the photographs are uploaded, a focus group with up to four other participants will be held using the Zoom teleconferencing platform to allow participants to discuss the photos. Attendance at a focus group is a requirement of the study; an incentive of $\$ 75$ will be distributed at the end of this effort to thank you for your time.

Please list your general weekday availability in [two-week window of dates]. Your final focus group time will be confirmed at a later date.
a. Open Response

5. Do you agree to let the photographs that you take be shared with other study participants in a small focus group (no more than five study participants) and with transportation industry professionals, so long as they contain no identifying or personal information?
a. Yes
b. No

6. Do you have a webcam, computer, and Internet that you can use teleconferencing applications like Zoom?
a. Yes 
b. No

The total estimated time commitment for the activities of this study are as follows:

\begin{tabular}{|c|l|c|}
\hline Activity & \multicolumn{1}{|c|}{ Description } & $\begin{array}{c}\text { Estimated Time } \\
\text { Commitment }\end{array}$ \\
\hline Survey & Demographic/travel behavior survey & 15 minutes \\
\hline Materials & View online learning materials for study photography & Up to 30 minutes \\
\hline Photography & Photography at three (3) pooling pick-up locations & Up to 60 minutes \\
\hline Focus Group & Focus group with other participants (held over Zoom) & 90 minutes \\
\hline & & \\
\hline & TOTAL & $\mathbf{3 . 2 5}$ Hours \\
\hline
\end{tabular}

You will be compensated with a $\$ 75$ gift card upon completion of the focus group.

7. Are you willing to commit up to 3.25 hours (or less depending on the photography tasks) of your time to take part in this study?
a. Yes
b. No

\section{Section 3: Future Contact Information}

If you are eligible to participate in our study, we will give you a short, 5-to-10-minute informational phone call to confirm your participation. Please provide your first name and the best phone number to reach you at for this call.

[Open Response] [Open Response]

[Date/Time Form]
First Name Phone Number Dates/times available for call

We are interested in knowing geographically where our study participants are located, given that this study will be conducted remotely. Please provide your zip code:

[Open Response] Zip Code

In order to participate in this study, we will need a reliable email address, which will be our primary mode of contact with you. We will also use this email address to send you your compensation upon completion of the focus group, so please ensure it is an account that you check regularly.

[Open Response] Email Address

\section{Section 4: Thank You!}

Thank you for your participation in this survey. If you meet the criteria for participation in this study, a member of our research staff will call you at the phone number provided at one of the available times listed to discuss next steps.

If you are not selected for this study, your responses to this survey including your first name, zip code, email address and phone number will be destroyed and will not be used for any further research. After submitting your responses, you can protect your privacy by clearing your browser's history, cache, cookies, and other browsing data. (Warning: This will log you out of online services.) 


\section{Appendix D - Photovoice Participant Demographic Survey}

Thank you for agreeing to be a part of this research. This survey will take approximately 15 minutes. You do not have to answer all questions, you may skip any questions you do not wish to answer, and you may terminate participation at any time. If you have questions about the survey, please email poolingstudy@berkeley.edu. Thank you!

\section{Section 1: Demographic Information}

1. How old are you?
a. Open Response
b. Prefer not to answer

2. What gender do you identify with?
a. Male
b. Female
c. Other, please specify:
d. Prefer not to answer

3. What is your race or ethnicity? (Please select all that apply.)
a. American Indian or Alaskan Native
b. Asian
c. Black or African American
d. Caucasian/White
e. Hispanic or Latino
f. Middle Eastern
g. Native Hawaiian or other Pacific Islander
h. South Asian (e.g., Indian, Pakistani, etc.)
i. Southeast Asian (Thai, Filipino, Malaysian, etc.)
j. Other, please specify:
k. Prefer not to answer

4. What is the highest level of education you have completed?
a. Less than high school
b. Currently in high school
c. High school graduate/GED
d. Currently in 2-year college
e. 2-year college degree
f. Some college (currently not in college)
g. Currently in 4-year college
h. 4-year college degree
i. Currently in post-graduate program
j. Post-graduate degree (MA, MS, PhD, MD, JD, etc.)
k. Prefer not to answer

5. What was your employment status in 2019? (Please select all that apply.)

a. Employed full-time (total 35 or more hours per week) 
b. Employed part-time (total less than 35 hours per week)

c. Self-employed full-time (total 35 or more hours per week)

d. Self-employed part-time (total less than 35 hours per week)

e. Student

f. Stay-at-home parent

g. Homemaker

h. Unemployed, active job seeker

i. Unemployed, not currently seeking a job

j. Retired

k. Other, please specify:

I. Prefer not to answer

6. What was your total annual household income in 2019?
a. Less than $\$ 20,000$
b. $\$ 20,000$ to $\$ 34,999$
c. $\$ 35,000$ to $\$ 49,999$
d. $\$ 50,000$ to $\$ 74,999$
e. $\$ 75,000$ to $\$ 99,999$
f. $\$ 100,000$ to $\$ 149,999$
g. $\$ 150,000$ to $\$ 199,999$
h. $\$ 200,000$ or more
i. Prefer not to answer

7. In 2019 , how many automobiles (e.g., car, SUV, pickup, or van) did your household own or lease?
a. 0
b. 1
c. 2
d. 3
e. 4
f. 5 or more
g. Prefer not to answer

8. In 2019, how many motorized bikes (e.g., motorcycle, scooter) did your household own or lease?
a. 0
b. 1
c. 2
d. 3
e. 4
f. 5 or more
g. Prefer not to answer

\section{Section 2: Transportation Profile}

1. Which of the following transportation modes did you use in the year prior to COVID-19 (from March 2019 to mid-March 2020)? (Please select all that apply.)

c. Drive alone (in a personal vehicle)

d. Drive/ride with others (non-commute; in a personal vehicle) 
e. Carpool (for commuting, not Uber/Lyft)

f. Vanpool (for commuting)

g. Employer shuttle (for commuting)

h. Public bus (e.g., AC Transit)

i. Rapid transit (e.g., BART)

j. Light rail (e.g., Muni)

k. Commuter rail (e.g., Caltrain)

I. Uber/Lyft ride alone (e.g., UberX, Lyft)

m. Uber/Lyft shared ride (e.g., Uber Pool, Lyft Shared rides, Uber Express Pool, Lyft Shared Saver)

n. Taxi (not Uber or Lyft)

o. Personal bicycle

p. Docked bikeshare (e.g., Bay Wheels)

q. Electric dockless bikeshare (e.g., JUMP Bikes)

r. Non-electric dockless bikeshare (e.g., Lime, Spin)

s. Round trip carsharing (e.g., Zipcar, Getaround, Turo)

t. One-way carsharing (e.g., GIG Car Share)

u. Hourly rental cars

v. Motorcycle or Scooter

w. Moped sharing (e.g., Revel)

x. Scooter sharing (e.g., Bird, Lime, Spin, etc.)

y. Microtransit (e.g., Via, AC Transit FLEX, Tri Delta Transit Tri MyRide)

z. Ferry (for commuting)

aa. Other, please specify.

2. Please indicate how frequently you used the following transportation modes in the year prior to COVID-19 (from March 2019 to mid-March 2020).

[All modes selected above will be displayed in a table format, with the following options as columns for each]

\begin{tabular}{|l|l|l|l|l|l|l|l|l|l|l|}
\hline $\begin{array}{l}\text { More } \\
\text { than 4 } \\
\text { times } \\
\text { a day }\end{array}$ & $\begin{array}{l}2 \text { to 4 } \\
\text { times } \\
\text { a day }\end{array}$ & $\begin{array}{l}\text { Once } \\
\text { a day }\end{array}$ & $\begin{array}{l}4 \text { to 6 } \\
\text { days } \\
\text { per } \\
\text { week }\end{array}$ & $\begin{array}{l}1 \text { to 3 } \\
\text { days } \\
\text { per } \\
\text { week }\end{array}$ & $\begin{array}{l}\text { Every } \\
\text { other } \\
\text { week }\end{array}$ & $\begin{array}{l}\text { Once a } \\
\text { month }\end{array}$ & $\begin{array}{l}\text { Once } \\
\text { every 3 } \\
\text { months }\end{array}$ & $\begin{array}{l}\text { Once } \\
\text { every 6 } \\
\text { months }\end{array}$ & $\begin{array}{l}\text { Once } \\
\text { a } \\
\text { year }\end{array}$ & $\begin{array}{l}\text { March } \\
\text { in } \\
\text { - mid- } \\
\text { March } \\
2020\end{array}$ \\
\hline
\end{tabular}

3. Prior to COVID-19 (i.e., mid-March 2020), how many days a week did you typically work and/or go to school?
a. I did not work/I did not go to school
b. 1
c. 2
d. 3
e. 4
f. 5
g. 6 
h. 7

4. Please indicate how you traveled for work/school prior to COVID-19 (i.e., mid-March 2020). (Please select all that apply.)

a. I commuted to/from work or school at least one day per week.

b. I traveled for work as my job involved teleworking (e.g., plumber, electrician, piano tuner).

c. I traveled for work as my job involved gig-working (e.g., driver, delivery).

d. I did not commute or travel for work or school (e.g., work from home, school at home, homemaker, stay-at-home parent, unemployed, retired).

5. Please indicate which transportation mode(s) you used for work- or school-related travel prior to COVID-19 (mid-March 2020). Please consider commuting, traveling to work- or school-related meeting locations, teleworking, and gig-working. (Please select all that apply.)
a. Drive alone (in a personal vehicle)
b. Drive/ride with others (non-commute; in a personal vehicle)
c. Carpool (for commuting, not Uber/Lyft)
d. Vanpool (for commuting)
e. Employer shuttle (for commuting)
f. Public bus (e.g., AC Transit)
g. Rapid transit (e.g., BART)
h. Light rail (e.g., Muni)
i. Commuter rail (e.g., Caltrain)
j. Uber/Lyft ride alone (e.g., UberX, Lyft)
k. Uber/Lyft shared ride (e.g., Uber Pool, Lyft Shared rides, Uber Express Pool, Lyft Shared Saver)
I. Taxi (not Uber or Lyft)
m. Personal bicycle
n. Docked bikeshare (e.g., Bay Wheels)
o. Electric dockless bikeshare (e.g., JUMP Bikes)
p. Non-electric dockless bikeshare (e.g., Lime, Spin)
q. Round trip carsharing (e.g., Zipcar, Getaround, Turo)
r. One-way carsharing (e.g., GIG Car Share)
s. Hourly rental cars
t. Motorcycle or Scooter
u. Moped sharing (e.g., Revel)
v. Scooter sharing (e.g., Bird, Lime, Spin, etc.)
w. Microtransit (e.g., Via, AC Transit FLEX, Tri Delta Transit Tri MyRide)
$x$. Ferry (for commuting)
$y$. Other, please specify.

\section{Section 3: Private Transportation Network Company (e.g., Uber or Lyft) and usage}

1. In what year did you use either Uber or Lyft for the first time? Please consider both private rides and shared (or pooled) rides with strangers.
a. 2020 

b. 2019
c. 2018
d. 2017
e. 2016
f. 2015
g. 2014
h. 2013
i. 2012 or earlier
j. I do not know/I do not remember

2. The following questions are related to your use of private Uber/Lyft trips. These are Uber/Lyft trips where you do not ride with strangers (other than the driver) and there are no additional passenger pick ups or drop offs (e.g., UberX, UberXL, Lyft, Lyft XL).

Prior to COVID-19 (i.e., mid-March 2020), how often did you use the private option of Uber/Lyft?
a. Never in the last year
b. Once a year
c. Once every 6 months
d. Once every 3 months
e. Once a month
f. Every other week
g. 1 to 3 days per week
h. 4 to 6 days per week
i. Once a day
j. 2 to 4 times a day
k. More than 4 times a day

3. Prior to COVID-19 (i.e., mid-March 2020), for what trip purposes did you use a private Uber/Lyft? (Please select all that apply.)
a. Go to or from a restaurant/bar
b. Go to or from major social/recreational events (e.g., sports events, concerts)
c. Go to or from other social/recreational activities (not a restaurant or bar or major event)
d. Commute to or from work
e. Commute to or from school
f. Go to or from public transit
g. Go to or from work-related meetings during the day
h. Go to or from grocery shopping
i. Go to or from other shopping (non-groceries)
j. Run non-shopping errands
k. To visit friends or relatives
I. To pick up or drop off children
m. Go to or from healthcare services
n. Go to or from the airport
o. Go to or from the gym
p. Other, please specify:
q. I did not take private Uber/Lyft trips 


\section{Section 4: Pooled TNC Trip Information}

The following questions are related to your use of shared (or pooled) Uber/Lyft trips. These are Uber/Lyft trips that pair you with strangers traveling in a similar direction (e.g., Uber Pool, Uber Express Pool, or Lyft Shared rides [formerly Lyft Line]).

1. Prior to COVID-19 (i.e., mid-March 2020), when you used Uber/Lyft, how often did you use the shared (or pooled) ride options?
a. Never in the last year
b. Once a year
c. Once every 6 months
d. Once every 3 months
e. Once a month
f. Every other week
g. 1 to 3 days per week
h. 4 to 6 days per week
i. Once a day
j. 2 to 4 times a day
k. More than 4 times a day

2. Prior to COVID-19 (i.e., mid-March 2020), for what trip purposes did you use shared (or pooled) Uber/Lyft? (Please select all that apply.)
a. Go to or from a restaurant/bar
b. Go to or from major social/recreational events (e.g., sports events, concerts)
c. Go to or from other social/recreational activities (not a restaurant or bar or major event)
d. Commute to or from work
e. Commute to or from school
f. Go to or from public transit
g. Go to or from work-related meetings during the day
h. Go to or from grocery shopping
i. Go to or from other shopping (non-groceries)
j. Run non-shopping errands
k. To visit friends or relatives
I. To pick up or drop off children
$\mathrm{m}$. Go to or from healthcare services
n. Go to or from the airport
o. Go to or from the gym
p. Other, please specify:
q. I did not take pooled Uber/Lyft trips

3. Prior to COVID-19 (i.e., mid-March 2020), when you used the shared (or pooled) ride option of Uber/Lyft, how often did you use the option to walk a short distance to a major road for pick-up, potentially for a reduced fare (e.g., Uber Express Pool or Lyft Shared Saver)?

When using a shared (or pooled) Uber/Lyft, I used the "walk to pick-up location" option...

a. Almost always 
b. Most of the time (more than $50 \%$ )

c. Half of the time $(50 \%)$

d. Some of the time (less than $50 \%$ )

e. Never

f. This option was not available in my region.

g. I didn't know there was a "walk to pick-up location" option.

\section{Section 5: Microtransit}

1. Have you ever used a microtransit service? Examples of microtransit include: AC Transit Flex, Emery GoRound, Tri Delta Transit Tri MyRide, and the former Chariot shuttle service.

f. I have never heard of a microtransit service.

g. I have heard of microtransit services, but these services are not available in my area.

h. I have heard of microtransit services and they are available in my area, but I do not know how to use these services.

i. I have heard of microtransit services, they are available in my area, and I know how to use these services, but I have never used them.

j. Yes, I have used a microtransit service.

2. Which of the following microtransit services have you used? (Please select all that apply.)
a. AC Transit Flex
b. Emery Go-Round
c. Tri Delta Transit Tri MyRide
d. SamTrans OnDemand
e. Chariot
f. Via
g. Other, please specify:

3. Prior to COVID-19 (i.e., March 2020), how often did you use the microtransit service?
a. Never in the last year
b. Once a year
c. Once every 6 months
d. Once every 3 months
e. Once a month
f. Every other week
g. 1 to 3 days per week
h. 4 to 6 days per week
i. Once a day
j. 2 to 4 times a day
k. More than 4 times a day

4. Prior to COVID-19 (i.e., March 2020), for what trip purposes did you use microtransit service? (Please select all that apply.)
a. Go to or from a restaurant/bar
b. Go to or from major social/recreational events (e.g., sports events, concerts)
c. Go to or from other social/recreational activities (not a restaurant or bar or major event)
d. Commute to or from work 

e. Commute to or from school
f. Go to or from public transit
g. Go to or from work-related meetings during the day
h. Go to or from grocery shopping
i. Go to or from other shopping (non-groceries)
j. Run non-shopping errands
k. To visit friends or relatives
I. To pick up or drop off children
m. Go to or from healthcare services
n. Go to or from the airport
o. Go to or from the gym
p. Other, please specify:
q. I did not use microtransit services

\section{Section 6: Pooled/Private TNC Trip Preferences}

Please consider your experiences using Uber/Lyft and/or microtransit prior to COVID-19 (i.e., mid-March 2020). Please indicate how often the following statements applied to you.

\begin{tabular}{|c|c|c|c|c|c|c|}
\hline & $\begin{array}{l}\text { Almost } \\
\text { Always }\end{array}$ & $\begin{array}{l}\text { Most of } \\
\text { the time }\end{array}$ & Sometimes & Rarely & Never & $\begin{array}{l}\text { I Don't } \\
\text { Know }\end{array}$ \\
\hline \multicolumn{7}{|l|}{$\begin{array}{l}\text { I was uncomfortable being driven by a } \\
\text { stranger. }\end{array}$} \\
\hline \multicolumn{7}{|l|}{ I enjoyed chatting with my driver. } \\
\hline \multicolumn{7}{|l|}{$\begin{array}{l}\text { I was uncomfortable sharing my rides with } \\
\text { strangers. }\end{array}$} \\
\hline \multicolumn{7}{|l|}{ I enjoyed chatting with other passengers. } \\
\hline \multicolumn{7}{|l|}{$\begin{array}{l}\text { When I was in a rush, I preferred to ride } \\
\text { alone. }\end{array}$} \\
\hline \multicolumn{7}{|l|}{$\begin{array}{l}\text { I think that shared ride options are optimally } \\
\text { routed (they travel the fastest route possible, } \\
\text { including pickups and drop offs for additional } \\
\text { passengers). }\end{array}$} \\
\hline \multicolumn{7}{|l|}{$\begin{array}{l}\text { Shared ride options took longer to match me } \\
\text { to a driver than the ride alone option. }\end{array}$} \\
\hline \multicolumn{7}{|l|}{$\begin{array}{l}\text { I think that TNC (Uber/Lyft) and microtransit } \\
\text { services have a positive overall impact on the } \\
\text { environment. }\end{array}$} \\
\hline $\begin{array}{l}\text { I think that using a shared ride option is } \\
\text { better for the environment than choosing to } \\
\text { ride alone. }\end{array}$ & & & & & & \\
\hline
\end{tabular}

\section{Section 8: Thank You!}

Thank you for completing this survey. After submitting your responses, you can protect your privacy by clearing your browser's history, cache, cookies, and other browsing data. (Warning: This will log you out of online services). 


\section{Appendix E - Photovoice Group Protocol}

1. Introduction of Researchers (1 minute)

2. Explanation of the Guidelines for Interacting with Others and Consent (1 minute)

3. Explanation of Goals of Discussion (2 minutes)

a. Definitions of TNC, pooling, direct trips, indirect trips

4. Opening General Questions and Ice Breaker (3 minutes)
a. What is your name?
b. Where in the Bay Area do you currently live?
c. How do you currently get around?

5. Small Group Discussion of Photographs (60 minutes)

a. Present "toolkit" slides with examples of curb infrastructure

b. [To person who submitted photo] Why did you take this picture? What about this location did you find important to capture in this picture?

c. [To group] What do you like about this location as a pick-up and drop-off spot? What do you dislike about this location? What could be changed about this location to improve it as a pickup drop-off spot?

d. Probes for each location:

i. Where do you get in/out of TNCs?

\section{Public Transit Connections}

a. Where does public transit stop?

b. How do you connect to public transit from this location?

c. Do you have to cross the street?

d. What do you do between connections?

i. Do you wait? How long is your wait? What types of things do you look for when waiting (e.g., food, benches, lighting, WiFi, etc.)? What could make waiting safer/easier? (e.g., amenities)

ii. Do you leave and come back?

\section{Waiting at Pick-Up Locations}

a. What if you selected the direct trip option (pooled or single occupant) at this location and the app showed a wait longer than expected (e.g., 12 minutes) for your pick-up?

i. Factors of decision to wait (e.g., shelter, bench, amenities, safety)

ii. Alternatives to waiting (e.g., walk to different street, look for other modes)

iii. Activities while waiting (e.g., shopping, looking at phone)

iv. Changes for safety (e.g., lighting, security features)

v. General improvements (e.g., amenities, shelter, benches)

vi. Limitations to improving location (e.g., narrow sidewalk, bike/bus lane) 


\section{Indirect Pooling}

a. What if you selected the indirect (corner-to-corner) pooled trip option (e.g., Uber Express Pool, Lyft Shared Saver) and the app assigned you this location to walk to (two blocks away from your selected trip origin)?

i. $\quad$ Factors of decision to walk (e.g., pedestrian infrastructure, wayfinding, safety)

ii. Trip type impact on decision to walk (e.g., linking to transit vs trip to an appointment versus trip to a friend's house)

\section{Other Considerations}

a. What if you were traveling with someone? What about traveling with children (as appropriate)?

i. Choose to wait (direct trips) (e.g., wait in a safer/quieter location, look for nearby amenities while waiting)

ii. Choose to walk (indirect trips) (e.g., opt for direct pick-up instead)

b. What do you think about the accessibility of this area?

i. Accessibility improvements (e.g., curb ramps, audio-cued pedestrian signals, loading space for wheelchair accessible vehicle at pick up or drop off)

c. What if it were nighttime (e.g., safety, lighting, eyes on the street)?

d. What if you were being dropped-off at this location (e.g., safe curb access, wayfinding to destination)?

e. Has the COVID-19 pandemic impacted your decision to walk to/wait at TNC pick-up locations (e.g., fewer people around, wait potentially increases exposure)?

\section{Comparing Locations}

a. Which locations would you prefer for walking to, waiting at, pick up, or drop off?

i. Perception of safety for some locations but not others

b. Which locations would you prefer for connecting to public transit?

i. Perception of some locations better for FMLM but not others

c. [Ask if time allows] Preferred locations for utility trips (e.g., commuting to/from work, traveling to appointments)

d. [Ask if time allows] Preferred locations for recreational trips (e.g., trip to friend's house, restaurant or bar)

e. Do you have any other preferences regarding the built environment, curb access, safety, wayfinding or amenities?

6. Discussion of Pricing Promotions and Incentives to Pool (20 minutes)

a. What factors into your decision to take a pooled trip versus a private trip?

i. Impact of discount or promotion (e.g., discounted TNC fare, purchase a bundle of pooled trips at a discount)

b. Have you ever taken a TNC (pooled or private) to public transit? What factors into your decision to (or not to) take a TNC to or from public transit (e.g., wait time, transfer time, stop/transfer distance)?

i. Impact of discount or promotion (e.g., percentage off TNC or transit fare, bundled first- and last-mile TNC service with transit trip) 
c. [Will likely be covered in photo discussion] What factors into your decision to take an indirect pooled trip versus a direct pooled trip?

i. Impact of discount or promotion (e.g., TNC fare with greater discount)

d. How has COVID impacted your desire to pool in the future?

i. Factors affecting decision to pool in future (e.g., mask requirements, vaccination requirements)

7. Closing Remarks (3 minutes)

a. Answer any remaining questions about the study

b. Invite group discussion participants to take part in the final workshop with stakeholders 


\section{Appendix F - Workshop Protocol}

\section{Participant Introductions [Slide 7] (10 minutes)}

\begin{tabular}{|l|l|l|l|}
\hline \multicolumn{1}{|c|}{ Individual } & \multicolumn{1}{|c|}{ City } & \multicolumn{1}{c|}{ Neighborhood } & \multicolumn{1}{c|}{ TNC Use } \\
\hline 1. & San Francisco & & $6-10$ times/month (1-3 times/week)* \\
\hline 2. & San Francisco & Pacific Heights & $1-2$ times/week \\
\hline 3. & San Francisco & Mission & 3-6 times/week* \\
\hline 4. & San Francisco & Castro & 2 times/month (0-1 times/week) \\
\hline 5. & Danville & & $1-2$ times/day (7-14 times/week) \\
\hline 6. & San Francisco & & $0-4$ times/week \\
\hline 7. & Daly City & & $3-4$ times/week* \\
\hline 8. & San Francisco & & $3-4$ times/week* \\
\hline 9. & San Francisco & & 2 times/week \\
\hline 10 & San Francisco & Mission & 3 times/week \\
\hline 11. & San Francisco & Mission & \\
\hline
\end{tabular}

*Prior to the COVID-19 pandemic

\section{Section 1. Infrastructure and Incentives (45 minutes)}

Infrastructure/Built Environment Features at TNC Waiting Locations and Public Transit Stops

[Slide 12-14] Slides with photos taken by participants will be presented for each of the following:

- Users prefer to wait in areas with wide sidewalks and open visibility of the road where it is easy to connect with drivers

- Users prefer pick-up spots located near retail opportunities in safe neighborhoods that are away from homeless encampments

- Users like waiting at pick-up locations that are well-lit, have some form of shelter or covering, and have benches/seating available.

Probes for Users

- What do you think about these observations? Do you agree or disagree, and why?

- What do you think about the other participants' photos? Have your thoughts on your preferred features changed after seeing others' photos?

- If these features were at public transit stops, would you be more likely to connect to transit using TNC? What could be improved at public transit stops to make connecting to/from a TNC trip easier?

Probes for Stakeholders

- What do you think about the photos that the participants took? Do any standout to you?

- What do you think about these features? What do you think would be feasible for what your organization can provide to support these user preferences?

- What challenges could you foresee with implementing this feature at TNC pick-up locations? At public transit stops?

Poll Question [Slide 15]

- Which features would you most like to see at TNC waiting locations and public transit stops? 
Incentives to Take Pooled Rides

[Slide 16] One slide will list the following pooling incentives:

- Individual trip discounts for pooling

- Additional discounts for walking to rides (indirect trip)

- Rewards programs for frequent riders

- "Bundled" trip discounts (e.g., order 10 of the same pooled trip for a bulk discount)

\section{Probes for Users}

- What do you think about these different incentives?

- Do you prefer a percentage discount or is there a specific dollar amount (to shift from private to pool and to shift from direct pool to indirect pool)?

Probes for Stakeholders

- What do you think about the users' thoughts on incentives?

- What incentives do you think would be most effective from your organization's perspective?

- What concerns do you have about incentivizing users to take pooled trips? To walk to pick-up locations? What could be done to help address these concerns?

\section{Poll Question [Slide 17]}

- Which incentive would be most effective to get you to shift from private TNC to a pooled ride?

Incentives to take Multimodal Trips

[Slide 18] One slide will list the following incentives to take multimodal trips (e.g., to use TNC to connect to public transit):

- Provide trip information for different modes

- Offer discounts for a transfer/integrated fare payment

- Increase price of parking at stations

\section{Probes for Users}

- What do you think about these incentives to take multimodal trips?

- Are there any incentives we have not mentioned that you think would be more effective in shifting you to use TNC to connect to public transit?

Probes for Stakeholders

- What do you think about the users' thoughts on incentives to connect TNC to transit?

- Which incentive do you think would be most effective from your organization's perspective?

- Do you have any concerns about incentivizing TNC users to connect TNC to transit? What could be done to help address these concerns?

\section{Poll Question [Slide 19]}

- Which incentive would be most effective to get you to walk to pick-up locations for pooled trips?

\section{Differences between Male and Female TNC Users}

[Slide 20]

- Female users prefer waiting in or near retail opportunities while male users prefer waiting in areas where they can use their phone 
- Female participants prefer well-traveled, not-isolated locations with open or transparent shelters while male participants preferred waiting in areas with low foot traffic

- Female users take a variety of additional precautions to ensure safety including:

- Having a male order the ride or walk out/wait with them

- Waiting near a security guard or police officer

- Changing the drop-off location so the driver/passengers don't know their home address

- Sharing location/ride information to friends/emergency contacts

\section{Probes for Users}

- What do you think about these observations? Do you agree or disagree, and why?

- Who do you think should be responsible for meeting an individual's preferred level of safety (e.g., the TNC, local government, regulators, the individual his/herself)?

Probes for Stakeholders

- What do you think about these differences? Do you see them in other aspects of your organization? What strategies does your organization use to address different levels of safety concern across types of users?

- What role does your organization play in meeting individuals' preferred level of safety?

\section{Poll Question [Slide 21]}

- Which incentive would be most effective to get you to take multimodal trips (e.g., use TNC to connect to public transit)?

Differences between Frequent and Periodic TNC users

[Slide 22]

- Frequent TNC users (those who take TNC more than three times per week) are more likely to use TNC to connect to public transit or to take indirect trips, prefer frequent rider promotions, and are less concerned about infrastructure/amenities at waiting locations.

- Periodic TNC users (those who use TNC three or fewer times per week) rarely connect TNC to public transit or walk to pick-up locations, prefer individual trip discounts, have strong preferences for built environment features and waiting locations (wide sidewalks, lighting, uncrowded areas, not on oneway streets).

\section{Probes for Users}

- What do you think about these observations? Do you agree or disagree, and why?

- How do you think stakeholders should go about prioritizing which user preferences to address?

\section{Probes for Stakeholders}

- What do you think about these differences in users?

- Have you seen similar differences in users in other aspects of your organization? What strategies does your organization use to meet the different expectations of different types of users? Could you see any of these strategies transferring to the application of pooling?

- Whose role is it to help meet the different expectations of users? (e.g., solely the TNC, partnerships between organizations, user has to make compromises) 
1) Break (5 minutes)

Section 2. Key Recommendation Feedback (45 minutes)

A slide presenting each recommendation and its strategies will be shown. The following probes will be used for each recommendation:

\section{Probes for Users}

- If these strategies were implemented, would they address your concerns about walking to, waiting for, and taking pooled trips? Why or why not? If not, do you have any recommendations for how to improve it?

- If these strategies were implemented, would you be more interested in taking pooled trips, taking indirect trips, and/or connecting TNC to public transit? Why or why not?

Probes for Stakeholder

- What do you think about these strategies?

- Who would be responsible for implementing these strategies (e.g., TNC company, local government, public transit agency, storefront merchant, etc.)?

- What would be the next steps to moving these strategies forward?

- What concerns do you have about implementing the strategies discussed? How could they be changed to be more feasible?

Recommendation \#1. Increased in-app safety information [Slide 25]

- Provide more information about the driver/trip upfront to improve feelings of safety

- Increase trip preferences (e.g., select gender, vaccine status of driver and other passengers)

- Offer the option to share trip information (about vehicle, driver, other passengers, route, etc.) to emergency contact

- Provide the option to select specific pick-up location or walking area for indirect trips

Recommendation \#2. Leverage geofencing and location features to uniquely address the different safety preferences and concerns of male and female TNC users [Slide 26]

- Suggest nearby retail opportunities or other publicly available, safe waiting venues nearby

- Geofence pick-up areas based on user-selected waiting area preferences

- Provide in-app information about nearby security personnel

- Allow for users to enter an address range for direct trips

Recommendation \#3. Deploy a network of designated TNC stops to address safety concerns and driver connection challenges [Slide 27]

- Develop a network of designated TNC stops with shelter, lighting, benches, safety features, and waiting amenities

- Locate stops in safe, centralized neighborhoods with high visibility of roadway and surroundings and busy areas (e.g., downtown districts, event centers, tourist destinations), near dining or retail, and near parks 
Wrap-up [Slide 28-29] (5 minutes)

- Final recommendations or areas for future research

- Last questions from stakeholders/users 


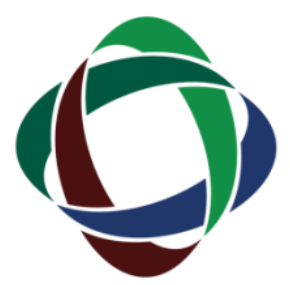

\section{N I C R NATIONAL INSTITUTE FOR CONGESTION REDUCTION}

The National Institute for Congestion Reduction (NICR) will emerge as a national leader in providing multimodal congestion reduction strategies through real-world deployments that leverage advances in technology, big data science and innovative transportation options to optimize the efficiency and reliability of the transportation system for all users. Our efficient and effective delivery of an integrated research, education, workforce development and technology transfer program will be a model for the nation. 